\title{
Title: Organic Matter Preserved in 3-Billion-Year-Old Mudstones at Gale Crater, Mars
}

Authors: Jennifer L. Eigenbrode ${ }^{1, *}$, Roger E. Summons ${ }^{2}$, Andrew Steele ${ }^{3}$, Caroline Freissinet $^{1,4} \uparrow$, Maëva Millan ${ }^{5}$, Rafael Navarro-González ${ }^{6}$, Brad Sutter ${ }^{7,8}$, Amy C. McAdam ${ }^{1}$, Heather Franz ${ }^{1,4}$, Daniel P. Glavin ${ }^{1}$, Paul D. Archer, Jr. ${ }^{7}$, Paul R. Mahaffy ${ }^{1}$, Pamela G. Conrad ${ }^{1} \S$, Joel A. Hurowitz ${ }^{9}$, John P. Grotzinger ${ }^{10}$, Sanjeev Gupta ${ }^{11}$, Doug Ming ${ }^{8}$, Dawn Y. Sumner ${ }^{12}$, Cyril Szopa $^{5}$, Charles Malespin ${ }^{1}$, Arnaud Buch ${ }^{13}$, and Patrice Coll ${ }^{14}$.

\section{Affiliations:}

${ }^{1}$ Solar System Exploration Division, NASA Goddard Space Flight Center, Greenbelt, MD 20771, USA.

${ }^{2}$ Department of Earth, Atmospheric and Planetary Sciences, Massachusetts Institute of Technology, Cambridge, MA 02139, USA

${ }^{3}$ Geophysical Laboratory, Carnegie Institution of Washington, Washington, DC 20015, USA.

${ }^{4}$ Center for Research and Exploration in Space Science \& Technology, University of Maryland Baltimore County, Baltimore, MD 21250, USA.

${ }^{5}$ Laboratoire Atmosphères, Milieux, Observations Spatiales, Université Pierre et Marie Curie, Université Versailles Saint-Quentin and CNRS, Paris, France.

${ }^{6}$ Instituto de Ciencias Nucleares, Universidad Nacional Autónoma de México, Ciudad Universitaria, México D.F. 04510, México.

$20 \quad{ }^{7}$ Jacobs Technology, Houston, TX 77058, USA.

${ }^{8}$ Astromaterials Research and Exploration Science Division, NASA Johnson Space Center, Houston, TX 77058, USA.

${ }^{9}$ Department of Geosciences, Stony Brook University, Stony Brook, New York 11794, USA

${ }^{10}$ Division of Geological and Planetary Sciences, California Institute of Technology, Pasadena, 25 California 91125, USA.

${ }^{11}$ Department of Earth Science and Engineering, Imperial College London, London SW7 2AZ, UK.

12 Department of Earth and Planetary Sciences, University of California, Davis, CA 95616, USA.

${ }^{13}$ Laboratory de Génie des Procédés et Matériaux, Ecole Centrale-Supelec, Gif-sur-Yvette,

30 France.

${ }^{14}$ Laboratoire Inter-Universitaire des Systèmes Atmosphériques, Université Paris-Est Créteil, Université Paris Diderot and CNRS, Créteil, France.

* Correspondence to: Jennifer.L.Eigenbrode@NASA.gov 
${ }^{\dagger}$ Current address: Laboratoire Atmosphères, Milieux, Observations Spatiales, Institut Pierre Simon Laplace, CNRS, Guyancourt, France.

† Current address: Department of Biology, Georgetown University, Washington, DC 20057, USA.

$\S$ Current address: Geophysical Laboratory, Carnegie Institution of Washington, Washington, DC 20015, USA.

Abstract: Establishing the presence and state of organic matter in martian materials, including its possible biosignatures, has been an elusive quest, despite limited reports of organic matter existence. We report the in situ detection of refractory organic matter preserved in lacustrine mudstones at the base of the 3.8-3.1 Ga Murray formation at Pahrump Hills, Gale crater, by the Sample Analysis at Mars instrument suite onboard the Curiosity rover. Diverse pyrolysis products including thiophenic, aromatic, and aliphatic compounds released at high temperatures $\left(500^{\circ}-820^{\circ} \mathrm{C}\right)$ were directly detected by evolved gas analysis. Thiophenes were also observed by gas chromatography mass spectrometry. Their presence suggests sulfurization aided organic matter preservation. At least 50 nanomoles of organic carbon persist as probable macromolecules having $5 \%$ carbon as organic sulfur molecules.

50 One Sentence Summary: In situ detection of refractory organic matter in martian mudstones implies preservation of ancient organic records on Mars.

Main Text: Organic matter preservation is central to understanding biological potential on Mars through time. Whether it holds a record of ancient life, is the food for extant life, or has existed in the absence of life, organic matter in martian materials holds chemical clues to planetary conditions and processes.

Prior reports of organic matter indigenous to martian sediments include 150-300 parts per billion (ppb) chlorobenzene, with lesser C2-C4 dichloroalkanes, detected in Sheepbed mudstone upon heating to $<400^{\circ} \mathrm{C}$ by the Sample Analysis at Mars (SAM) instrument suite of the Mars Science Laboratory (MSL) mission (1). Martian organic carbon may have also contributed to CO and $60 \mathrm{CO}_{2}$ pyrolysis and combustion products evolved below $700^{\circ} \mathrm{C}$ from various sediments by $\mathrm{SAM}$ $(2,3)$. Chloromethanes detected in Viking's pyrolysis gas chromatograph mass spectrometer (GCMS) analysis of martian regolith have been reinterpreted as having a martian origin (4). Additionally, indigenous organic matter in martian meteorites (e.g., 5) is related to a deep igneous domain excavated by impact events. While these reports indicate the presence of martian organic matter, they do not constrain our understanding of ancient organic matter in sediments.

Exploration of the lowermost exposed sedimentary rocks at the base of Aeolis Mons in Gale crater by the Curiosity rover has led to the discovery of a finely laminated mudstone succession, the Murray formation, that is interpreted to record deposition in a long-lived ancient 
circumneutral to alkaline lake fed by a fluvio-deltaic sedimentary system (6-8). Mudstones are composed of basaltic minerals mixed with phyllosilicate, sulfate, iron oxide, and x-ray amorphous components (7). The 3.6-3.1 Ga Gale lake environment(s) are expected to have been ideal settings for concentrating and preserving organic matter (9).

Drilled samples delivered to $\mathrm{SAM}$ were heated at $\sim 35^{\circ} \mathrm{C} / \mathrm{min}$ to $\sim 860^{\circ} \mathrm{C}$. Evolved gas analysis (EGA) continuously and directly measured bulk gas composition during heating with the mass spectrometer. A portion of the evolved gas from the same sample was trapped and analyzed by GCMS for molecular identifications $(10,11)$. Here we report analysis of gases evolved at high temperature $\left(>500^{\circ} \mathrm{C}\right)$ from the Mojave and Confidence Hills. Comparisons are made with Sheepbed and other Murray mudstones.

Figure 1A-B shows the release of organic sulfur compounds from Mojave reaching their peak between $500^{\circ} \mathrm{C}$ and $820^{\circ} \mathrm{C}$ in mass-to-charge ratio $(\mathrm{m} / \mathrm{z})$ profiles that are diagnostic of particular compounds or fragments of similar structures. In this case, the $\mathrm{m} / \mathrm{z}$ profiles are consistent with thiophene $\left(\mathrm{C}_{4} \mathrm{H}_{4} \mathrm{~S}\right)$, 2- and 3-methylthiophenes $\left(\mathrm{C}_{5} \mathrm{H}_{6} \mathrm{~S}\right)$, methanethiol $\left(\mathrm{CH}_{3} \mathrm{~S}\right)$, and dimethylsulfide $\left(\mathrm{C}_{2} \mathrm{H}_{6} \mathrm{~S}\right)$. The presence of benzothiophene $\left(\mathrm{C}_{8} \mathrm{H}_{6} \mathrm{~S}\right)$, a bicyclic thiophene that usually co-occurs with thiophenes, is also suggested by a weak peak in both Mojave (Fig 1A) and Confidence Hills EGA data (Fig. S1F). Other volatiles evolve concurrently: carbonyl sulfide (COS), $\mathrm{CS}_{2}, \mathrm{H}_{2} \mathrm{~S}, \mathrm{SO}_{2}, \mathrm{O}_{2}, \mathrm{CO}$, and $\mathrm{CO}_{2}$, but not $\mathrm{H}_{2}$ (Fig. 1C-E). A similar release of organic sulfur compounds and related volatiles is observed for Confidence Hills (Fig. S1).

Other, non-thiophenic, aromatic compounds are also observed in EGA of Mojave (Fig. 2B) and Confidence Hills (Fig. S2F). Their peak releases and representative molecular groups are: $\sim 800^{\circ} \mathrm{C}$ for benzene $\left(\mathrm{C}_{6} \mathrm{H}_{6}\right), \sim 750^{\circ} \mathrm{C}$ for the toluene (or tropylium ion; $\mathrm{C}_{7} \mathrm{H}_{7}$ ), plus two peaks at $625^{\circ} \mathrm{C}$ and $790-820^{\circ} \mathrm{C}$ for alkylbenzenes $\left(\mathrm{C}_{8} \mathrm{H}_{9}\right.$ or benzoate ion $\left.\mathrm{C}_{7} \mathrm{H}_{5} \mathrm{O}\right)$, and possible chlorobenzene $\left(\mathrm{C}_{6} \mathrm{H}_{5} \mathrm{Cl}\right)$ (17). A peak near detection limits in Mojave suggests naphthalene $\left(\mathrm{C}_{10} \mathrm{H}_{8}\right)$ might also be present assuming the Confidence Hills blank (Fig. S2E) is representative of noise levels.

EGA mass profiles for $m / z$ 15, 26, 27, 29c, 30, 41-43, 55-57, and 69-71 from Mojave (Fig. 2A) and Confidence Hills (Fig. S2B), are consistent with a $550-820^{\circ} \mathrm{C}$ evolution of aliphatic compounds products composed of $\mathrm{C} 1-\mathrm{C} 5$ chains or their branched moieties. Correlation and relative intensities of peaks suggest molecular structures that differ by single carbon additions (i.e., - $\mathrm{CH}-,-\mathrm{CH}_{2}-$, and $-\mathrm{CH}_{3}$ additions), which are characteristic of an array of aliphatic 100 fragments from larger molecules (12) and commonly observed in high-temperature pyrolysis products of terrestrial kerogens and coals (13), and carbonaceous chondrites (14). Some structures may contain $\mathrm{N}$ - and O-bearing groups, such as amides, carboxyl, or carbonyl groups, but these cannot be clearly identified in EGA because mass spectra are not resolvable in EGA and other molecules share their diagnostic $\mathrm{m} / \mathrm{z}$ value. 
105 Three temperatures characterize the peaks of the aliphatic compound signals in Mojave (Fig. 2A): $625^{\circ} \mathrm{C}$ (square), $750^{\circ} \mathrm{C}$ (circles) and $790-820^{\circ} \mathrm{C}$ (triangles). Immediately preceding the $750^{\circ} \mathrm{C}$ peak set is a notable $\mathrm{O}_{2}$ release from sulfate decomposition (3) with an increase in $\mathrm{CO}_{2}$ (Fig. 1E) suggesting combustion limited to the most ignitable volatiles (12) occurred in parallel with pyrolysis. It is also possible that a portion of the $\mathrm{CO}_{2}$ and $\mathrm{CO}$ (Fig. 2A) are derived from 110 decarboxylation (2-3) and decarbonylation of larger organic compounds, which has been observed for Murchison macromolecular isolate (15). The same three peaks are present but less discernable in Confidence Hills where the $750^{\circ} \mathrm{C}-\mathrm{O}_{2}$ peak is lower, suggesting combustion was less influential on hydrocarbon evolution (Fig. S1-S2).

Abundance estimates for thiophenes, C1-C2 sulfur, aromatic and aliphatic compounds in Mojave and Confidence Hills are in the nanomolar $\mathrm{C}$ range (Table 1) (11). The total organic carbon (TOC) abundance in these samples (10-100 nmol C) reflects only the portion detected in EGA and does not account for any char remaining in the sample after heating. Calculated TOC abundances are considered lower limits for the actual amount of organic carbon in the samples.

Organic-sulfur, aromatic and aliphatic components evolve between $550^{\circ} \mathrm{C}$ and $820^{\circ} \mathrm{C}$ and share peak maxima (noted by symbols in Figs. 1, 2, S1, and S2). This matching indicates the presence of diverse molecular structures in organic matter of the Mojave and Confidence Hills samples. In contrast, peaks for aromatic or thiophenic volatiles in the Sheepbed and other Murray mudstones (Fig. S1-S6), are weaker, less defined and have inconsistent temperatures, despite a clear indication of aliphatic compound presence. Thiophenic and aromatic hydrocarbon abundances for these mudstones are less than 50\% as observed in Mojave and Confidence Hills (Table S1). In the Cumberland sample of the Sheepbed mudstone, thiophene abundances are equivalent to or less than blanks indicating their absence.

GCMS analysis of the $226-860^{\circ} \mathrm{C}$ cut of gases released from Mojave (Fig. 3) confirms the presence of thiophene, 2-methylthiophene and 3-methylthiophene. Dimethylsulfide was observed 130 in all GCMS analyses for most samples (Table S2). The abundance of thiophenes detected in Mojave by GCMS is $20( \pm 5)$ pmol molecules (Table S2), which is equivalent to 100 pmol C, indicating 10x less thiophenic $\mathrm{C}$ than in EGA. The difference reflects a combination of 1) other unknown molecules contributing to the $m / z$ 84c profile in Figure 1A (e.g., other thiophenic or sulfur aromatic compounds, $\mathrm{C}_{6} \mathrm{H}_{12}$ fragments from $>\mathrm{C} 6$ aliphatic chains) and $m / z, 97$ (e.g., $\mathrm{C}_{7} \mathrm{H}_{13}$ 135 fragments, or $\mathrm{HSO}_{4}{ }^{-}$cleaved from aliphatic and aromatic sulfates) $(12,15)$ in EGA, leading to inflation of calculated EGA abundances, 2) incomplete hydrocarbon trapping by the SAM hydrocarbon and injection traps of the GC system due to interference from other volatiles, and 3) incomplete release from flash heating of the injection trap.

GCMS confirmations of molecular identities assigned to EGA aromatic signals are limited. Benzene, alkylbenzenes, naphthalene, and chlorobenzene are observed in GCMS data of Mojave 
and Confidence Hills, but molecules from the GC instrument background contribute to these signals and the $\mathrm{GC}$ detections likely include contributions evolved at low temperature $\left(<500^{\circ} \mathrm{C}\right)$ due to the broad GC cut (Table S2). Sample-to-sample carryover is also known to impact low GCMS signals (1). Together, these issues make distinction of low amounts of high-temperature, sample-derived aromatic molecules difficult. Moreover, since peaks in EGA profiles reflect the sum of hydrocarbon fragments having a characteristic structure contributed by numerous, lowabundance pyrolysis products, signals of individual molecules can be significantly lower in GCMS. Such diverse molecular contributions are consistent with the complex chemistry of meteoritic and geological organic matter and the interactions that occur during pyrolysis of sediments (12). In summary, the Mojave and Confidence Hills GCMS data do not and are not expected to provide unequivocal molecular identifications for the low amounts of aromatic compounds indicated by the EGA data.

Aliphatic compound identifications in GCMS data for Mojave and Confidence Hills do not reflect those observed in EGA. Generally, the strongest $\mathrm{m} / \mathrm{z}$, values in mass spectra of aliphatic compounds are from the C2-C5 fragments of parent molecules having larger carbon structures. Thus, the EGA-GCMS disparity is largely attributed to C2-C5 fragment contributions from a large molecular pool in EGA, which renders identification of any one molecule below-detectionlimits by GCMS, as previously described for aromatic compounds.

The SAM EGA instrument background is not the source of the molecular diversity observed at 160 high temperatures (17). Sample signals are significantly greater than blanks. Laboratory tests demonstrate that in the presence of silicates and perchlorates, instrument background has little impact on signals above $550^{\circ} \mathrm{C}$ (Fig. S7). Other possible, but unlikely, contamination sources cannot account for temperature breadth and the molecular diversity observed. Lastly, C5 structures suggested by $\mathrm{m} / \mathrm{z}$ profiles cannot be explained by SAM's instrument background that is limited to $\mathrm{C} 1-\mathrm{C} 4$ carbon backbones.

The diversity, composition, and temperatures of co-evolving volatiles observed in the Mojave and Confidence Hills analyses above $500^{\circ} \mathrm{C}$ are consistent with the pyrolysis of geologically refractory organic macromolecules that are typically found in carbonaceous chondrites (14-15), kerogens (18), and coals (19-20). The more stable these macromolecules are, the higher the 170 temperature needed to thermally cleave fragments from them. Pyrolysis of organic-laden sediments with co-occurring inorganic materials that also decompose, or act as catalysts, can results in a complex array of chemical reactions during heating including sulfurization, addition, cyclization, and condensation reactions (Diels-Alder type) that might produce cyclic structures (thiophenes and other aromatics). Sufficient He flow mitigates these secondary reactions. In spite of this complexity, larger molecular fragments can maintain structural information regarding the parent organic matter $(12,13)$. In Mojave, $\mathrm{CO}, \mathrm{COS}, \mathrm{CS}_{2}, \mathrm{CH}_{3} \mathrm{SH},\left(\mathrm{CH}_{3}\right)_{2} \mathrm{~S}$, likely reflect cleavage directly from the precursor organic structures and reaction products. Similarly, $\mathrm{CO}_{2}$, 
$\mathrm{H}_{2} \mathrm{~S}, \mathrm{H}_{2}$, and $\mathrm{H}_{2} \mathrm{O}$ may be partly derived from organic matter in addition to mineral decomposition $(3,21)$. However, under SAM oven conditions at high temperatures and low pressure under flowing $\mathrm{He}$, entropic factors govern reactions $(12,22,23)$ and formation of thiophenic and other aromatic volatiles in the oven are not favored. This conclusion is supported by 1) EGA blank analyses that indicate the absence of cyclic structures (Fig. S2) despite available reactants from the background organic molecules (Fig. S7), and 2) the absence of thiophenes in EGA data for the sulfide-bearing Cumberland sample of the Sheepbed mudstone indicating no cyclization occurred (Table S1). Thus, the thiophenic and aromatic volatiles likely reflect compounds directly released from organic matter in the Murray mudstones. It is very plausible that aliphatics and some portion of the C1-C2 sulfur compounds also reflect the in situ sample chemistry. Even if some portion of these compounds are not direct pyrolysis products from sediments, their carbon must largely be derived from organic matter indigenous to martian sediments.

The weaker and less diverse organic signals of the Sheepbed and other Murray mudstones indicate less organic input to sediments at the time of deposition or that the organic inputs were more significantly degraded over geological time. Organic materials in the lacustrine mudstones at Yellowknife Bay and in the lower Mount Sharp group strata have survived multiple, aqueous 195 diagenetic events (6-8), though the number and extent of these is difficult to constrain. Further, direct and indirect reactions induced by ionizing cosmic rays degrade organic matter (24) and SAM measurements of noble gas isotopes in the Sheepbed mudstones indicate the sediments have been irradiated for $\sim 80$ My implying significant degradation (25). It is possible that the Murray mudstones experienced less exposure.

200 Within the lower Murray at Pahrump Hills, sulfide minerals were likely altered to jarosite (1-3\% in Mojave and Confidence Hills) by acidic diagenetic fluids ( $\mathrm{pH} 2-6$ ) at $2.1 \mathrm{Ga}$ (30) though it is unclear if these fluids were localized to sediment grains $(8)$ or more pervasive in the strata, leaching mafic minerals of metals and increasing in $\mathrm{pH}$ as they passed downward through the section (7). In either case, the exposure must have been limited in time and space, since $\mathrm{pH}$ sensitive minerals such as apatite and olivine persist. Acidic fluids can effectively oxidize exposed organics; however, acidic diagenesis in the lower Murray may have had a low impact on organics as they did on $\mathrm{pH}$-sensitive minerals. If these fluids moved downward through the Pahrump Hills section as proposed by Rampe et al. (7)., Confidence Hills and Mojave would have been exposed to only mildly acidic fluids ( $\mathrm{pH}$ 6), resulting in milder organic degradation compared to overlying Murray mudstones. Alternatively, variations in organic matter abundance and composition in Murray mudstones may reflect geological inputs from transported detritus that were already in a refractory state, which would support their survival varying lake redox conditions (8). Ultimately, the fate of organic matter is determined by both degradation and 
preservation mechanisms. Both are likely important to the mudstones in Gale Crater. By what preservation mechanisms did the martian organic matter survive?

Macromolecules on their own are self-preserving since surface organics shield interior organics from oxidation and stabilize the bulk organic mass (26). Ancient biomacromolecules deposited in lake sediments may have been transformed into geomacromolecules (kerogen) over time. Other possible sources of recalcitrant macromolecules include interplanetary dust particles (IDPs) (27) and abiotic organic materials from igneous rocks (5). In an effort of better constrain the composition and possible origin of organic matter in the mudstones, we conducted SAM testbed EGA of the Murchison meteorite, a proxy for IDP composition, and laboratory EGA of the Tissint martian meteorite, which hosts igneous related organics. Both show the evolution of C1-C2 sulfur volatiles and aliphatic, aromatic, and thiophenic pyrolysis products during EGA above $500^{\circ} \mathrm{C}$ (Fig. S9-S10), but the profiles related to these molecular groups are distinctive for each sample type. These results are consistent with the known presence of refractory organic matter in each meteorite but indicate differences in their organic chemistry and mineral associations. The supplemental EGA analyses do not provide constraints on organic matter origin. However, they do support the interpretation that the mudstones host refractory organic matter that is most likely macromolecular.

Minerals can further aid preservation by several mechanisms: occlusion by minerals, organicmineral interactions (e.g., organic binding to phyllosilicate and Al-Fe oxyhydroxide surfaces), and establishing chemically reducing microenvironments that host organics (28). If organic matter entering sediments was labile, such as autochthonous biomolecules (e.g., carbohydrates, amino acids, fatty acids, etc.), then reactions with mineral surfaces or sedimentary chemicals would have been favored. Phyllosilicate, iron oxyhydroxide, and amorphous materials, are prevalent in all of the studied mudstones $(7,8)$. Further, iron sulfides detected in the Sheepbed mudstone (29) and suspected in the original Murray mudstone detritus $(7,8)$ may have aided organic matter preservation by providing an additional oxygen sink during diagenesis.

240 Reduced permeability limits the exposure of organics to migrating fluids and gas, and is generally enhanced by abundant fine-grained sediments and precipitates (e.g., sulfate cement, vein fill, and nodules). All mudstones studied exhibit indications of groundwater alteration (6-8, 31 ); however, the timing of cementation and post-depositional aqueous alteration is not wellconstrained so the extent of organic exposure to these fluids is unknown.

245 Macromolecules, mineral interactions, and permeability factors were all likely contributors to organic matter preservation in the Murray mudstone, but sulfurization of organic molecules was probably the principal preservation mechanism responsible for the distinct record in Mojave and Confidence Hills based on the presence of 3-10 times more thiophenic and total organic sulfur in these samples compared to the other mudstones (Table S1 and S4). Natural vulcanization results 
250 in an enhanced refractory state for organic materials. The addition of sulfur structurally links the organic components into a macromolecular form and provides an additional oxidative sink for degradation reactions. On Earth, sulfurization enhances initial preservation while also imparting long-term recalcitrance to structural transformations and oxidation, such as during acidic diagenesis. Sulfurization probably occurred during early diagenesis in the presence of reduced sulfur species $\left(\mathrm{HS}^{-}\right.$or $\mathrm{H}_{2} \mathrm{~S}$ ) gas (32) over $3 \mathrm{Ga}$ ago. The large sulfur isotopic fractionation observed in the $\mathrm{SO}_{2}$ evolved via EGA from the mudstones indicates that sulfide was transported via hydrothermal groundwater to the Gale lake basin (33). Alternatively, organic sulfur was native to the detritus deposited in the lake.

SAM's molecular observations do not clearly reveal the source of the organic matter in the Murray formation. Biological, geological, and meteoritic sources are all possible. Certainly, if ancient life was the organic source, then, despite sulfur incorporation, there has either been sufficient alteration to the material, such as by diagenesis or ionizing radiation (30), to obscure original molecular features more consistent with life (e.g., a greater diversity of molecules or lipid-derived hydrocarbons) or an insufficient amount of organic matter was deposited to allow detection by pyrolysis-GCMS.

Past habitability interpreted for the Sheepbed lacustrine mudstones focused on chemolithoautotrophy $(8,31)$, but observations of geologically refractory organic matter in Murray lacustrine mudstones opens the door for past and present habitability by heterotrophy as well. Organic matter can directly or indirectly fuel both energy and carbon metabolisms and in doing so can support carbon cycling at the microbial community level.

Our results suggest that it is likely that organic matter from various sources may be widely distributed in the martian rock record. Even if life was not a key contributor, meteoritic and igneous/hydrothermal sources have a strong potential to be broadly emplaced. Our determination of the preservation of organic matter at the martian surface, where ionizing and oxidizing conditions are extreme, suggests better-preserved molecular records may present at depth or in materials exposed in the last several thousand years.

\section{References and Notes:}

1. C. Freissinet, et al., Organic molecules in the Sheepbed Mudstone, Gale Crater, Mars, J. Geophys. Res. Planets 120, 495 (2015).

2. D. W. Ming, et al., Volatile and organic compositions of sedimentary rocks in Yellowknife Bay, Gale crater, Mars., Science 343, 1245267 (2014).

3. B. Sutter, et al., Evolved Gas Analyses of Sedimentary Rocks and Eolian Sediment in Gale Crater, Mars: Results of the Curiosity Rover's Sample Analysis at Mars (SAM) Instrument from Yellowknife Bay to the Namib Dune, J. Geophys. Res. Planets 122, 1 (2017). 
4. R. Navarro-González, E. Vargas, J. de la Rosa, A. C. Raga, C. P. McKay, Reanalysis of the Viking results suggests perchlorate and organics at midlatitudes on Mars, J. Geophy. Res. Solid Earth 115, E12010 (2010).

290 5. A. Steele, F. M. McCubbin, M. D. Fries, The provenance, formation, and implications of reduced carbon phases in Martian meteorites, Meteorit. Planet. Sci. 51 (2016) doi: 10.1111/maps.12670.

6. J. P. Grotzinger, et al., Deposition, exhumation, and paleoclimate of an ancient lake deposit, Gale crater, Mars, Science 350, aac7575 (2015).

295 7. E. Rampe, et al., Mineralogical trends in mudstones from the Murray formation, Gale crater, Mars, Earth Planet. Sci. Lett. 471, 172 (2017).

8. J. A. Hurowitz, et al., Redox stratification of an ancient lake in Gale crater, Mars, Science 356, eaah6849 (2017).

9. R. E. Summons, et al., Preservation of martian organic and environmental records: final report of the Mars biosignature working group, Astrobiology 11, 157-181 (2011).

10. P. R. Mahaffy, et al., The Sample Analysis at Mars Investigation and Instrument Suite, Space Sci. Rev. 170, 401 (2012).

11. Information on materials and methods is available at the Science Web site.

12. S. C. Moldoveanu, Pyrolysis of Organic Molecules with Applications to Health and Environmental Issues. S. C. Moldoveanu, Ed., Techniques and Instrumentation in Analytical Chemistry (Elsevier, New York, 2010), vol. 28, pp. 724.

13. S. C. Moldoveanu, Analytical Pyrolysis of Natural Organic Polymers. S. C. Moldoveanu, Ed., Techniques and Instrumentation in Analytical Chemistry (Elsevier, New York, 1998), vol. 20, pp. 496.

310 14. F. Okumura, K. Mimura, Gradual and stepwise pyrolyses of insoluble organic matter from the Murchison meteorite revealing chemical structure and isotopic distribution, Geochim. Cosmochim. Acta 75, 7063 (2011).

15. L. Remusat L., S. Derenne, F. Robert, H. Knicker, New pyrolytic and spectroscopic data on Orgueil and Murchison insoluble organic matter: A different origin than soluble?

315 Geochim. et Cosmochim. Acta 69, 3919-3932 (2005).

16. F. W. McLafferty, F. Tureek, Interpretation of Mass Spectra. (University Science Books, Sausalito, California, 1993), pp. 371.

17. Supplementary Text is available at the Science Web site.

18. J. S. Sinninghe Damsté, T. I. Eglinton, J. W. De Leeuw, P. A. Schenck, Organic sulphur in macromolecular sedimentary organic matter: I. Structure and origin of sulphurcontaining moieties in kerogen, asphaltenes and coal as revealed by flash pyrolysis, Geochim. Cosmochim. Acta 53, 873 (1989).

19. B. P. Baruah, P. Khare, Pyrolysis of high sulfur Indian coals, Energy \& Fuels 21, 3346 (2007).

20. L. Xu, J. Yang, Y. Li, Z. Liu, Behavior of organic sulfur model compounds in pyrolysis under coal-like environment, Fuel Processing Technology 85, 1013 (2004). 
21. A. C. McAdam, et al., Sulfur-bearing phases detected by evolved gas analysis of the Rocknest aeolian deposit, Gale Crater, Mars, J. Geophy. Res. Planets 119, 373 (2014).

22. R. F. C. von Brown, Pyrolytic Methods in Organic Chemistry. Application of Flow and Flash Vacuum Pyrolytic Techniques. (Academic Press, Inc., New York, 1980), pp. 362.

23. M. Bajus, et al., Sulfur Compounds In Hydrocarbon Pyrolysis. (Taylor \&Francis, London, 1989), pp. 76.

24. D. M. Hassler, et al., Mars' Surface Radiation Environment Measured with the Mars Science Laboratory's Curiosity Rover, Science 3431244797 (2014).

25. K.A. Farley, et al., In situ radiometric and exposure age dating of the Martian surface. Science 343, 1247166 (2014).

26. L. Mayer, The inertness of being organic, Marine Chemistry 92, 135 (2004).

27. G. J. Flynn, L. R. Nittler, C. Engrand, Composition of Cosmic Dust: Sources and Implications for the Early Solar System, Elements 12, 177 (2016).

340 28. R. G. Keil, L. M. Mayer, Mineral Matrices and Organic Matter, Org. Geochem. 12, 337 (2014).

29. D. T. Vaniman, et al., Mineralogy of a mudstone at Yellowknife Bay, Gale Crater, Mars, Science 343, 1243480 (2014).

30. P. E. Martin, et al., A two-step K-Ar experiment on Mars: dating the diagenetic formation of jarosite from Amazonian groundwaters, J. Geophys. Res. Planets 122, 28032818 (2017).

31. J. P. Grotzinger, et al., A habitable fluvio-lacustrine environment at Yellowknife Bay, Gale crater, Mars., Science 343, 1242777 (2014).

32. Y. Hebting, et al., Biomarker evidence for a major preservation pathway of sedimentary organic carbon, Science 312, 1627 (2006).

33. H. B. Franz, et al., Large sulfur isotope fractionations in Martian sediments at Gale crater, Nature Geoscience 10, 658 (2017).

34. P. J. Linstrom, W. G. Mallard, Eds., NIST Chemistry WebBook, (National Institute of Standards and Technology, Gaithersburg, MD, 2015).

355 35. K. M. Stack, et al., Diagenetic origin of nodules in the Sheepbed member, Yellowknife Bay formation, Gale crater, Mars, J. Geophy. Res. Planets 119, 1637 (2014).

36. R. V. Morris, et al., Silicic volcanism on Mars evidenced by tridymite in high-SiO 2 sedimentary rock at Gale crater, Proc. Nat. Acad. Sci. 113, 7071 (2016).

37. T. F. Bristow, et al., The origin and implications of clay minerals from Yellowknife Bay, $360 \quad$ Gale crater, Mars, Am. Mineral. 100, 824 (2015).

38. M. Nachon, et al., Chemistry of diagenetic features analyzed by ChemCam at Pahrump Hills, Gale crater, Mars, Icarus 281, 121 (2017).

39. R. C. Anderson, et al., Collecting Samples in Gale Crater, Mars; an Overview of the Mars Science Laboratory Sample Acquisition, Sample Processing and Handling System, Space Sci. Rev. 170, 57 (2012).

40. L. A. Leshin, et al., Volatile, isotope, and organic analysis of martian fines with the Mars Curiosity rover, Science 341, 1238937 (2013). 
41. D. P. Glavin, et al., Evidence for perchlorates and the origin of chlorinated hydrocarbons detected by SAM at the Rocknest aeolian deposit in Gale Crater, J. Geophys. Res. Planets 118, 1955 (2013).

42. D. R. Knapp, Handbook of Analytical Derivatization Reactions. (Wiley-Interscience, New York, 1979), pp. 768.

43. F. Stalport, et al., The influence of mineralogy on recovering organic acids from Mars analogue materials using the "one-pot" derivatization experiment on the Sample Analysis at Mars (SAM) instrument suite, Planet. Space Sci. 67, 1 (2012).

44. P. D. Archer, Jr., et al., Abundances and implications of volatile-bearing species from evolved gas analysis of the Rocknest aeolian deposit, Gale Crater, Mars, J. Geophys. Res. Planets 119, 237 (2014).

45. J. Stern, et al., Evidence for indigenous nitrogen in sedimentary and aeolian deposits from the Curiosity rover investigations at Gale crater, Mars, Proc. Nat. Acad. Sci. 112, 4245 (2014).

46. J. L. Eigenbrode, et al., Fluorocarbon contamination from the drill on the Mars Science Laboratory: Potential science impact on detecting martian organics by Sample at Mars (SAM). Paper presented at the 44th Lunar Planet. Sci. Conf., Houston, TX, March 18-22, 2013.

47. F. Li, et al., The Thermal and Mechanical Properties of High Performance Polyimide Fibers, fire.tc.faa.gov, (1998).

48. K. E. Miller, et al., Evaluation of the Tenax trap in the Sample Analysis at Mars instrument suite on the Curiosity rover as a potential hydrocarbon source for chlorinated organics detected in Gale Crater, J. Geophys. Res. Planets 120, 1446 (2015).

49. Y.-K. Kim, et al., Electron-Impact Cross Sections for Ionization and Excitation Database (version 3.0). (National Institute of Standards and Technology, Gaithersburg, Maryland, 2004).

50. H. B. Franz, Calibration Constants for Calculation of Volatile Abundances from Sample Analysis at Mars (SAM) Evolved Gas Analysis (EGA) Data, NASA TM-2017-217552 (2017).

51. T. Shin, O. Chuichi, W. Hajima, Pyrolysis - GC/MS Data Book of Synthetic Polymers. (Elsevier, Amsterdam, 2011), pp. 390.

52. P. G. Conrad, et al., The Mars Science Laboratory Organic Check Material. Space Sci. Rev. 170, 479-501 (2012).

53. H. Arito, R. Soda, Pyrolysis products of polytetrafluoroethylene and polyfluorethylenepropylene with reference to inhalation toxicity, Ann. Occup. Hyg. 20, 247 (1977).

54. H. Busemann, et al., Interstellar Chemistry Recorded in Organic Matter from Primitive Meteorites, Science 312, 727 (2006).

55. M. A. Sephton, Pyrolysis and mass spectrometry studies of meteoritic organic matter, Mass Spectrom. Rev. 31, 560 (2012).

56. J. M. Hayes, Organic constituents of meteorites - a review, Geochim. Cosmochim. Acta 31, 1395 (1967).

410 57. C. Tian, C. R. Vidal, Electron impact dissociative ionization of $\mathrm{CO}_{2}$ : Measurements with a focusing time-of-flight mass spectrometer, J. Chem. Phys. 108, 927 (1998).

58. K. K. Irikura, Semi-empirical estimation of ion-specific cross sections in electron ionization of molecules, J. Chem. Phys. 145, 224102 (2016). 
59. V. Grill, et al., Absolute partial and total electron impact ionization cross sections for $\mathrm{C}_{3} \mathrm{H}_{8}$ from threshold up to $950 \mathrm{eV}$, Zeitschrift für Physik D Atoms, Molecules and Clusters 25, 217 (1993).

Acknowledgments: The authors thank reviewers for their constructive comments, the MSL and SAM teams for successful operations of SAM on Mars and thoughtful science discussions, and Dr. Karl Irikura for calculating ionization cross sections. Funding: This work was funded by NASA's Mars Exploration Program. NASA's MSL Participating Scientist program supported J.L.E., R.E.S., and D.P.G. for this effort. Author contributions: J.L.E. developed data processing methods, calculated and interpreted EGA data, and wrote most of the manuscript and Supplementary Material. R.E.S, A.S, B.S., and P.R.M. wrote sections of text on pyrolysis, meteorites, geological context, and methods, respectively. C.F., M.M., D.P.G., A.S., and C.S. calculated and interpreted GCMS data. M.M. performed SAM GC breadboard tests. H.F., P.D.A., and B.S. contributed to analysis of EGA data. R.N-G. performed laboratory analyses necessary to understand SAM background. All authors participated in data acquisition, discussion of results, and/or editing of the manuscript. Competing Interests: The authors declare no competing financial interests. Data and materials availability: Reduced data records (RDRs) from SAM flight experiments are archived in the Planetary Data System (pds.nasa.gov) and identifiable by sol or test identification (TID) numbers listed in Table S6. All processed data are available in the manuscript or the supplementary material.

\section{List of Supplementary Materials:}

Materials and Methods

Supplementary Text

Figures S1-S11

440 Tables S1-S10

References and Notes (35-59) 


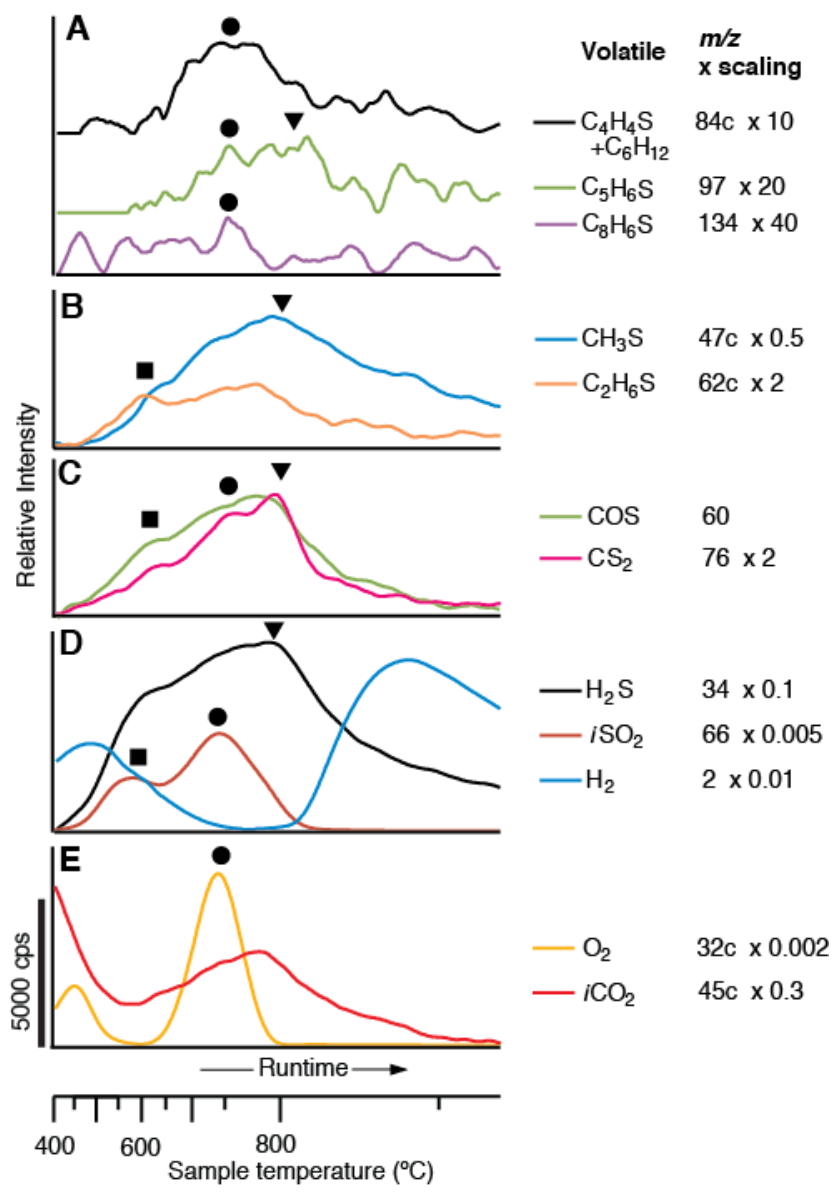

Fig. 1. Mojave EGA profiles showing thiophenes (A), thiols and sulfides (B-C), other volatiles (D), and $\mathrm{O}_{2}$ and $\mathrm{CO}_{2}(\mathrm{E})$. Legend shows volatile, $\mathrm{m} / \mathrm{z}$, and scaling factor for each profile. Profiles within panes are multiplied by scaling factors. Symbols mark correlations between panes in peak maxima within $\pm 25^{\circ} \mathrm{C}$ error due to signal smoothing. Axes and temperature placement of symbols are the same in Fig. 2 and S1-S6. X-axis is scaled linearly to runtime and the corresponding sample temperature is shown. Y-axis scale bar in counts per second (cps) is for all panes. Profiles in A are shifted along the y-axis to show peaks clearly. " $i$ ", isotopologues in formulas. "c", corrections to profiles to remove other volatile contributions (11). 


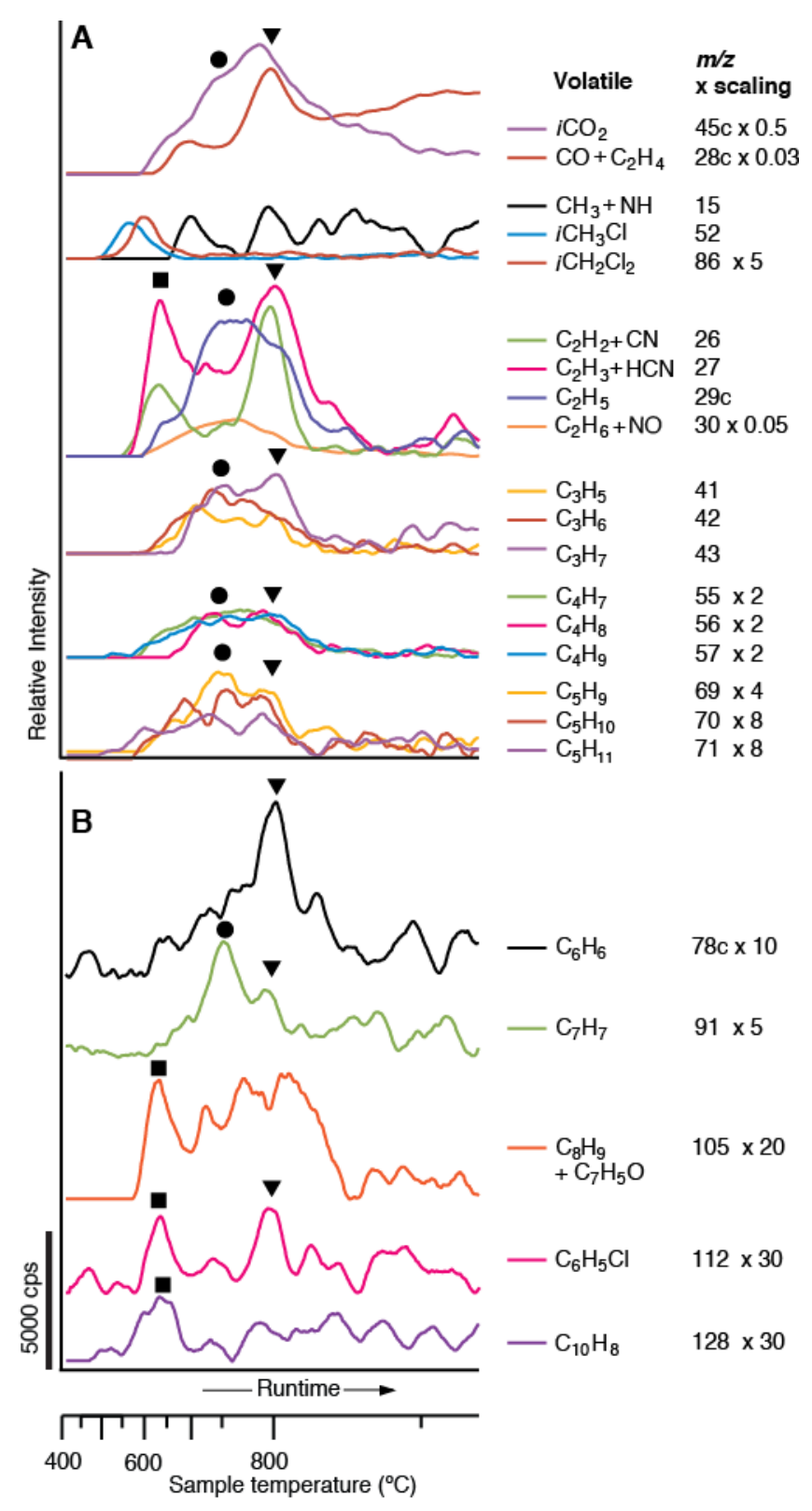

Fig. 2. Mojave EGA profiles for aliphatic (A) and aromatic (B) compounds. $\mathrm{CO}$ and $\mathrm{CO}_{2}$ profiles are included in A. Legend and plotting details are described in Figure 1 (11). Profiles in A are grouped by carbon number and shifted along the $y$-axis for clarity. Profiles in B are similarly shifted. 


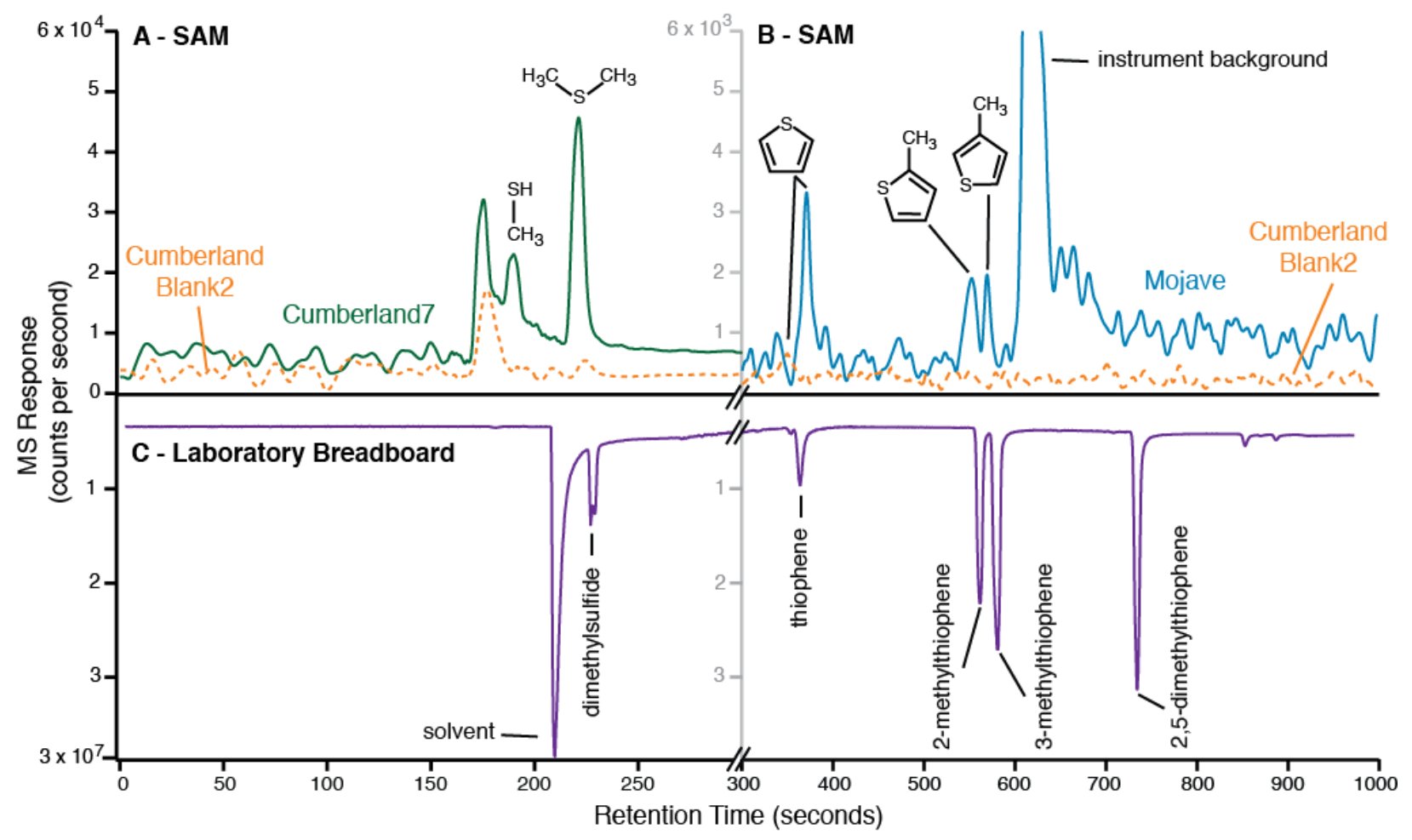

Fig. 3. Example of SAM GCMS identification of S-containing pyrolysis products (A-B) compared to a high-fidelity SAM-like GC run in the same manner, but in the laboratory (C). A) Chromatograms summing $\mathrm{m} / \mathrm{z} 47$ and 62, over 0 to $300 \mathrm{~s}$, for Cumberland 7 of the Sheepbed mudstone and blank showing methanethiol and dimethylsulfide. B) Chromatograms summing $m / z$ 84, 97, and 98, over 300 to $1000 \mathrm{~s}$, for Mojave and blank showing the presence of thiophene, 2-methylthiophene and 3-methylthiophene. 2,5-dimethylthiophene was not identifiable. Chromatograms were smoothed and the 2 off-nominal GC run from Mojave resulted in the 20-s offset for thiophene retention time as observed in B (11). GCMS identifications are based on both retention times (Table S3) compared to standards and mass spectra in reference database (34). "//" denotes a change in X-axis scale. 
Table 1. Organic carbon abundance (nanomole C) estimates for EGA signals above $500^{\circ} \mathrm{C}^{*}$. See Table S1 for abundances of individual molecules and abundances in other mudstones.

\begin{tabular}{|c|c|c|c|c|c|c|}
\hline \multirow[b]{2}{*}{ Sample } & \multicolumn{5}{|c|}{ Compound Classes $* \dagger$} & \multirow[b]{2}{*}{$\begin{array}{c}\text { Total } \\
\text { Organic } \\
\text { Carbon }\end{array}$} \\
\hline & Thiophenic & Aromatic & Aliphatic & $\begin{array}{l}\text { Thiophenic, } \\
\text { Aromatic, } \\
\text { and Aliphatic }\end{array}$ & $\begin{array}{l}\text { C1-C2 } \\
\text { Sulfur }\end{array}$ & \\
\hline Mojave & $2.20=$ & $9 \pm 1.99$ & 38.4 & $47.61 \pm 6.04$ & 43.8 & $91.4 \pm 13.1$ \\
\hline $\begin{array}{l}\text { Confidence } \\
\text { Hills }\end{array}$ & $2.02 \pm 0.84$ & $8.03 \pm 2.11$ & $20.8 \pm 2.79$ & $30.8 \pm 3.60$ & $29.3 \pm 7.61$ & $60.2 \pm 8.42$ \\
\hline $\begin{array}{l}\text { Confidence } \\
\text { Hills -Blank }\end{array}$ & $0.49 \pm 0.18$ & $3.04 \pm 0.86$ & $5.35 \pm 0.83$ & $8.88 \pm 1.21$ & $1.49 \pm 0.42$ & $10.4 \pm 1.28$ \\
\hline
\end{tabular}

$*$ Errors are propagated from integration uncertainty $(30 \%, \pm 1 \sigma \mathrm{SD}, \mathrm{N} \geq 3)$, smoothing error $(5 \%$,

$485 \pm 1 \sigma \mathrm{SD}, \mathrm{N} \geq 3$ ), and ionization cross section uncertainties (reported in the literature).

$\dagger$ Total thiophenic hydrocarbon is the sum of thiophene, methyl thiophenes, and dimethylthiophenes abundances. Total other aromatic compounds is the sum of benzene, toluene, and benzoic acid (a proxy for benzoate ion or alkylbenzene contributions) abundances. Total aliphatic compounds is the sum of C1C3 alkanes and C2-C5 alkenes determined from modeling. Total C1-C2 sulfur compounds is the sum of methanethiol, dimethylsulfide, carbonyl sulfide, and carbon disulfide abundances (11). 


\section{Science AlAAAS}

495

\section{Supplementary Materials for}

Organic Matter Preserved in 3-Billion-Year-Old Mudstones at Gale Crater, Mars

Jennifer L. Eigenbrode, Roger E. Summons, Andrew Steele, Caroline Freissinet, Maëva Millan, Rafael Navarro-González, Brad Sutter, Amy C. McAdam, Heather Franz, Daniel P. Glavin, Paul

500 D. Archer, Jr., Paul R. Mahaffy, Pamela G. Conrad, Joel A. Hurowitz, John P. Grotzinger, Sanjeev Gupta, Doug Ming, Dawn Y. Sumner, Cyril Szopa, Charles Malespin, Arnaud Buch, and Patrice Coll.

correspondence to: Jennifer.L.Eigenbrode@ nasa.gov

505

This PDF file includes:

510

Materials and Methods

Supplementary Text

Figures. S1 to S11

Tables S1 to S10

References (32-56) 


\section{Materials and Methods}

\section{$\underline{\text { Samples and Geological Context }}$}

Samples are from three key locations: Yellowknife Bay, Pahrump Hills and Marais Pass. 525 They comprise the Sheepbed member of the Yellowknife Bay formation and the Murray formation for the two other localities. All of the samples have similar lithology dominated by parallel, finely laminated mudstones deposited in an ancient deltaic-lacustrine setting $(6,31)$. The lacustrine environments like that interpreted for Gale lake(s) strongly support the concentration, preservation, and potential formation (by microbiology) of organic matter as they do on Earth (9).

530 Details of the stratigraphy and geological context are presented elsewhere (3, 6-8, 31). In brief, John Klein (JK) and Cumberland (CB) drill targets are located in Yellowknife Bay. Yellowknife Bay occurs in the lowest point along the rover traverse ( $-4520 \mathrm{~m}$ elevation) which resides in a broad valley between the crater rim and central mound of Gale crater. This mudstone is thought to contain sediments transported by fluvial and deltaic processes from the crater rim

535 area to the north (31). They are stratigraphically within $\approx 10 \mathrm{~cm}$ apart, laterally about $3 \mathrm{~m}$ apart and differ in their diagenetic state, such that JK contains calcium sulfate-filled concretions and veins, while CB was observed to be largely vein-free (29). The veins and concretions likely indicate postdepositional diagenesis by groundwater (35). Pahrump Hills and Marais Pass are drill targets in the Murray formation of the lowermost portion of the Gale Crater central mound located about 6-

$5407 \mathrm{~km}$ southwest of Yellowknife Bay. The Pahrump Hills samples Confidence Hills (CH sample at $-4460 \mathrm{~m}$ elevation) is at the base followed by drill target Mojave 2 (MJ at $-4461 \mathrm{~m}$; number designates the second drill hole), and Telegraph Peak (TP at $-4453 \mathrm{~m}$ ). Buckskin (BK at $-4447 \mathrm{~m}$ ) occurs higher in the Marias Pass region.

Mineralogy of the mudstone samples consistently exhibits basaltic components (i.e.,

545 feldspar and mafic igneous minerals); however, in bulk composition they show significant differences (7). The Sheepbed mudstone contains iron oxides/hydroxides, traces of iron sulfides ( $1 \%$ by mass pyrrhotite in $\mathrm{JK}$ and $\mathrm{CB}$, and perhaps $0.3 \%$ pyrite in $\mathrm{JK}$ ), a Si/Fe/S-rich amorphous phase $(\sim 30 \%)(29,36)$, and authigenic Fe-smectite $(\sim 20 \%)$, which was probably formed by reaction of magnetite and olivine under circumneutral $\mathrm{pH}$ conditions (37). Oxychlorine phases

550 detected by SAM EGA and CheMin instruments are likely composed of perchlorate/chlorate and akaganeite $(2,3)$. The oxygen evolved from the perchlorate is responsible for combustion of SAM background and possibly some sample organics (2).

At Pahrump Hills/Marais Pass, the Murray mudstones mineralogy exhibits 27-54\% x-ray amorphous material composed largely of silica (5). The $\mathrm{CH}$ and $\mathrm{MJ}$ targets exhibits dendrites and 555 crystal laths of probable magnesium sulfate composition $(6,38)$. The $\mathrm{CH}$ and $\mathrm{MJ}$ samples also host phyllosilicates (5-8\%) of unknown origin and lesser amounts of jarosite and apatite (7). Magnetite abundance increases upsection but returns to low amounts at Marais Pass (BK target) and hematite consistently decreases upsection $\mathrm{CH}$ through $\mathrm{BK}$ samples. The top of this section (TP and BK) is unique in that it contains a high abundance of crystalline silica minerals: cristobalite 560 and tridymite. The $\mathrm{CH}, \mathrm{MJ}, \mathrm{TP}$, and BK samples also contain an oxychlorine phase that generates an $\mathrm{O}_{2}$ release below $500^{\circ} \mathrm{C}$. $\mathrm{CH}, \mathrm{MJ}$, and TP samples show a second higher temperature $\mathrm{O}_{2}$ release that is attributed to sulfate decomposition (3). Similar to the JK and CB samples, the presence of evolved $\mathrm{O}_{2}$ can complicate detection of organic molecules. Iron sulfides were not detected by the CheMin X-ray diffractometer in the lower Murray formation (7). 
The mineralogy and sedimentological features of the Yellowknife Bay and lowermost Murray formations suggest a complex geochemical history for the evolving Gale lake environment. Various hypotheses for lake conditions during Yellowknife Bay and early Murray deposition and subsequent aqueous events have been reported $(7,8,33)$. It is likely that both surface fluvial water and groundwater fed the lake basin. The lake surface environment may have

570 been relatively oxidizing due to ultraviolet radiation and oxidizing surface chemicals compared to more reducing, ferrous-iron bearing groundwater feeding the lake (8). Groundwater may have also delivered sulfides from hydrothermal sources (33). Lake water was probably circumneutral $\mathrm{pH}$ or alkaline; however, during diagenesis acidic fluids may have passed through the lower Murray formation $(7,35)$.

\section{$\underline{\text { SAM experimental methods }}$}

The SAM Evolved Gas Analysis/Gas Chromatography Mass Spectrometry (EGA/GCMS) 580 experiments described in the main text are for analysis of solid samples. Each sample was collected by a rotary-percussive drill from a depth of 1-5 centimeters from the rock surface and then was passed through a $150-\mu \mathrm{m}$ sieve in the Collection and Handling for In-Situ Martian Rock Analysis (39) before delivery of the $<150-\mu \mathrm{m}$ sized fraction to SAM via the Solid Sample Inlet Tube (SSIT). For each set of EGA/GCMS experiments, before samples were received by SAM, an empty quartz

585 cup was placed in the oven and heated to $\sim 900^{\circ} \mathrm{C}$, a process referred to as preconditioning. The cup design allows pure helium (99.999\%) to flow through a frit at the bottom of the sample reservoir and the outside of the cup to sweep analytes to the manifold. The pressure in the oven is held constant pressure at $\sim 25 \mathrm{mbar}$ and flows at $0.03 \mathrm{bar}-\mathrm{ml} / \mathrm{sec}$ (equivalent to $\sim 0.77$ standard $\mathrm{cm}^{3}$ per minute). Helium is introduced through a flow restrictor was flushed through the oven and

$590135^{\circ} \mathrm{C}$-heated manifolds, traps, GC, and then to the vent to condition the instrument suite for analysis $(10,40)$. No mass spectral data was collected by the quadrupole mass spectrometer (QMS) to conserve resources. On a subsequent sol, one or multiple portions of drill fines were then deposited into a quartz glass cup within the Sample Manipulation System (SMS) of SAM. Based on estimates of the portion volume and powder density from MSL's Sample Acquisition, Sample 595 Processing, and Handling testbed (39) experiments, models using geological materials with similar properties, and drop tests of a drilled mudstone in MSL testbeds at the Jet Propulsion Laboratory, each SAM portion is estimated to be $45 \pm 18 \mathrm{mg}$ ( $2 \sigma$ standard deviation). Each aliquot of sample delivered to SAM is designated target name-\# (e.g., Mojave 2-1 is the Mojave 2 drill target, first aliquot delivered to SAM but herein referred to as MJ for brevity).

600 For analysis, the samples were heated under the same helium flow from an initial temperature $\left(35^{\circ}-50^{\circ} \mathrm{C}\right.$, unless noted as a preheat temperature in Table S6) at nominal rate of $35^{\circ}$ $\mathrm{C} / \mathrm{min}$; however, the heating rate is significantly reduced once the sample temperature exceeds $\sim 750^{\circ} \mathrm{C}$ and the heater output is maximized. During heating, organic molecules evolve from larger organic components and minerals via several mechanisms: thermal desorption (volatilization), 605 pyrolysis (cleavage), or thermochemical reactions (e.g., hydrolysis induced by the presence of water during pyrolysis). In some cases, minerals that occlude organics at grain boundaries or within mineral crystals must first thermally decompose or decrepitate to allow organic materials to evolve. Inorganic chemicals also undergo chemical reactions; thus, heating induces an ongoing complex reaction chemistry. The efficiency of extraction of organic components is dependent on 610 instrument conditions and sample chemistry. 
For EGA, gases were sent through a short manifold and then passed by a capillary inlet to the QMS. The fixed capillary conductance is sized to keep the MS in a safe operating range while still admitting sufficient gas to realize good sensitivity and dynamic range in the QMS signal. The QMS scanned the 2-535 Da range for EGA characterization of bulk gases.

615 Only $0.125 \%$ of the gas flowing through the manifold enters the QMS for EGA. The remainder is sent to the GC, tunable laser spectrometer, or a vent. Gases sent to the GC represent the portion evolved over a select temperature range (called the GC cut) (Table S2). This portion is first passed over the cooled hydrocarbon adsorption trap and then thermally released to the GC injection trap $(1,10)$.

620 Following the EGA part of the EGA/GCMS experiment, the manifold is pressurized to nearly 1 bar and a flow of gas is established through one or more GC columns. Gas is thermally released from the hydrocarbon trap and the less volatile component is trapped on an injection trap in front of the GC column. After the column has been conditioned by flowing the carrier gas through the column and the QMS has been turned on, the gas trapped on the injection trap is rapidly 625 released by heating and held for several seconds. The injection trap focuses the analytes in a narrow band at the front of the column to achieve sufficiently narrow elution peaks for MS analysis. For all the GCMS experiments described here, the column used was a wall-coated open tubular column with a phenyl- and cyanopropyl-polydimethylsiloxane film. The column that targets organic compounds in the C5-C15 molecular weight range is designated GC5. More details of the GC oven 630 and MS parameters are reported elsewhere $(1,2)$. GCMS analyses were conducted on all solid samples except Telegraph Peak, for which only the EGA portion was implemented, and Buckskin, for which the GC portion of the experiment did not complete.

The sample mass and the temperature cuts selected for the GCMS analysis are given in Table S2 and S6. In the EGA part of the Mojave experiment, sufficient material was apparently 635 released to temporarily clog the injection trap. This was established by examining diagnostic data from pressure sensors and the signal from the QMS, which showed a backflow of atmospheric gas that would not have been present with the nominal flow through the GC column. Diagnostic experiments that introduced a pulse of helium gas into the manifold cleared the flow path through the injection trap, and since most of the gases evolved from Mojave were still trapped, a successful

640 GCMS run was subsequently implemented. As a result of this off-nominal GC run, some compounds show a $20 \mathrm{~s}$ shift in retention time.

Blank tests were conducted on preconditioned, empty cups prior to initial sample delivery at each site and were run under the same conditions as the first sample with the intent of providing a gauge for background signal strength and the presence of "sticky" volatiles from sample-to-

645 sample carryover, such as $\mathrm{SO}_{2}$ and $\mathrm{HCl}$. During blank experiments, the empty cup is exposed to the SMS and SSIT in the same manner as sample delivery.

A modified sample delivery approach was used for CB6, CB6-reheat, CB7 and CB blank2 tests in an attempt to reduce the amount of SAM instrument background. This modified approach entailed He-flushing and pumping of the SMS for $360 \mathrm{~min}$ and venting SMS volatiles to the 650 atmosphere. During this time, the SAM manifold was heated to $135^{\circ} \mathrm{C}$ and the oven was flushed with He. In addition, the sample cup was heated in the oven for 20 minutes to either $200^{\circ}$ or $249^{\circ} \mathrm{C}$ (Table S6) before moving the cup to the SSIT for sample delivery. During hot-cup transfer, the cup and contents (if any) cool to an unknown extent. For triple portion samples (CB6 and CB7), cup heating was done before each of the three separate portions, such that some of the sample was 655 heated to $249^{\circ} \mathrm{C}$ and the volatiles vented to atmosphere without detection. During CB6 reheat analysis (i.e., rerun of the residue remaining after the first analysis) and CB blank2 tests, the cup 
was processed in the same manner as $\mathrm{CB} 6$ and $\mathrm{CB} 7$, mimicking the motions of three sample portion deliveries (without actual delivery) so that SMS exposure would be comparable to the triple portion samples.

\section{SAM GC breadboard tests for confirmation of organic-sulfur compounds and naphthalene}

The retention times of the organic sulfur molecules were determined using a laboratory 665 ThermoFisher Scientific UltraTrace GC coupled to an ITQ mass spectrometer and run with SAMlike analytical conditions (column temperature and the carrier gas pressure and flow). Laboratory results offer a direct comparison to the retention time of molecules observed on the SAM flight model on Mars (Table S3). The GC column was a duplicate of the SAM GC5 column. Retention times for compounds (e.g. naphthalene) eluting from the column at high temperatures, i.e., after

670 the second injection trap flash heating, are challenging to replicate for the flight SAM instrument and retention times are not precise. Consequently, the possible EGA naphthalene detection for Mojave could not be precisely confirmed on the SAM GC breadboard. Benzothiophene does not elute from the GC5 column operated under SAM conditions.

\section{Characterization of the SAM instrument background in EGA}

A diverse set of masses in the bulk gas were released up to $350^{\circ}$ to $550^{\circ} \mathrm{C}$ (depending on the sample) that reflect both thermal desorption and pyrolysis largely attributable to reaction 680 products of the derivatization fluid composed of N-tert-butyldimethylsilyl-Nmethyltrifluoroacetamide (MTBSTFA) and dimethylformamide (DMF). This fluid leaked into the sample manipulation system after a foil-seal failed (41). Consequently, the reagents adsorb onto cup and sample surfaces, as cups are moved between oven and sample receiving position. For this reason, only EGA signals for the high temperature range $\left(>400^{\circ}\right.$ or $>550^{\circ} \mathrm{C}$ depending on sample)

685 are closely examined. Furthermore, contributions from known and suspected residual derivatization reaction products that evolve at high temperatures are subtracted from the raw data. Mass channels of interest were corrected for inputs from specific products and for trending background signals. This dual approach enables robust examination of the SAM EGA data for mudstone-derived signals.

Characterization of SAM instrument background in EGA derived from derivatization reagents

Understanding the nature and significance of the observed organic signatures in analyses of martian samples requires evaluation of the gases evolved over the full thermal range and a comprehensive, reproducible approach to distinguishing background from sample-derived organics. Organic molecules in the SAM instrument background are largely derived from the 4:1 (volume/volume) solution of N-methyl-N-(tert-butyldimethylsilyl)-trifluoroacetamide 700 (MTBSTFA; $\mathrm{C}_{9} \mathrm{H}_{18} \mathrm{~F}_{3} \mathrm{NOSi}$ ) and dimethylformamide (DMF; $\mathrm{C}_{3} \mathrm{H}_{7} \mathrm{NO}$ ) reagent $(1,41)$ stored in seven sealed cups within the SAM SMS to support the SAM derivatization experiment (10). No derivatization cups have been punctured as of the Pahrump Hills investigation, but the presence of 
reaction products in all martian analyses indicates a cup is leaking derivatization vapors into the SMS where they can be adsorbed and react with water, quartz glass cups and sample in the SMS $705(1,41)$.

In EGA, SAM background signals change in character during heating from $45^{\circ}$ to $860^{\circ} \mathrm{C}$. DMF is a solvent and proton acceptor for MTBSTFA and its presence has not been observed in SAM EGA or GCMS analyses. MTBSTFA is a silylating reagent that that replaces active hydrogen atoms of polar functional groups (alcohol hydroxyl, phenol hydroxyl, carboxyl, amine, and amide).

710 The reaction involves nucleophilic attack by the analyte heteroatom $(\mathrm{O}, \mathrm{N}, \mathrm{Cl}$, or $\mathrm{F})$ on the $\mathrm{Si}$ atom of the silylation reagent and forms tert-butyldimethylsilyl (TBDMS) derivatives (usually as TBDMS ethers $\left.\left[\left(\mathrm{CH}_{3}\right)_{3} \mathrm{CSi}\left(\mathrm{CH}_{3}\right)_{2}-\mathrm{O}-\mathrm{R}\right)\right]$ as intended for the experiment) and the byproduct: 2,2,2trifluoro- $\mathrm{N}$-methyl-acetamide (TFMA; $\mathrm{C}_{3} \mathrm{H}_{4} \mathrm{~F}_{3} \mathrm{NO}$ ). It also preferentially reacts with water vapor and hydrated minerals, $\mathrm{HCl}$, and $\mathrm{OH}$-sites on mineral surfaces $(40,41)$. Reaction products are both 715 volatile and non-volatile. Both volatile products and derivatized mineral surfaces can undergo pyrolysis (thermal cracking involving covalent bond cleavage). They are also susceptible to combustion in the presence of $\mathrm{O}_{2}$ released from the samples $(2,40,41,44,45)$. Combustion occurs in all samples due to the presence of oxychlorine phases and in some samples, other unknown chemicals. The MTBSTFA reagent in its most pure commercially available form is only $\geq 97 \%$

720 determined by GC and thus some of the signals observed in EGA at low temperatures may be directly volatilized impurities and the impurities would also be susceptible to combustion.

Consequently, a suite of molecular products characterizes the SAM instrument background (Table S5). Most products are released below $550^{\circ} \mathrm{C}$ in the presence of martian sediments $\left(400^{\circ} \mathrm{C}\right.$ for Yellowknife Bay mudstones) (Fig. S7). Both SAM solid sample analyses and laboratory analyses indicate that the inorganic sample chemistry (e.g., oxychlorine phases, other reactive phases, and mineral catalysts) has a significant effect on the temperature and character of MTBSTFA reaction products released. In blanks, products are released more continuously into $>550^{\circ} \mathrm{C}$ temperature range, which is comparable to laboratory silylation experiments of ashed fused silica. Pyrolysis of TBDMS-minerals generates C1-C4 aliphatic compounds, particularly

730 methane and methylpropene. This pyrolytic release reaches its maximum after the thermal desorption of volatile products and within the $400^{\circ}-750^{\circ} \mathrm{C}$ window.

After the bulk of the SAM instrument background volatiles are released below $550^{\circ} \mathrm{C}$, a steady but low level of the molecules persists into higher temperatures (Fig. S11). This portion is referred to as the tailing of the main release peak in any mass channel and is the portion of signal 735 removed during data processing to resolve the presence or absence of sample-related organic volatiles (see below). SAM EGA experiments occur at $\sim 0.03$ bar-ml/min helium flow (10) to conserve helium gas, which is a limited resource on the multiyear Mars mission. The SAM EGA flow condition differ from traditional laboratory thermal experiments conducted at $\geq 20 \mathrm{bar}-\mathrm{ml} / \mathrm{min}$ in the pyrolysis oven. The difference in volumetric flow and different pressures results in several 740 hundred times more mass flow in traditional lab analyses compared to SAM experiments on Mars. Lower mass flow in the oven is likely responsible for peak broadening and tailing of some analytes.

Based on SAM and laboratory analyses, the MTBSTFA reaction and pyrolysis products in Table S5 have been observed. Halogenated organic molecules are observed when inorganic halogen-containing species are present. Some molecules in the SAM instrument background include ions in their mass spectra with masses the same as those that are most diagnostic for some organic sulfur and aromatic compounds. For each potential conflict in molecular source assignments, tests were implemented to estimate the relative portion of the mass signal from background. Further, there are no known MTBSTFA-related contributions to $m / z$ 112; thus, these 
likely reflect another source of organic carbon (1).

750 Characterization of SAM instrument background in EGA from PTFE-contaminant delivery to SAM

The only known organic contaminant external to SAM is polytetrafluoroethylene (PTFE, trademarked as Teflon by DuPont, Inc.) debris physically abraded from a seal in the drill bit

755 assembly. Samples are delivered to SAM via Curiosity's drill and CHIMRA systems. Pyrolysis of PTFE has been well characterized (46) and it is responsible for a reproducible $\mathrm{m} / \mathrm{z} 81$ and 100 peak observed as a discrete peak at $\sim 550^{\circ} \mathrm{C}$ in some SAM analysis of drilled sample (Fig. S8), though of varying magnitude. Lab analyses demonstrate that PTFE pyrolysis products are not aromatic in nature and appear to be relatively non-reactive. Thus, PTFE does not contribute to any of the

760 signals assigned to organic sulfur or aromatic compounds and is unlikely to be related to aliphatic compounds observed at higher temperatures in samples.

Besides PTFE, the only other potential and suspect contaminants would be polyimide from tape (trademarked as Kapton by DuPont, Inc.) and phthalate plasticizers ubiquitous in terrestrial airborne particulates. If by remote chance these contaminants entered the SAM quartz cups for 765 pyrolysis, polyimide would have produced a very wide variety of aromatic compounds that should be readily detectable by SAM in both EGA and GC and they would evolve over the entire 500$860^{\circ} \mathrm{C}$ range (47). The results observed for drilled samples by SAM are inconsistent.

Phthalate esters thermally decompose at $\sim 425^{\circ} \mathrm{C}$ and their products are largely functionalized single-ring aromatic moieties that are expected to produce chlorobenzene (48) in

770 the presence of $\mathrm{HClgas}$. Martian samples show $\mathrm{HCl}$ gas release into high temperatures (3). If this scenario had occurred, then chlorobenzene should have been observed in the four Rocknest series of analyses. Chlorobenzene was not observed in Rocknest. Since phthalate particles are not expected from the martian environment or from delivery via the drill and CHIMRA systems, particularly after multiple uses, and the temperature of pyrolysis is inconsistent with all observed

775 occurrences of chlorobenzene and other masses suggestive of aromatics, it is highly unlikely that terrestrial phthalates are the source of aromatic compounds in the SAM analyses.

\section{Characterization of the SAM instrument background in GC}

780

Additional components contribute to the SAM internal background for GC analyses. These are the hydrocarbon trap that contains Tenax TA adsorbent and the injection trap to the GC5 column that contains Tenax GR. Both are made of 2,6-diphenyl-p-phenylene oxide that undergoes thermal and chemical degradation with use and releases aromatic compounds and perhaps aliphatic

785 compounds. Miller et al. (48) and Freissinet et al. (1) review details of Tenax degradation products and their implications.

Importantly, several valves present in the flow path between the He tanks, oven and the gas-line manifold with the hydrocarbon trap prevent backflow of Tenax degradation products to the portion of the instrument used for EGA (see Figure 3 of Freissinet et al. (1)). When the valves 790 are open, helium flows away from the EGA portion and flushes the traps and GC portion to a vent. Furthermore, the $135^{\circ} \mathrm{C}$-heated manifolds are sufficiently warm to volatilize $\mathrm{GC} /$ trap derived background organic molecules, which would be flushed from the gas lines during the preparation and preheat stages of each experiment and could not produce peaks in EGA profiles. GC/trapderived background organic molecules are not contributing to EGA signals. 

organic molecules

EGA mass channel data (or $\mathrm{m} / \mathrm{z}$ profiles) were corrected for known or assumed ion 800 The objective of the corrections was to calculate a $\mathrm{m} / \mathrm{z}$ profile that more accurately reflects the evolution of particular volatiles and their abundances.

Relative molar response (RMR) of mass fragment intensities were determined based on the mass spectra for one or multiple volatile contributions to be removed. The RMR calculated for

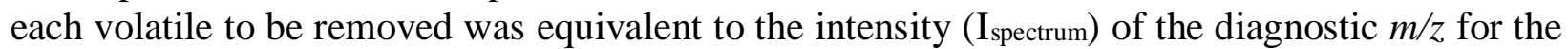
805 volatile of interest (X) relative to that of the diagnostic $\mathrm{m} / \mathrm{z}$ for volatile contribution to be removed (Y) (Eq. 1). Published NIST mass spectra were used if SAM pre-flight or testbed data were not available.

Eq. $1 \quad \mathrm{RMR}_{\mathrm{X} / \mathrm{Y}}=\mathrm{IX}$, spectrum $/ \mathrm{IY}$, spectrum

Each RMR was then applied to the signal intensity for each time stamp of Y measured by $\mathrm{SAM}\left(\mathrm{Y}_{\mathrm{m}}\right)$ in counts per second (cps) to determine the amounts to be removed from one or more volatiles (volatiles $\mathrm{A}, \mathrm{B}$, etc.) from X measured by SAM ( $\left.\mathrm{X}_{\mathrm{m}}\right)$ (Eq. 2a-c). Importantly, all mass channel data measured by SAM was first mildly smoothed (11-point moving average) to some

815 reduced analytical noise. Mass channel corrections also required that the data of different $\mathrm{m} / \mathrm{z}$ profiles be checked for matching time stamps so that data of the same scan were used in each calculation.

Eq. 2a $\quad X_{c}=X_{m}-\left(Y_{m} * R M R X / Y\right)$

Eq. 2b $\quad \mathrm{X}_{\mathrm{c}}=\mathrm{X}_{\mathrm{m}}-\left(\mathrm{Y}_{\mathrm{m}} * \mathrm{RMRX/Y}\right.$ for volatile $\left.\mathrm{A}\right)-\left(\mathrm{Y}_{\mathrm{m}} * \mathrm{RMRX/Y}\right.$ for volatile $\left.\mathrm{B}\right)$

Eq. 2c $\mathrm{X}_{\mathrm{c}}=\mathrm{X}_{\mathrm{m}}-\left(\mathrm{Y}_{\mathrm{m}} * \mathrm{RMR} \mathrm{X} / \mathrm{Y}\right.$ for volatile $\left.\mathrm{A}\right)-\left(\mathrm{Y}_{\mathrm{m}} * \mathrm{RMR} \mathrm{X} / \mathrm{Y}\right.$ for volatile $\left.\mathrm{B}\right)$ $-\left(\mathrm{Y}_{\mathrm{m}} * \mathrm{RMR} \mathrm{X} / \mathrm{Y}\right.$ for volatile $\left.\mathrm{C}\right)$

Corrections to the $\mathrm{m} / \mathrm{z} 78$ mass channel are given here as an example and the explanation for these corrections is given in the "Data Processing: EGA mass profile corrections for SAM instrument background and dichloromethane" section. In this case, the fully corrected $\mathrm{m} / \mathrm{z} 78$ profile $(\mathrm{m} / z$ 78c) used in interpretations reflects the presence of benzene and related single-ring 830 aromatics that produce a $\mathrm{m} / \mathrm{z} .78$ ion (e.g., aryl ethers) in evolved gases, i.e., the "volatile of interest." To remove contributions from TFMA and TBDMS-Cl (when applicable) from the SAM instrument background, the RMR of $m / z 78$ to 127 was calculated from the TFMA mass spectrum, the RMR of $\mathrm{m} / \mathrm{z} 78$ to 77 was calculated from the TBDMS-F mass spectrum, and the RMR of $\mathrm{m} / \mathrm{z}$ 78 to 93 was calculated from the TBDMS-Cl mass spectrum (Eq. 3a-c). Each data point in the $\mathrm{m} / \mathrm{z}$ $83578 \mathrm{c}$ profile $\left(\mathrm{X}_{\mathrm{c}, 78)}\right.$ for each sample according to Eq. 4a, except for Confidence Hills which required an additional correction for TBDMS-Cl contributions to $\mathrm{m} / \mathrm{z}, 78$ (Eq. $4 \mathrm{~b}$ ).

Eq. 3a RMR $78 / 127$ for TFMA $=\mathrm{I}_{78} / \mathrm{I}_{127}$ from the TFMA mass spectrum 
Eq. 3c $\quad \mathrm{RMR}_{78 / 93}$ for TBDMS-Cl $=\mathrm{I}_{78} / \mathrm{I}_{93}$ from the TBDMS-Cl mass spectrum

Eq. 4a $\quad \mathrm{X}_{\mathrm{c}, 78}=\mathrm{X}_{\mathrm{m}, 78}-\left(\mathrm{Y}_{\mathrm{m}, 127} * \mathrm{RMR}_{78 / 127 \text { for TFMA }}\right)-\left(\mathrm{Y}_{\mathrm{m}, 77} * \mathrm{RMR}_{78 / 77 \text { for TBDMS-F})}\right.$

Eq. 4b $\quad \mathrm{X}_{\mathrm{c}, 78}=\mathrm{X}_{\mathrm{m}, 78}-\left(\mathrm{Y}_{\mathrm{m}, 127} * \mathrm{RMR} 78 / 127\right.$ for TFMA $)-\left(\mathrm{Y}_{\mathrm{m}, 77} * \mathrm{RMR}_{78 / 77 \text { for TBDMS-F })}\right.$ $-\left(\mathrm{Y}_{\mathrm{m}, 93} * \mathrm{RMR} 78 / 93\right.$ for TBDMS-Cl$)$

850 Data Processing: EGA mass profile corrections for SAM instrument background and dichloromethane

Mass profiles of interest for potential thiophene and aromatic compounds were corrected for contributions assumed to be from known SAM instrument background, though it is uncertain

855 if some dichloromethane is from the sample (41). See "Characterization of SAM instrument background in EGA derived from derivatization reagents" section above for more detailed information of the source of the molecules._Applicability and utility of corrections were explored on a case-by-case basis. Details of that investigation are presented here.

TFMA (2,2,2-Trifluoro-N-methylacetamide) is clearly detected in EGA by the correlated

$860 \mathrm{~m} / \mathrm{z}, 58$ and 127 profiles. TFMA mainly evolves below $350^{\circ} \mathrm{C}$ in CB2-5 and JK4, below $400^{\circ} \mathrm{C}$ in $\mathrm{MJ}, \mathrm{CH}$, and TP samples, and below $525^{\circ} \mathrm{C}$ in BK. In nominal blanks, TFMA evolves up to $800^{\circ} \mathrm{C}$. SAM experimental modifications for the CB6, CB7, and CBblank2 tests were effective at eliminating this MTBSTFA reaction product all together. In other samples, TFMA may be contributing ion fragments of other masses of interest (Table S5) at higher temperatures due to its

865 tailing evolution (e.g., Fig S7). No TFMA correction was applied to reported $\mathrm{m} / \mathrm{z}, 97$ or 128 data because these masses are of sufficiently low RMR $(<0.02)$ compared to $m / z 58$, the base peak. In contrast, TFMA contributions to $m / z 78$ (diagnostic for benzene) are significant enough to warrant correction. A comparative test was conducted to determine which $\mathrm{m} / \mathrm{z}$ value to use as representative of TFMA contributions to the $m / z 78$ profile. Two options for the TFMA correction

870 were considered: Assuming $\mathrm{m} / \mathrm{z}, 58$ is solely from TFMA and using it for the correction, or using the much lower intensity, $m / z 127$ channel (RMR of 0.24 ) for the correction. The former approach results in over-correction since it ignores small amounts of $m / z 58$ contributed from $\geq C 4$ aliphatic compounds. Correction based on $\mathrm{m} / \mathrm{z}, 127$ may result in under-correction due to the weaker intensity representative for TFMA. There is no single solution. Thus $\mathrm{m} / \mathrm{z} 127$ was used to correct

875 for TFMA contributions to the $m / z, 78$ signal and further correction for the baseline was applied if necessary to remove residual signal suspected of a TFMA peak. This approach was taken to be certain of the presence of some sample-related signal that suggest a benzene composition. All data for $m / z, 78 \mathrm{c}$ is reported with TFMA contributions removed using $m / z 127$.

TBDMS-F (tert-butyldimethylsilyl fluoride) also contributes to $m / z, 78$ as well as $m / z 134$.

880 It is detected below $500^{\circ} \mathrm{C}$ in $\mathrm{CB} 2-5, \mathrm{JK} 4, \mathrm{CH}, \mathrm{MJ}, \mathrm{TP}$, and BK samples. In CB6-7, TBDMS-F is barely detectable below $500^{\circ} \mathrm{C}$. $\mathrm{CB}$ blank1, $\mathrm{CB}$ blank2, and $\mathrm{CH}$ blank show a release up to at least $700^{\circ} \mathrm{C}$. TBDMS-F corrections were investigated assuming all of $\mathrm{m} / \mathrm{z} 77$ above $400^{\circ} \mathrm{C}$ is from TBDMS-F. As with the TFMA correction above, the TBDMS-F probably over-corrects the data since it ignores lesser contributions of $m / z, 77$ from possible sample-derived aromatic compounds.

885 Despite this methodology shortcoming, a TBDMS-F correction applied to $\mathrm{m} / \mathrm{z} 134$ and $\mathrm{m} / \mathrm{z}$.78c profiles had no qualitative impact on interpretations of peak presence and absence, but the 
TBDMS-F correction applied to $\mathrm{m} / \mathrm{z} 78 \mathrm{c}$ did influence the peak areas on a qualitative basis. Thus, all $\mathrm{m} / \mathrm{z} 78 \mathrm{cc}$ data is reported with an additional TBDMS correction. No correction for TBDMS-F was applied to $m / z 134$.

890 TBDMS-Cl (tert-butyldimethylsilyl chloride) is a third potential contributor to $\mathrm{m} / \mathrm{z} 78$ but it is readily identifiable by the correlated $\mathrm{m} / z 93$ and 95 traces. The only EGA profiles where its presence is suspected is in $\mathrm{CH}$ sample at $\sim 500^{\circ} \mathrm{C}$, so the TBDMS-Cl contribution of $\mathrm{m} / \mathrm{z} 78$ was subtracted from the mass channel in addition to the above.

Cyanogen bromide is observed below $500^{\circ} \mathrm{C}$ as strongly correlated $\mathrm{m} / \mathrm{z} 105$ and 107

895 profiles in a 1:1 ratio in JK4, CB2-5. At higher temperatures and in other samples, qualitative correlations are observed, but the 105/107 mass ratio is inconsistent with $\mathrm{CNBr}$, suggesting contributions from other components that contribute both $\mathrm{m} / \mathrm{z} 105$ and 107 in different proportions. No corrections for $\mathrm{CNBr}$ were applied to data.

Bromomethane (BM) is observed in JK4, CB6, CB7 CH, TP, and BK samples at $\angle 500^{\circ} \mathrm{C}$, 900 as strongly correlated $\mathrm{m} / \mathrm{z}, 94$ and 96 profiles in a $\sim 1: 1$ ratio and may contribute to $\mathrm{m} / \mathrm{z} 91$. However, the variations in the $\mathrm{m} / \mathrm{z}, 91$ mass channel for samples above $500^{\circ} \mathrm{C}$ are large and the RMR for 91/94 is small enough (0.07) that BM corrections had no quantitative or qualitative impact on the profile at an interpretable level.

Chloromethylpropene was also investigated as a contributor to the $\mathrm{m} / \mathrm{z} 91$ profile. It is 905 difficult to identify in EGA due to a lack of diagnostic ions. More importantly, the 90/91 mass ratio observed contradicts the expected ratio if most of $\mathrm{m} / \mathrm{z}, 91$ was from chloromethylpropenes. Thus, no mass channel corrections were applied to $m / z 91$.

Dichloromethane can interfere with the detection of thiophene $(\mathrm{TH})$ by EGA via its diagnostic mass, $\mathrm{m} / \mathrm{z}$ 84. Only in $\mathrm{CH}$ and MJ samples does DCM evolution (confirmed by both

$910 \mathrm{~m} / z 84$ and 86 for its ${ }^{35} \mathrm{Cl}$ and ${ }^{37} \mathrm{Cl}$ isotopologues) overlap with thiophene. There is no indication of DCM release above $400^{\circ} \mathrm{C}$ in other analyses, based on the lack of correlative variations in the $\mathrm{m} / \mathrm{z} 84$ and 86 profiles. In $\mathrm{CH}$ and $\mathrm{MJ}$ samples, the $\mathrm{m} / \mathrm{z} 86$ channel that records ${ }^{37} \mathrm{Cl}$-DCM evolution is complicated by the evolution of $\mathrm{SiF}_{4}$ above $766^{\circ} \mathrm{C}$ also observed only in these two samples. Therefore, before applying the DCM correction to $m / z 84$ for assessment of thiophene, the $\mathrm{m} / \mathrm{z} 86$

915 channel was first corrected for contributions from $\mathrm{SiF}_{4}$ derived from an unknown mineral source in samples. This was achieved most effectively by baseline subtraction using $\mathrm{m} / \mathrm{z} 85$ (base peak of $\mathrm{SiF}_{4}$ ) as a guide for the peak temperature range (see below for a description of baseline subtraction) to generate $m / z$ 86c. The $m / z 84$ channel for $\mathrm{CH}$ and $\mathrm{MJ}$ samples was then corrected for contributions from dichloromethane (using $\mathrm{m} / \mathrm{z}$ 86c).

920 SAM instrument background also contributed to signals interpreted as aliphatic hydrocarbons or cyanides (e.g., methylpropene, propene, ethylene, methane, and hydrogen cyanide), however these were corrected using background subtraction (see "Data Processing: Baseline subtraction of SAM instrument background above $400^{\circ} \mathrm{C}$ " section) guided by SAM blank and laboratory experimental results.

\section{Data Processing: EGA mass profile corrections for other volatiles}

The following mass channel corrections were applied to mass channels diagnostic of particular 930 gases:

- $\boldsymbol{m} / \mathbf{z}$ 62c is derived from the $\mathrm{m} / \mathrm{z} 62$ channel (diagnostic of dimethylsulfide) corrected for contributions from carbonyl sulfide $(\mathrm{m} / \mathrm{z} 60)$ 
- $m / z 47 \mathrm{c}$ is derived from the $\mathrm{m} / \mathrm{z} 47$ channel (diagnostic of methane thiol) corrected for contributions from dimethylsulfide $(\mathrm{m} / \mathrm{z}, 62 \mathrm{c})$

$935-\boldsymbol{m} / \mathbf{z} \mathbf{4 5} \mathrm{c}$ is derived from the $\mathrm{m} / \mathrm{z} 45$ channel (diagnostic of $\mathrm{CO}_{2}$ isotopologue) corrected for contributions from dimethylsulfide $(\mathrm{m} / \mathrm{z} 62)$

- $\quad m / z 28 c$ is derived from the $m / z 28$ channel (assumed to be mostly from carbon monoxide with lesser amounts from possible hydrocarbons) corrected for contributions from $\mathrm{CO}_{2}$ ( $\mathrm{m} / \mathrm{z}, 45$ for the $\mathrm{CO}_{2}$ isotopologue; $\mathrm{m} / \mathrm{z}, 44$ saturates the detector), carbonyl sulfide $(\mathrm{m} / \mathrm{z}, 60)$

$940 \quad$ and dimethylsulfide $(\mathrm{m} / \mathrm{z}, 62 \mathrm{c})$

- $m / z 29$ is derived from $m / z, 29$ channel corrected for contributions from isotopically enriched $\mathrm{CO}$ base on $\mathrm{m} / \mathrm{z} 28 \mathrm{c}$

- $m / z$ 32c reflects oxygen evolution and it was derived from $m / z 32$ channel corrected for significant contributions from $\mathrm{SO}_{2}(\mathrm{~m} / \mathrm{z} 66)$. RMR for $66 / 32$ used in calculations was $6.3 \mathrm{e}-$

$94501 \pm 1.0 \mathrm{e}+01(1 \sigma$ standard deviation) and was based on five analyses of calcite/melanterite on the SAM flight model before launch. The $\mathrm{SO}_{2}$ isotopologue is used since $\mathrm{m} / \mathrm{z} 64$ saturates the detector on occasion.

- $\quad m / z 34 c$ reflects dihydrogen sulfide evolution and it was derived from the $m / z 34$ channel corrected for contributions from $\mathrm{SO}_{2}(\mathrm{~m} / \mathrm{z}, 66)$ and $\mathrm{O}_{2}(\mathrm{~m} / \mathrm{z}, 32 \mathrm{c})$. RMR for 66/34 used in

950 calculations was $4.8 \mathrm{e}-02 \pm 2.3 \mathrm{e}-01$ ( $1 \sigma$ standard deviation) and was based on five analyses of calcite/melanterite on the SAM flight model before launch. RMR for 34/32 used in calculations, 4.0Ee-03 $\pm 2.0 \mathrm{e}-01$ ( $1 \sigma$ standard deviation), is the ratio observed in Rocknest analyses and assumes the low temperature evolution of $m / z, 34$ reflects the main $\mathrm{O}_{2}$ release (3).

955

Data Processing: Smoothing and implications on peak maxima and minima in EGA moving average since this two-step smoothing was found to reduce most analytical noise without compromise to the identification of peak maxima and valley minima. Peaks and valleys in the smoothed EGA data are not smoothing artifacts as determined by comparison to data smoothed using only 5-, 11-, 21-, and 31- point moving averages. Consequently, temperatures assigned to peaks have an error of $\pm 25^{\circ} \mathrm{C}$. Peak areas (described in the baseline subtraction section below) 965 determined using the smoothing approach described here compared to peaks areas using raw data indicate that smoothing introduces $5 \%$ uncertainty $(1 \sigma$ standard deviation for many $\mathrm{m} / \mathrm{z}$ profiles and many samples).

\section{Data Processing: Baseline subtraction of SAM instrument background above $400^{\circ} \mathrm{C}$}

Figures show EGA profiles with the trending baseline subtracted (Fig. S11) from the profile. The baseline subtraction approach assumes that all organic volatiles that begin their evolution below $500^{\circ} \mathrm{C}$ are potentially derived from the instrument background (i.e., MTBSTFA 975 reagent and its reaction products; see "Characterization of SAM instrument background in EGA from derivatization reagents" section above). While this may not be the case for all molecules (e.g., chlorobenzene (1)) it was a necessary simplification in the data processing rationale. It was also assumed that the background volatiles that started evolving below $500^{\circ} \mathrm{C}$ are best 

two features are observed in SAM analyses of samples and blanks as well as laboratory EGA tests with the derivatization reagents (Fig. S7). For blanks, the main peaks tend to reach its maximum

Furthermore, it was assumed that all $\mathrm{m} / \mathrm{z}$ profiles for mudstone analyses were impacted by combustion. All mudstones analyzed by SAM showed an $\mathrm{O}_{2}$ release attributed to the decomposition of oxychlorine phases (e.g., perchlorates, chlorates, etc.) that largely occurred

985 below $500_{-}^{\circ} \mathrm{C}$ and this $\mathrm{O}_{2}$ results in combustion of organic components (cite Leshin, Ming, Glavin, Freissinet, Sutter, Stern). In EGA, combustion is indicated by the release of $\mathrm{CO}_{2}$ closely associated the $\mathrm{O}_{2}$ release. A consequence of combustion, particularly for readily ignitable volatile components, is an interruption in their detectable signal because there is a momentary loss in actual volatiles. Examples of this interruption in signal are shown in the $\mathrm{CF}_{3}$ (orange line) and 990 methylpropene (pink line) at $\sim 280^{\circ} \mathrm{C}$ for the Laboratory: TBDMS-FS120 + $1 w t . \% \mathrm{Fe}(\mathrm{II})-$ Perchlorate EGA profiles of Figure S7. In some cases, this feature was easily recognizable because the $\mathrm{m} / \mathrm{z}$ profiles of interest showed a valley during $\mathrm{O}_{2}$ release followed by a peak that fit the tailing trend of the main peak. In other cases, it was not so obvious. In those cases, it was assumed that the first peak observed in the $\mathrm{m} / \mathrm{z}$ profile on interest that followed the $\mathrm{O}_{2}$ release, was the last 995 portion of the main peak. Such is the case for the Mojave EGA $m / z 43$ profile in Figure S11. Although we cannot be certain that combustion is impacting every $m / z$ profile in the manner described, a conservative approached claiming this assumption was adopted to rule out as many known and suspect contributions from the SAM instrument background.

The assumptions were used to set two criteria for the baseline: 1) the baseline curve must

1000 approximate the tail of main peak that occurred below $500_{-}^{\circ} \mathrm{C}$, and 2 ) the baseline curve must begin immediately after any post-combustion peak that may represent a return to release of components associated with the main peak. Each baseline was drawn using OriginPro software (Origin Lab Corporation, USA) and the "spline" baseline option on smoothed data. Baselines were determined by the person conducting the data processing to meet the two criteria. Baseline subtraction from 1005 each $\mathrm{m} / \mathrm{z}$ profiles results in a flat line prior to the start of the baseline and the flat line denotes signal that is not relevant to the subsequent analysis. Accordingly, blanks with main peaks extending well past the $500_{-}^{\circ} \mathrm{C}$ mark have processed EGA profiles with a flat line past $500_{-}^{\circ} \mathrm{C}$. If there was no main peak in a $m / z$ profile, then the baseline was drawn as a horizontal line from the lowest point in the profile after $500_{-}^{\circ} \mathrm{C}$.

1010 EGA profiles shown in figures and abundance estimates found in tables reflect results using the most cautious estimate of SAM background contributions to the $m / z$ profile. As such, estimated abundances reflect the lower limit of non-background, organic components released at high temperature. Further, these estimates take no account of any organic components remaining in the sample residue after heating. Estimated abundances have propagated errors that include a 30\%

1015 uncertainty in peak integration ( $1 \sigma$ standard deviation) that was determined by drawing different baselines for several $\mathrm{m} / \mathrm{z}$ profiles and for different SAM analyses. This uncertainty was generalized and applied to all abundance calculations.

1020 Quantitation: Thiophenes, aromatics and C1-C2 sulfur compounds observed in EGA

The goal of the molar estimate was to establish a lower limit for the order of magnitude of carbon abundance. Thus, a conservative approach was taken to assess molecular abundances for gases evolved at high temperature that employs baseline-subtracted mass channels as described 
1025 above such that the resulting abundances represent a lower limit to the amount present. Molar abundances were estimated assuming the molecule diagnostic of a mass channel was solely responsible for the signal observed unless the mass profile was previously corrected (described above). For the $\mathrm{C} 1-\mathrm{C} 2$ sulfur compounds $\left(\mathrm{COS}, \mathrm{CS}_{2}, \mathrm{CH}_{3} \mathrm{SH}\right.$, and $\left.\left(\mathrm{CH}_{3}\right)_{2} \mathrm{~S}\right)$ the baseline was assumed horizontal from the time marker "start of pyrolysis," unless there appeared to be an overall 1030 decreasing background trend (e.g., most blanks) and then a slope was used. If a slope was applied it was based on slope established by the earliest portion of the pyrolysis.

It was assumed that the primary ion used for identification of molecules in EGA solely reflected contributions from the designated molecule. Estimates of molar abundances require application of $70-\mathrm{eV}$ electron-impact ionization cross section (ICS) constants as either total 1035 ionization cross section of a molecule $\left(\right.$ TICS $\left._{M}\right)$ or partial ionization cross sections for an ion

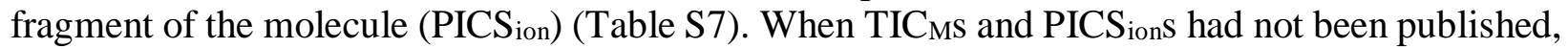
either they were calculated using the Binary-Encounter-Bethe (BEB) model by Karl Irikura (Chemical and Biochemical Reference Data Division, National Institute of Standards and Technology, Gaithersburg, MD), or the relative molar response (in this case, RMR is the ratio of 1040 one ion to the sum of ions for the molecule (M) and is also called the molecular-ion branching fractions) was applied to the TICS $_{M}$ according to Equation 5 in order to derive a PICS(ion). RMRs were based on NIST mass spectral references and were assumed to have $20 \%$ uncertainty (34)TICSMS calculated from the BEB model were also assumed to have $20 \%$ uncertainty (49) if uncertainty was not specified in publication. Of note, the SAM QMS was tuned to match the

1045 relative intensities in the NIST mass spectrum of PFTBA and thus we expect observed molecular spectra to closely match NIST spectra.

Cross sections were applied to estimate molar abundances according to Equation 6. The $\mathrm{CO}_{2}$ calibration factors were determined using pre-flight data of calcite (50). Specifically, those calibration factors are: $2.012808 \times 10^{-6} \pm 7.371886 \times 10^{-8}$ nanomol calcite/counts $\mathrm{CO}_{2}$ for SAM 1050 FM oven $1,1.681215 \times 10^{-6} \pm 1.399504 \times 10^{-7}$ nanomol calcite/counts $\mathrm{CO}_{2}$ for SAM FM oven 2. A single portion was assumed for all blanks except the repeated analysis of the CB6 material (CB6r). Single portion size of drilled fines was $45 \pm 18 \mathrm{mg}$ (135 $\pm 31 \mathrm{mg}$ for triple portions). Results are presented as nanomole C or S in Table 1, S1 and S4. Results calculates as nanomole molecules are in Table S8. Respective concentrations are given in Table S9 and S10.

Eq. 5. $\mathrm{PICS}_{\mathrm{ion}}=\mathrm{TICS}_{\mathrm{M}} * \mathrm{RMR}_{\mathrm{ion} / \mathrm{M}}$

Eq. 6. nanomole of molecule $=\mathrm{CO}_{2}$ calibration factor $*$ [Peak Area of ion / PICS $\mathrm{S}_{\text {ion }}$, where $\mathrm{CO}_{2}$ calibration factor $=$ nanomol calcite/counts $\mathrm{CO}_{2} * \mathrm{TICSCO}_{2}$

Quantitation of aromatic contributions from the $\mathrm{m} / \mathrm{z} 105$ profiles, which may reflect various alkylbenzene contributions or benzoate ion, such as from benzoic acid, were limited to the availability of ionization cross sections. Only benzoic acid ICSs were available. Thus, for 1065 quantitation purposes, benzoic acid was used as a proxy for carbon and molecular abundances reflected in the $\mathrm{m} / \mathrm{z} 105$ profiles. 


\section{Quantitation: Aliphatic compounds observed in EGA}

Aliphatic compounds abundance estimates are, at best, semi-quantitative and the calculations require several assumptions. Mass profile data of EGA reflects parent and fragment

1075 ions of the bulk gas evolving from the oven at any time during the experiment. The possible molecular contributions are numerous and the uncertainty is difficult to constrain.

In general, hydrocarbon pyrolysis products tend to have higher abundances in low carbon number structures compared to many carbon structures. This applies to molecular groups, such as alkanes and alkenes. Alkane abundance tends to be greater than or equivalent to alkene abundance

1080 (13). These generalities are assumed for mudstone aliphatic compound abundance estimates. In EGA, disparate fragmentation patterns for $\mathrm{C} 1-\mathrm{C} 5$ components complicate such relationships, especially if the C1-C5 contributions are derived from >C5 parent molecules that have significantly weaker ion intensities for fragments that exceed 5 carbons. Such is typical of aliphatic components. The C1-C5 hydrocarbon contributions observed in Gale crater mudstones may be

1085 from a diverse suite of molecules that extend to higher carbon identities, but for the sake of simplifying the abundance estimates, only $\mathrm{C} 1-\mathrm{C} 4$ molecular components are considered and in proportions that reflect $\mathrm{C} 1>\mathrm{C} 2>\mathrm{C} 3>\mathrm{C} 4$ and alkane $\geq$ alkene trends. Further, the peak areas for $\mathrm{m} / \mathrm{z} 15$ and $\mathrm{m} / \mathrm{z} 56$ were assumed to reflect contributions primarily from methane and butenes, since the ions have strong relative intensities in these spectra and are the only reasonable sources with the $\mathrm{C} 1-\mathrm{C} 5$ constraint. Estimates maximize the saturated and unsaturated hydrocarbon inputs and account for most of the residual $\mathrm{m} / 2$ 30, 27, and 26 signals with the addition of $\mathrm{NO}$ and $\mathrm{HCN}$.

Estimates are modeled using step-by-step subtraction of the signal intensities attributable to each component. Each step resulted in a set of residual ion peak areas. Residual ion values were maintained within the propagated errors for initial integrated $\mathrm{m} / \mathrm{z}$ profile peak areas. For example, 1095 a percentage of the $\mathrm{m} / \mathrm{z}, 15$ counts that make up the total $\mathrm{m} / \mathrm{z}, 15$ signal was assigned to methane (usually 90-99\%). Since methane has few ions in its mass spectra, no subtractions from total counts for other $\mathrm{m} / \mathrm{z}$ values were made. Next, a percentage of $\mathrm{m} / \mathrm{z} 30$ counts was assumed to be from ethane. Correlative amounts of other ions based on the ethane mass spectra were subtracted from residual $\mathrm{m} / \mathrm{z}$ counts. This process continued with propane $(\mathrm{m} / \mathrm{z} 29)$, ethene $(\mathrm{m} / \mathrm{z} 27)$, propene $(\mathrm{m} / \mathrm{z}$ 1100 41), 1-butene and 2-butene $(\mathrm{m} / z$ 56), and $\mathrm{HCN}$ (assigned to leftover $\mathrm{m} / z 27$ ). Not all of the residuals were expended and the percentage of the sum of peak areas represented is reported. Modeled $\mathrm{m} / \mathrm{z}$ counts attributed to each molecule were then used to calculate nanomole carbon abundances of each aliphatic compounds. Percentages used for each step were adjusted until the alkane-alkene pattern described above was achieved. Total aliphatic compounds abundances and propagated

1105 errors are given in Table 1. Respective concentrations are given in Table S10.

\section{Quantitation: GCMS data}

1110 Estimated abundances of molecules detected in GC (Table S1) were determined by comparison to the five measurements of hexane conducted on the SAM instrument during preflight calibration (10). Hexane calibration error is propagated from the standard error of the hexane measurements (14.2\% of average) and hexane TICS error (Table S7).

A Gaussian fit was applied to detected peaks. For each molecule quantified in GC data, the

1115 total ion signal for the molecule was calculated from the sum of integrated peak areas and extrapolated peak areas for the other masses based on the RMR from NIST mass spectra (34). The 
sum of peak areas was assumed to be equivalent to the total ion count for the molecule. Total ionization cross sections for both hexane (TICS hexane$_{\text {) }}$ and the selected molecule (TICSM) detected in GC were applied in the molecular abundance calculation (Eq. 7). GCMS quantitation errors are

1120 propagated from hexane calibration error, peak integration error (assumed 14.2\%), and TICS $_{M}$ errors (Table S7).

Eq. 7 nanomole of molecule $=$ Hexane calibration factor $*$ Sum of Peak Areas $/$ TICS $_{\mathrm{M}}$, where hexane calibration factor $=$ nanomole hexane/counts hexane $*$ TICS $_{\text {hexane }}$

\section{Analog Tests: SAM Testbed EGA method for Murchison meteorite}

A powdered aliquot of the Murchison meteorite (USNM 6650) was acquired from the

1130 Smithsonian Institution. Six milligrams were added to a small nickel cup with ashed quartz wool to hold it in place. The capsule was lowered into a quartz cup in the SAM testbed SMS using a pronged grabbing tool. It was later run using similar analytical conditions as CB3 with the testbed in the Mars environmental chamber set to conditions similar to those experienced by SAM during martian analyses. EGA results are presented in Fig. S9.

\section{Analog Tests: Laboratory EGA analysis of the Tissint meteorite}

A small chunk of the Tissint martian meteorite $(87 \mathrm{mg})$ was very finely powdered in an

1140 agate mortar with pestle that was first rinsed once with acidic methanol $\left(2 \% \mathrm{HCl}, 8 \% \mathrm{H}_{2} \mathrm{O}, 90 \%\right.$ methanol) then three times each with methanol, acetone, and $n$-hexane before each use. All solvents were Fisher Optima brand. Hydrochloric acid used for making acidic methanol was double-distilled $\mathrm{HCl}$ from GFS Chemicals.

The Tissint martian meteorite was analyzed using a Frontier Autoshot-PY3030D pyrolyzer 1145 attached to an Agilent 7890A gas chromatograph (GC) fitted with a Restek MTX-5 (length 30 m, internal diameter $0.25 \mathrm{~mm}$, and film thickness $0.25 \mu \mathrm{m}$ ), and 5975C inert XL mass spectrometer detector (MSD). The pyrolyzer was initially held at $50^{\circ} \mathrm{C}$ for $25 \mathrm{~min}$ and ramped at $35^{\circ} \mathrm{C} / \mathrm{min}$ to $1050^{\circ} \mathrm{C}$, where it was held for $5 \mathrm{~min}$. Pyrolysis occurred under $25 \mathrm{mbar} H \mathrm{He}$ and $12 \mathrm{ml} / \mathrm{min}$ flow. Volatiles were split at a ratio of $10: 1$ and carried by $1.5 \mathrm{ml} / \mathrm{min}$ helium flow through the inlet,

1150 column, and transfer line, all held at an isotherm of $300^{\circ} \mathrm{C}$, to the MSD. The MSD was operated in select ion monitoring (SIM) mode and monitored 60 different $\mathrm{m} / \mathrm{z}$ values with 50 -ms dwell times. Masses were selected based on team recommendation and prior GCMS analysis of the 600$1000^{\circ} \mathrm{C}$ evolved gas fraction. EGA results are presented in Fig. S10.

\section{Supplementary Text}

Evaluation of SAM instrument background as a possible source of the organic detections

The SAM EGA instrument background, including derivatization-reagent (MTBSTFA) vapor deposition on samples (41), is not the source of the observed molecular diversity observed

1160 at high temperatures. First, SAM analyses and lab tests demonstrate that the majority of MTBSTFA derived products (Table S5) are volatile and thermally desorbed at $<500^{\circ} \mathrm{C}$ (Fig. S7), 
especially in the presence of reactive and catalytic minerals, such as (per)chlorates, phyllosilicates, and iron oxides, common of all the mudstone samples analyzed by SAM. Although SAM blanks and laboratory tests with silica demonstrate that tert-butyldimethylsilyl- (TBDMS-) derivatized

1165 active $\mathrm{OH}$ sites on silica surfaces undergo pyrolysis above $500^{\circ} \mathrm{C}$, there is no indication of a correlative process occurring on samples having reactive and catalytic minerals (Fig. S7). In an effort to be extra cautious, all possible traces of suspect instrument background were removed in data processing. Second, MTBSTFA products in sample analyses are highly susceptible to oxidation by $\mathrm{O}_{2}$ and chlorination because of oxychlorine decomposition below $550^{\circ} \mathrm{C}$. Third, there

1170 are no structures in the SAM EGA instrument background that contain >C4 carbon backbones. Methylthiophenes, C5-alkyl fragments, and aromatics are C5 or greater structures. Condensation reactions in the $\mathrm{SAM}$ oven below $500^{\circ} \mathrm{C}$ would have produced volatile products and such reactions above $500^{\circ} \mathrm{C}$ are unlikely. The only known non-SAM terrestrial contaminant is polytetrafluoroethylene (PTFE) shed from the diaphragm seal of the MSL drill bit assembly (46).

1175 Traces of perfluoroethene $(<0.4 \mathrm{nmol} \mathrm{C}$ ) observed in samples (Fig. S8) cannot explain the 60-90 nmol $\mathrm{C}$ of other organics evolved at high temperature in Mojave and Confidence Hills (Table 1) evolved at the same and higher temperatures. Theoretically, PTFE is a very unlikely precursor for the observed molecules in Mojave. Lastly, SAM observations are inconsistent with the delivery of other polymer or plasticizer contaminants (51).

\section{Potential for chlorination of aromatic moieties in the SAM oven}

Chlorobenzene, chloromethanes, and other chlorinated hydrocarbons were observed in EGA below $400^{\circ} \mathrm{C}$ in the Cumberland drill sample from the Sheepbed mudstones at the base of

1185 Gale Crater (1) and interpreted to be reaction products of chlorine and organic carbon derived from martian sources. Analysis of the Mojave mudstone revealed chloromethanes release at $500-670^{\circ} \mathrm{C}$ (Fig. 2A) that is accompanied by a peak in the $m / z 112$ profile at $\sim 550^{\circ} \mathrm{C}$, which is consistent with a chlorobenzene release. The ${ }^{37} \mathrm{Cl}$-chlorobenzene isotopologue in the $\mathrm{m} / \mathrm{z} 114$ profile (not shown) was not possible due to low signal-to-noise ratio to provide confirmation of this molecular

1190 assignment. These peaks coincide with a rise in $\mathrm{HCl}$ from an undetermined chemical component of the sample (3). This package of observations supports the possibility that aromatic moieties are being chlorinated in the SAM oven, a reaction supported by analog studies in the laboratory (1, 48 ), but it does not rule out the possibility that some chlorobenzene is directly evolving from the sediments. A second peak at $\sim 780^{\circ} \mathrm{C}$ in the $\mathrm{m} / \mathrm{z} 112$ profile is consistent with another

1195 chlorobenzene release in Mojave (Fig. 2B). Most likely, this is part of a release that began at $\sim 550^{\circ} \mathrm{C}$ and was interrupted by the oxygen release and lost to combustion. 
CH blank
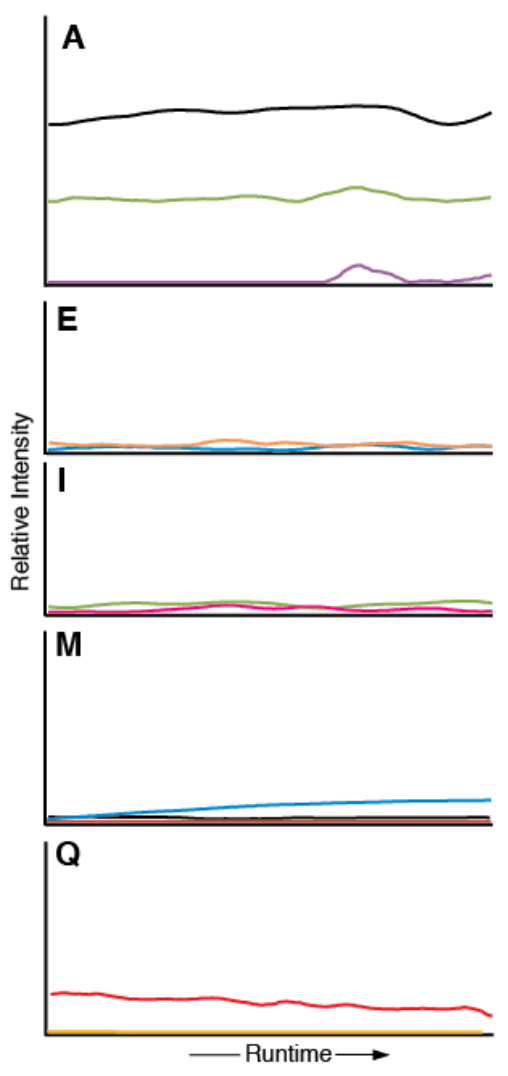

400
$\mathrm{CH}$
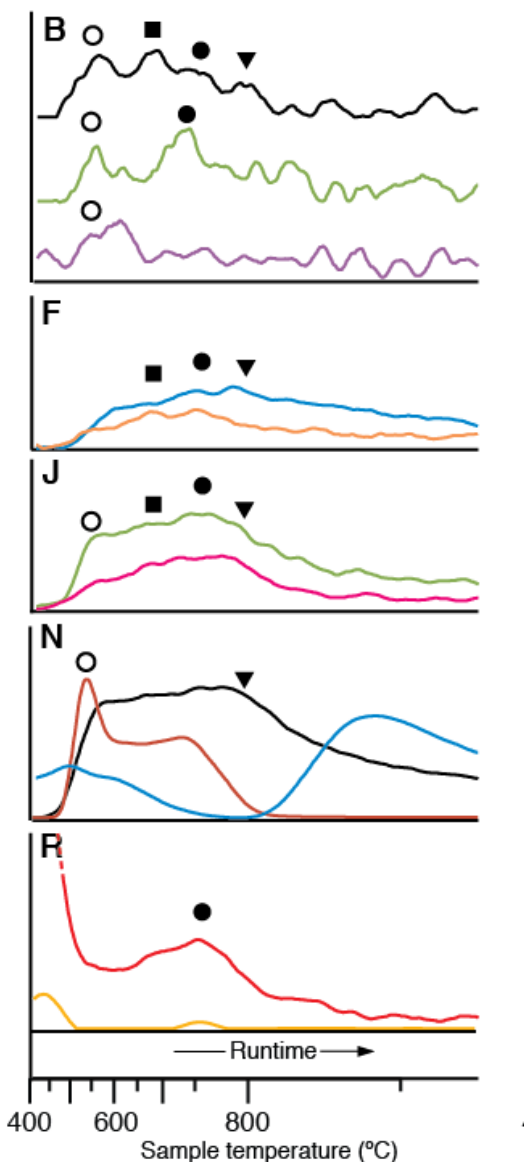

TP
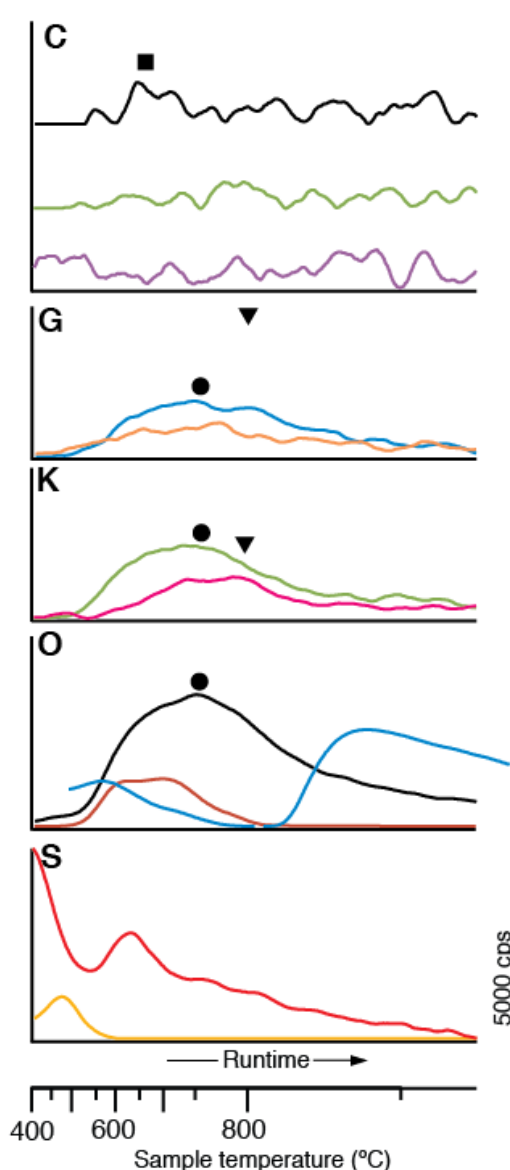

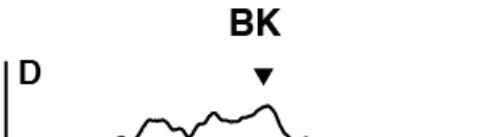

Volatile

$-\mathrm{C}_{4} \mathrm{H}_{4} \mathrm{~S}$
$+\mathrm{C}_{6} \mathrm{H}_{12}$

$-\mathrm{C}_{5} \mathrm{H}_{6} \mathrm{~S} \quad 97 \times 20$

$-\mathrm{C}_{8} \mathrm{H}_{6} \mathrm{~S} \quad 134 \times 40$
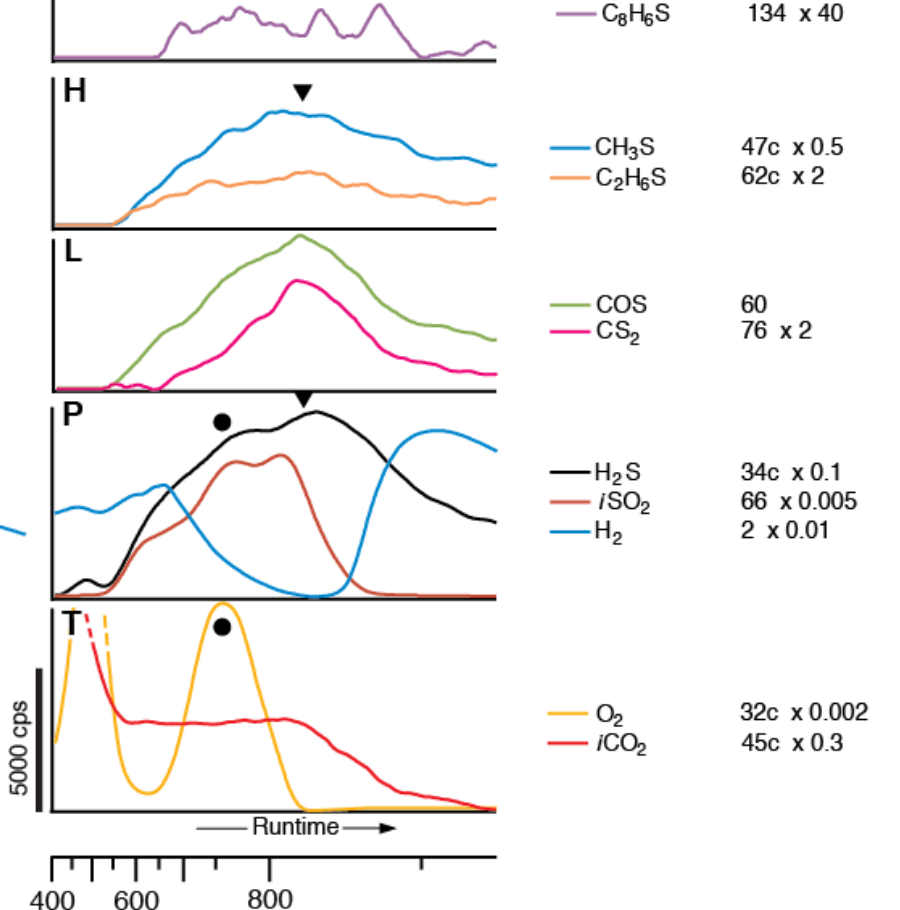

$\begin{array}{ll}\mathrm{O}_{2} & 32 \mathrm{c} \times 0.002\end{array}$

Sample temperature $\left({ }^{\circ} \mathrm{C}\right)$

Fig. S1. EGA profiles for thiophenes (A-D), thiols and sulfides (E-L), other volatiles (M-P), and $\mathrm{O}_{2}$ and $\mathrm{CO}_{2}(\mathrm{Q}-\mathrm{T})$ with peaks indicating possible combustion in Murray mudstone samples: Confidence Hills blank (CH blank), Confidence Hills (CH sample), Telegraph Peak (TP) and Buckskin (BK). Legend shows volatile, $\mathrm{m} / z$, and scaling factor for each profile. Symbols mark correlations between panes in peak maxima within $\pm 25^{\circ} \mathrm{C}$ error due to signal smoothing. Axes and scaling factors are the same in Fig. 1-2 and S1-S6. Temperature placement of symbols are the same in Fig. 1-2, S1-S3. X-axis is scaled linearly to runtime to show the changing oven ramp rate and peak areas that scale to abundances. Y-axis scale bar in counts per second (cps) is for all panes. Profiles within panes are multiplied by scaling factors. All profiles are background subtracted, but profiles in A-D are shifted along the y-axis to show peaks clearly. " $i$ ", isotopologues in formulas. "c", corrections to profiles to remove other volatile contributions (11). 


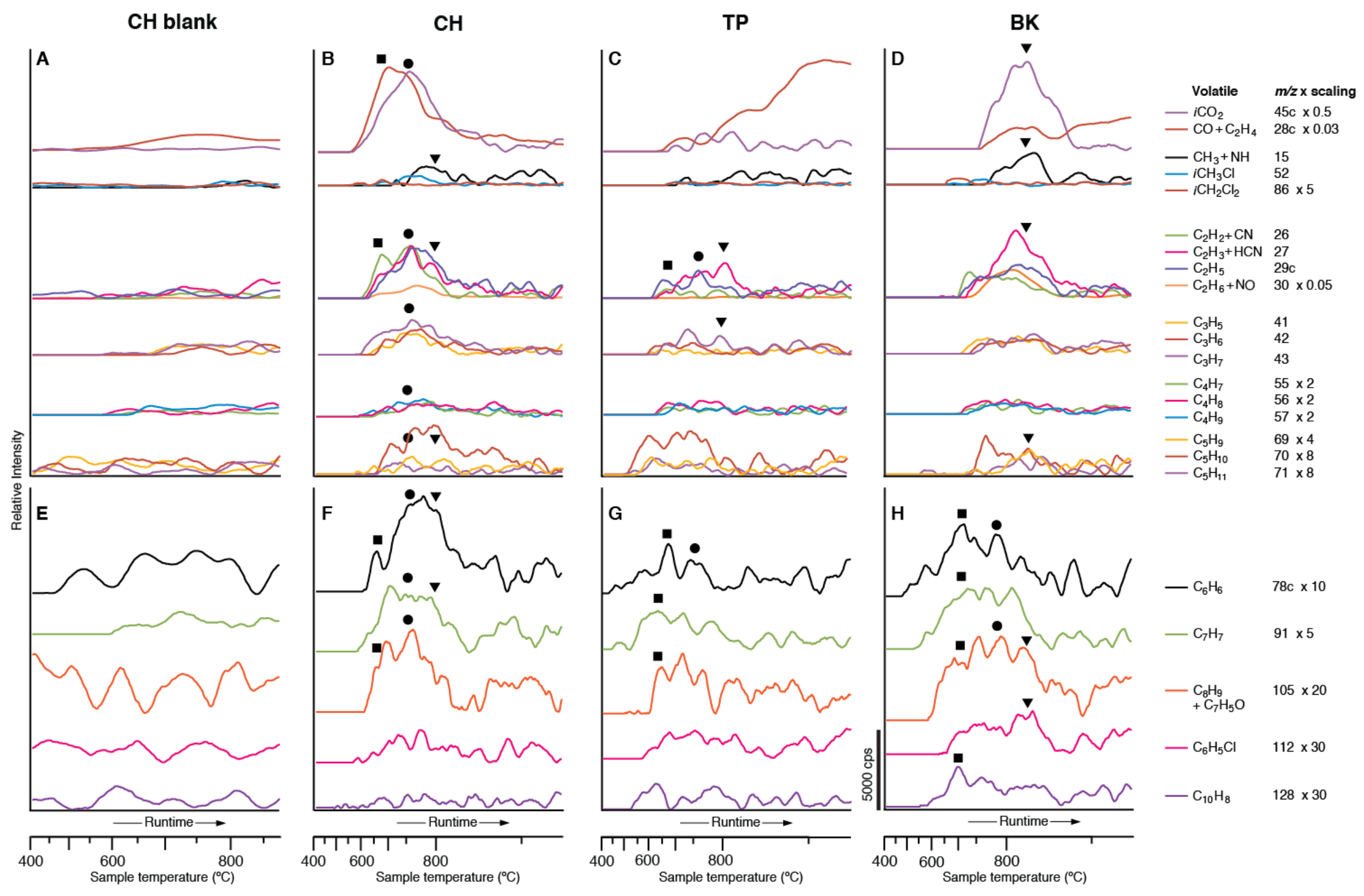

Fig. S2. EGA profiles for aliphatic (A-D) and aromatic (E-H) compounds in Murray mudstone samples: Confidence Hills blank (CH blank), Confidence Hills (CH sample), Telegraph Peak (TP) and Buckskin (BK). CO and $\mathrm{CO}_{2}$ profiles are included in A-D. Legend and plotting details are described in Figure S1. All profiles are background subtracted and on the same scale after applying scaling factor. Profiles in A-D are grouped by carbon number and shifted along the y-axis to show peaks clearly. Profiles in E-H are similarly shifted. 

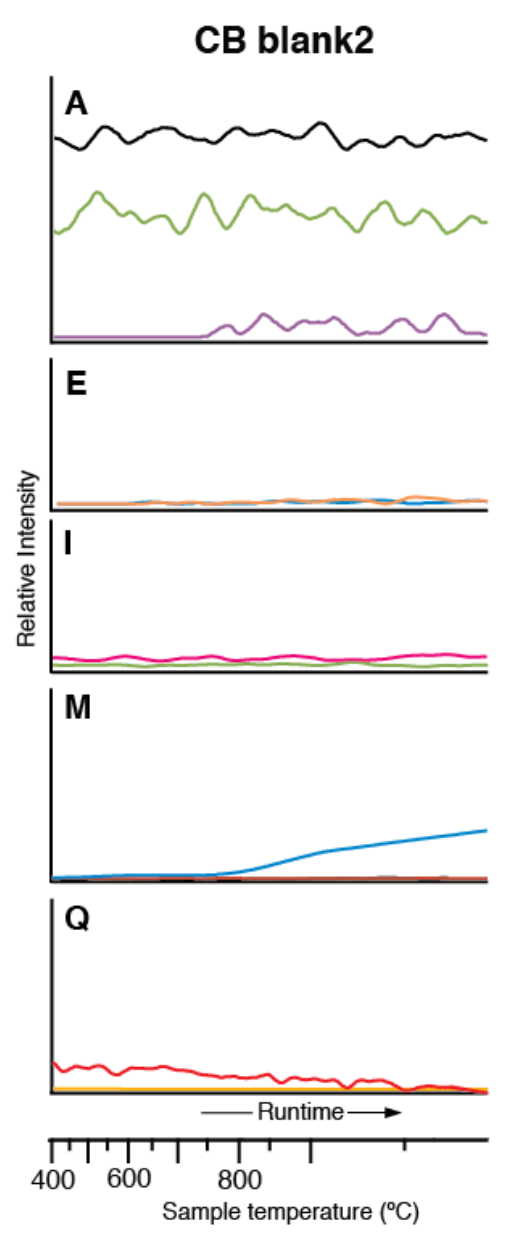
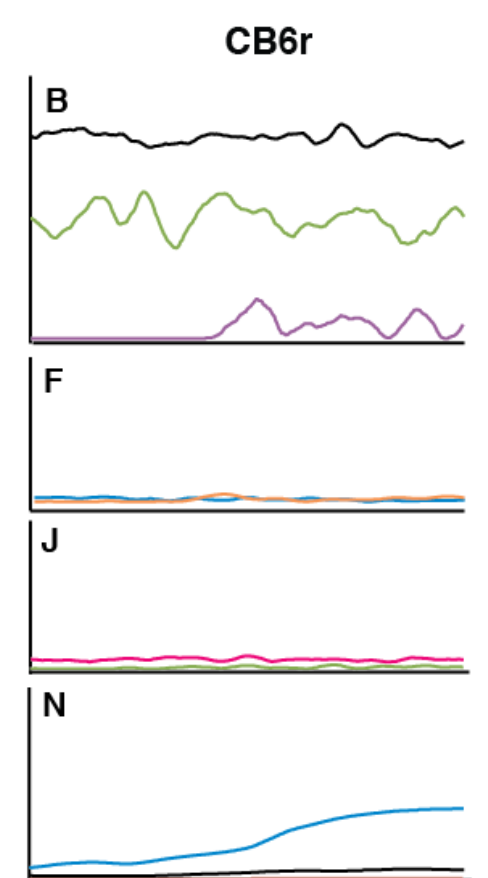

R
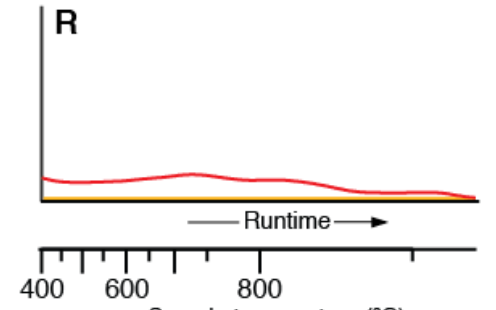

$400600 \quad 800$

Sample temperature $\left({ }^{\circ} \mathrm{C}\right)$
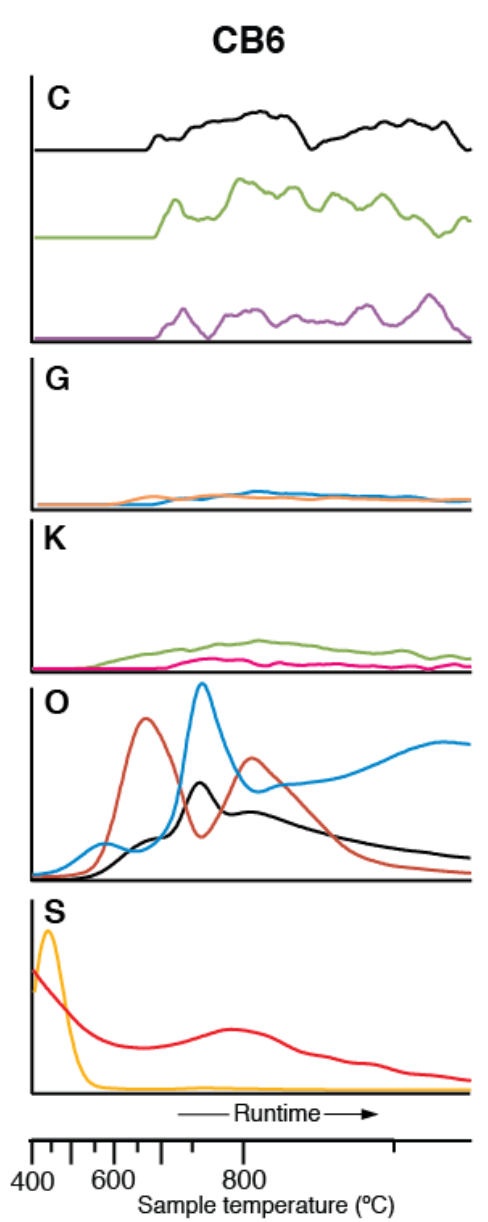

CB7

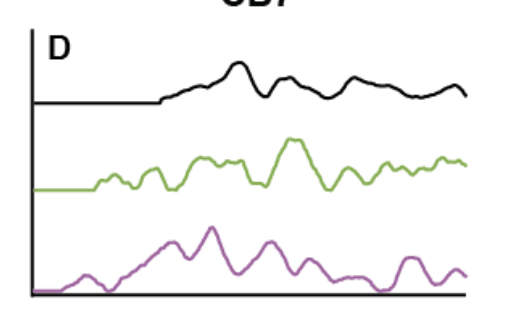

Volatile $\quad m / z \times$ scaling

$-\mathrm{C}_{4} \mathrm{H}_{4} \mathrm{~S} \quad 84 \mathrm{c} \times 10$

$-\mathrm{C}_{5} \mathrm{H}_{6} \mathrm{~S} \quad 97 \times 20$

$-\mathrm{C}_{8} \mathrm{H}_{6} \mathrm{~S} \quad 134 \times 40$

\section{H}

$-\mathrm{CH}_{3} \mathrm{~S}$

$47 \mathrm{c} \times 0.5$

$62 \mathrm{c} \times 2$
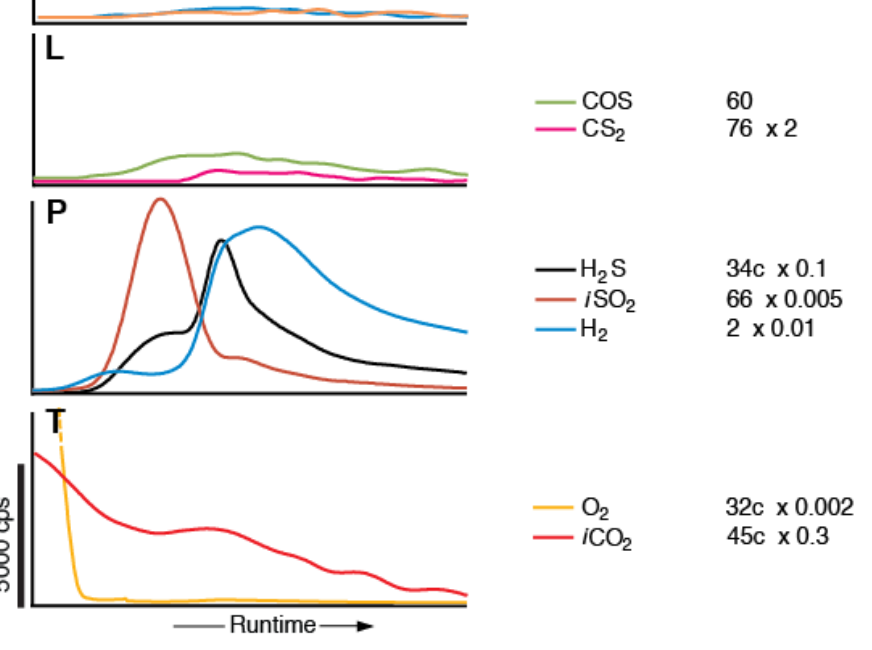

$-\mathrm{O}_{2}$

$-\mathrm{C}_{2}$

$32 \mathrm{c} \times 0.002$
$45 \mathrm{c} \times 0.3$
${ }_{400}^{\Gamma}{ }_{600}^{1}{ }^{T}{ }^{T}$

Fig. S3. EGA profiles for thiophenes (A-B), thiols and sulfides $(\mathrm{C}-\mathrm{F})$, other volatiles $(\mathrm{G}-\mathrm{H})$, and $\mathrm{O}_{2}$ and $\mathrm{CO}_{2}(\mathrm{I}-\mathrm{J})$ with peaks indicating possible combustion in Sheepbed mudstone samples: Cumberland blank-1 (CB blank1) and John Klein-4 (JK4). Legend and plotting details are described in Figure S1. All profiles are background subtracted and on the same scale after applying scaling factor. All profiles are background subtracted, but profiles in A-B are shifted along the y-axis to show peaks clearly. 

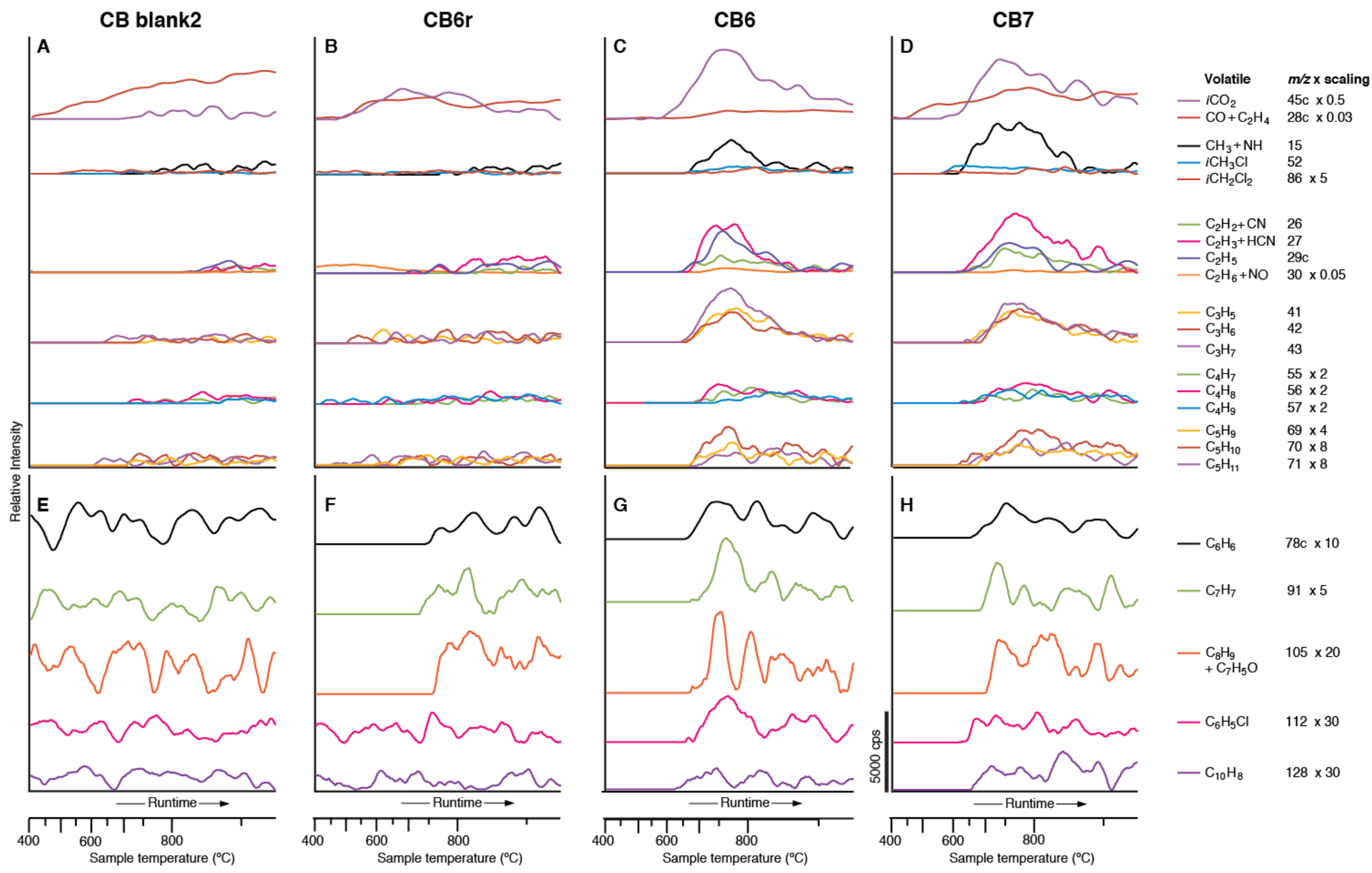

Fig. S4. EGA profiles for aliphatic (A-B) and aromatic (C-D) compounds in Sheepbed mudstone samples: Cumberland blank-1 (CB blank1) and John Klein-4 (JK4). $\mathrm{CO}$ and $\mathrm{CO}_{2}$ profiles are included in A-B. Legend and plotting details are described in Figure S1. All profiles are background subtracted and on the same scale after applying scaling factor. Profiles in A-B are grouped by carbon number and shifted along the $\mathrm{y}$-axis to show peaks clearly. Profiles in C-D are similarly shifted. 
CB blank1
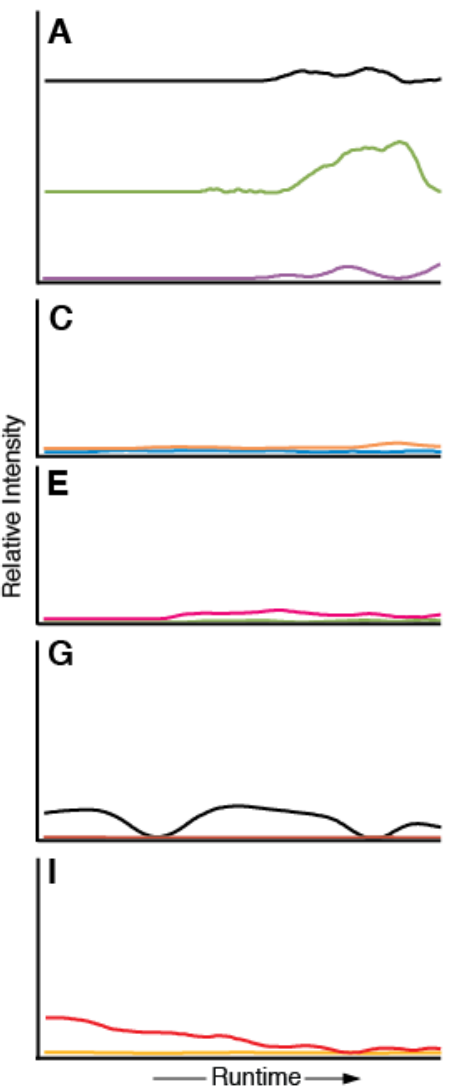

$\Gamma_{400}^{\top}$

$\longrightarrow$ Runtime $\longrightarrow$

Sample temperature $\left({ }^{\circ} \mathrm{C}\right)$

JK4

B

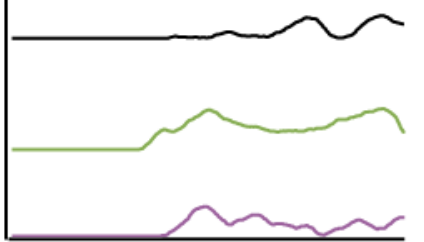

$-\mathrm{C}_{4} \mathrm{H}_{4} \mathrm{~S}$

$-\mathrm{C}_{5} \mathrm{H}_{6} \mathrm{~S} \quad 97 \times 20$

$-\mathrm{C}_{8} \mathrm{H}_{6} \mathrm{~S} \quad 134 \times 40$

D

$-\mathrm{CH}_{3} \mathrm{~S} \quad 47 \mathrm{c} \times 0.5$

$-\mathrm{C}_{2} \mathrm{H}_{6} \mathrm{~S} \quad 62 \mathrm{c} \times 2$

F

$\begin{array}{ll}-\mathrm{COS} & 60 \\ -\mathrm{CS}_{2} & 76 \times 2\end{array}$

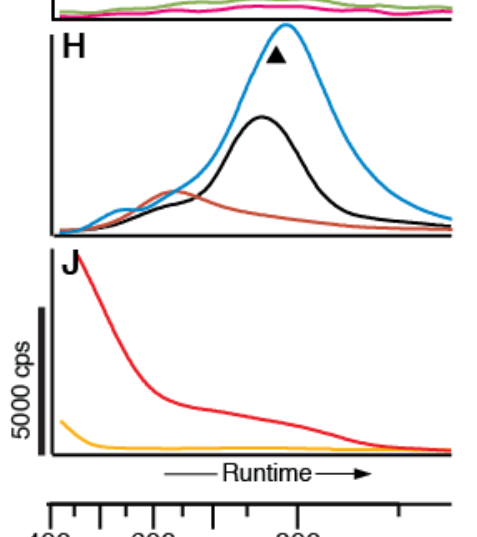

$-\mathrm{H}_{2} \mathrm{~S} \quad 34 \mathrm{c} \times 0.1$

$-\mathrm{ISO}_{2} \quad 66 \times 0.005$

$2 \times 0.01$

$\begin{array}{ll}-\mathrm{O}_{2} & 32 \mathrm{c} \times 0.002 \\ -i \mathrm{CO}_{2} & 45 \mathrm{c} \times 0.3\end{array}$

Sample temperature $\left({ }^{\circ} \mathrm{C}\right.$

Fig. S5. EGA profiles for thiophenes (A-D), thiols and sulfides (E-L), other volatiles (M-P), and $\mathrm{O}_{2}$ and $\mathrm{CO}_{2}(\mathrm{Q}-\mathrm{T})$ with peaks indicating possible combustion in Sheepbed mudstone samples: Cumberland blank-2 (CB blank2), Cumberland 6 reheat (CB6r), Cumberland 6 (CB6), and Cumberland 7 (CB7). Legend and plotting details are described in Figure S1. All profiles are background subtracted and on the same scale after applying scaling factor. All profiles are background subtracted, but profiles in A-D are shifted along the y-axis to show peaks clearly. 
CB blank1

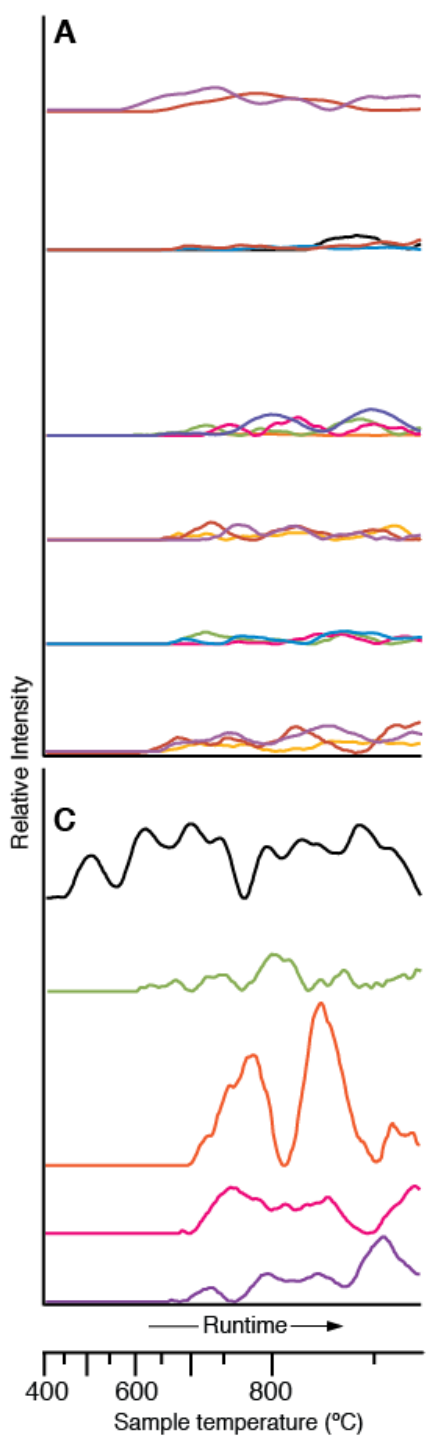

JK4

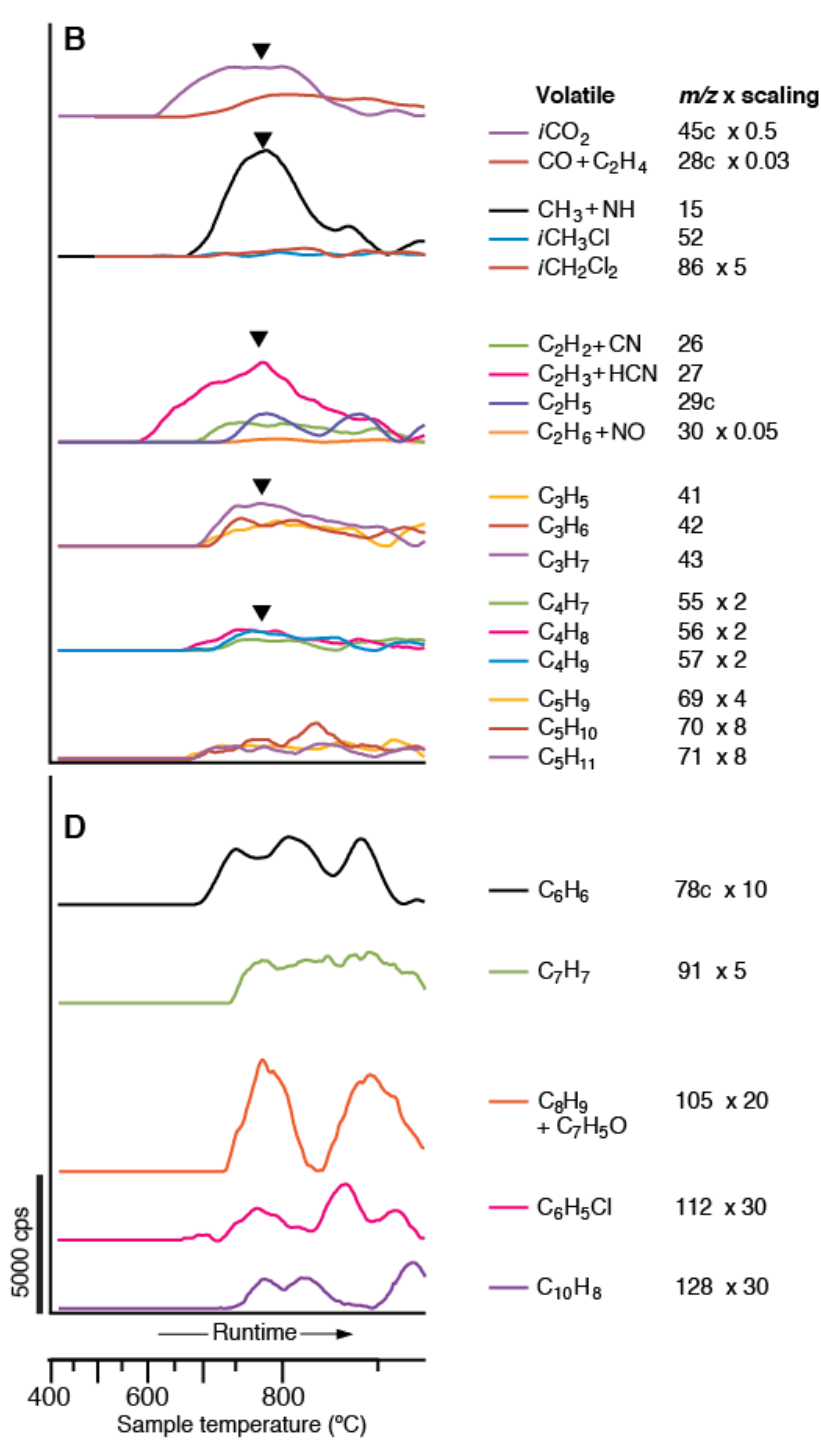

Fig. S6. EGA profiles for aliphatic (A-D) and aromatic (E-H) compounds in Sheepbed mudstone samples: Cumberland blank-2 (CB blank2), Cumberland 6 reheat (CB6r), Cumberland 6 (CB6), and Cumberland 7 (CB7). CO and $\mathrm{CO}_{2}$ profiles are included in A-D. Legend and plotting details are described in Figure S1. All profiles are background subtracted and on the same scale after applying scaling factor. Profiles in A-D are grouped by carbon number and shifted along the y-axis to show peaks clearly. Profiles in E-H are similarly shifted. 
Lab:

Lab:

CB2
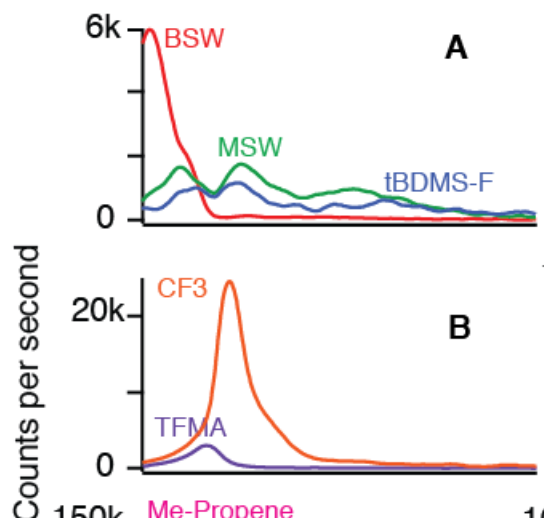

$150 \mathrm{k}$ Me-Propene

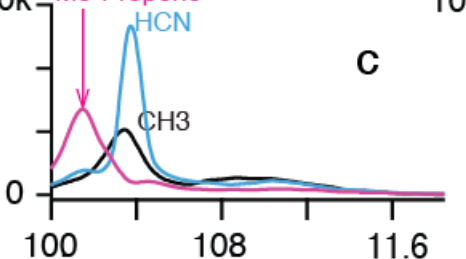

Runtime (seconds x1000)

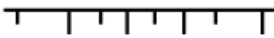

$5_{0} \times \sigma_{0} 0_{0}$

Sample Temperature $\left({ }^{\circ} \mathrm{C}\right)$
MJ
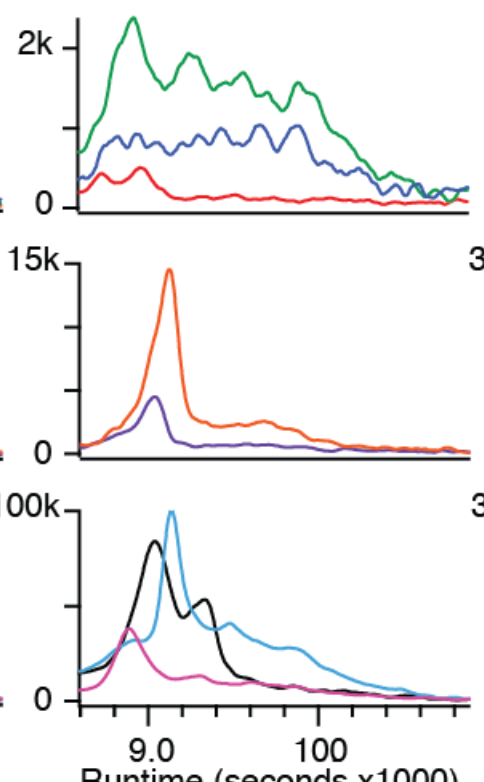

Runtime (seconds x1000)

Tागा।

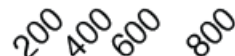

Sample Temperature $\left({ }^{\circ} \mathrm{C}\right)$
TBDMS-FS120
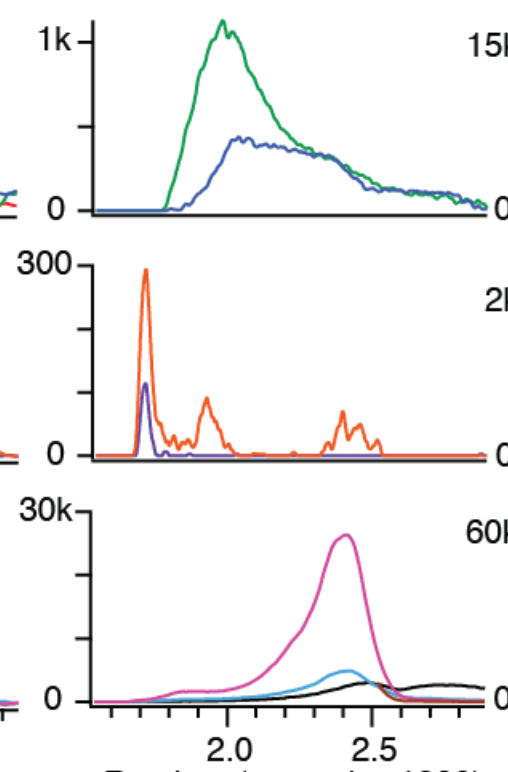

Runtime (seconds x1000)

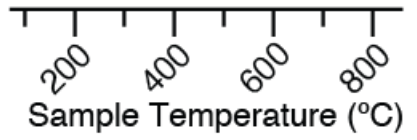

$\mathrm{CH}$ blank
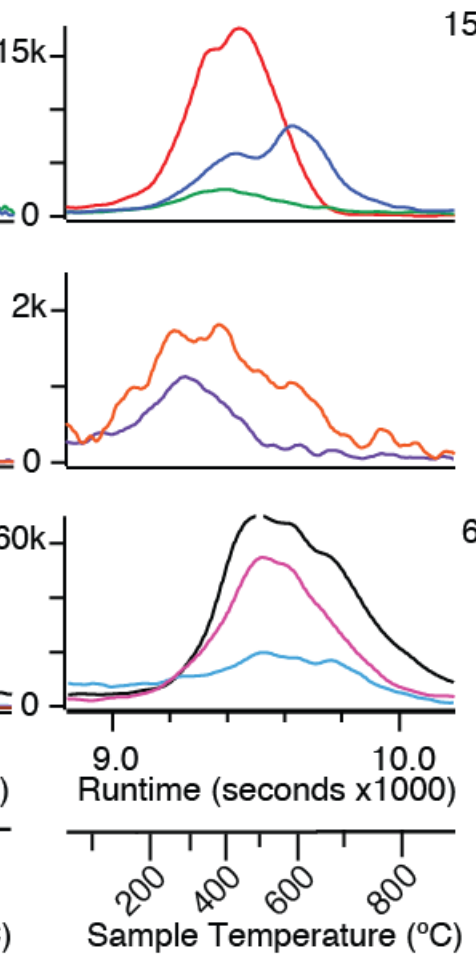

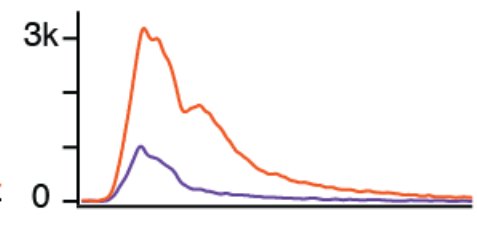

TBDMS-FS120 +1 wt\% Fe(II)Perchlorate
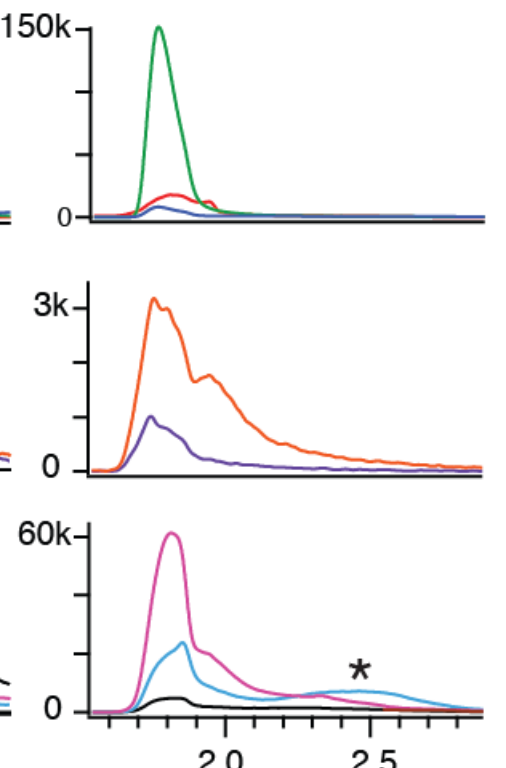

Runtime (seconds x1000)

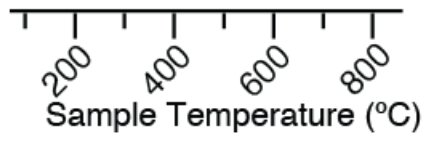

Fig. S7. Variations in the evolution of MTBSTFA reaction products in the SAM instrument background (Sheepbed mudstone: CB2, Murray mudstone: MJ, and $\mathrm{CH}$ blank) and in lab control experiments. TBDMS-organic derivatives thermally desorbed at low temperatures as shown in row A of plots show bisilylated water (BSW; $m / z, 147$ ), monosilylated water (MSW or tert-butyldimethylsilanol; $m / z$ 75), and TBDMS-F (tertbutyldimethylsilyl fluoride; $\mathrm{m} / \mathrm{z}$ 77). Row B shows trifluoromethylacetamide (TFMA) related byproducts of silylation thermally desorb next as shown in B: TFMA $(\mathrm{m} / \mathrm{z}, 127)$ and $\mathrm{CF}_{3}$ fragment of other trifluorinated products $(\mathrm{m} / \mathrm{z} 69)$. Row $\mathrm{C}$ shows pyrolysis products of remaining TBDMS-derivatives, especially derivatized $\mathrm{OH}$ sites on mineral surfaces are shown in C: methylpropene $(\mathrm{m} / \mathrm{z} 41,56$, and 27$)$, methane (represented by methylene: $\mathrm{m} / \mathrm{z}, 15)$. The asterisk indicates signals from trace contaminants in the perchlorate standard. Mass profiles are from laboratory EGA analysis of ashed fused silica (FS120; (52)) mixed with $1 \mathrm{wt} \% \mathrm{Fe}(\mathrm{II})$ perchlorate and silylated with MTBSTFA at $25^{\circ} \mathrm{C}, 1$ bar for 1 hour. Excess MTBSTFA was removed by gently flowing $\mathrm{N}_{2}(\mathrm{~g})$ over the sample. Analytical conditions approximate those of SAM. The pattern observed above is representative of analyses with other perchlorates except for differences in the $\mathrm{O}_{2}$ evolution temperature. $\mathrm{X}$-axis is scaled linearly to runtime to show the changing oven ramp rate and peak areas that scale to abundances. 


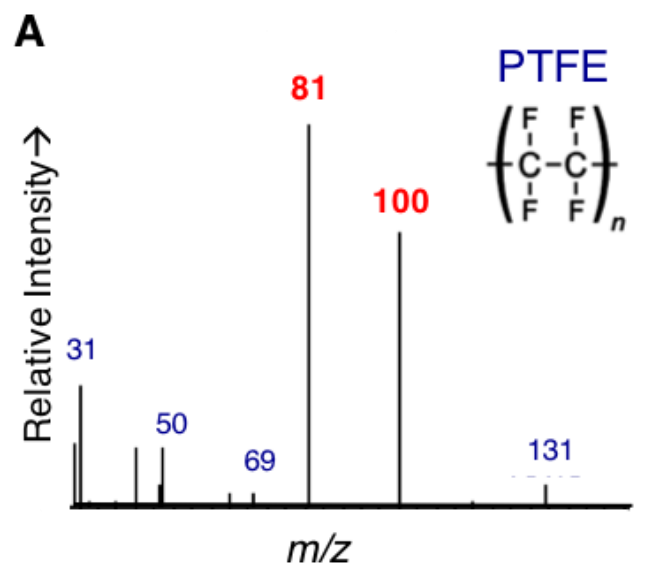

D

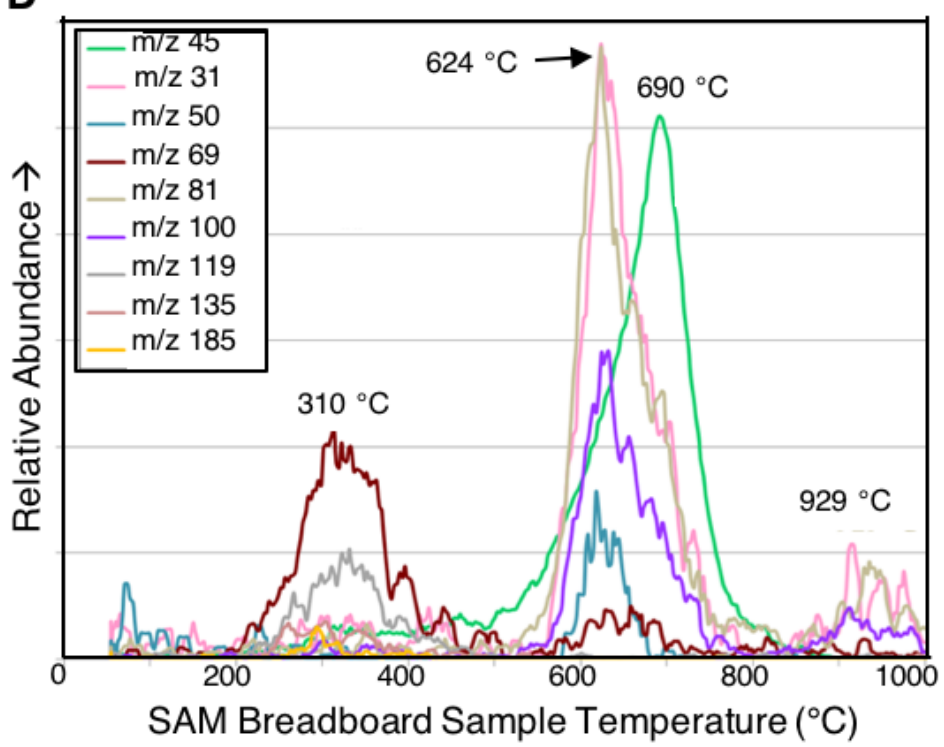

B

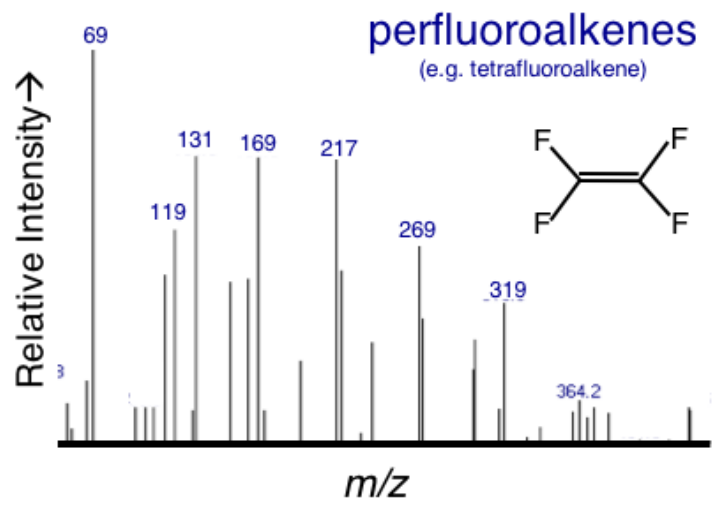

E

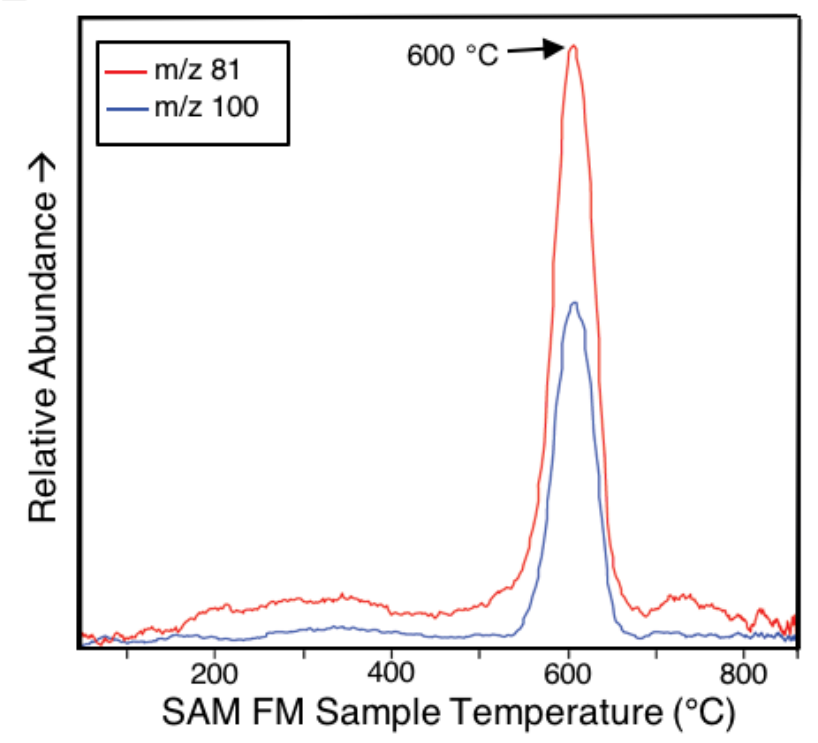

Fig. S8. Caption on next page.

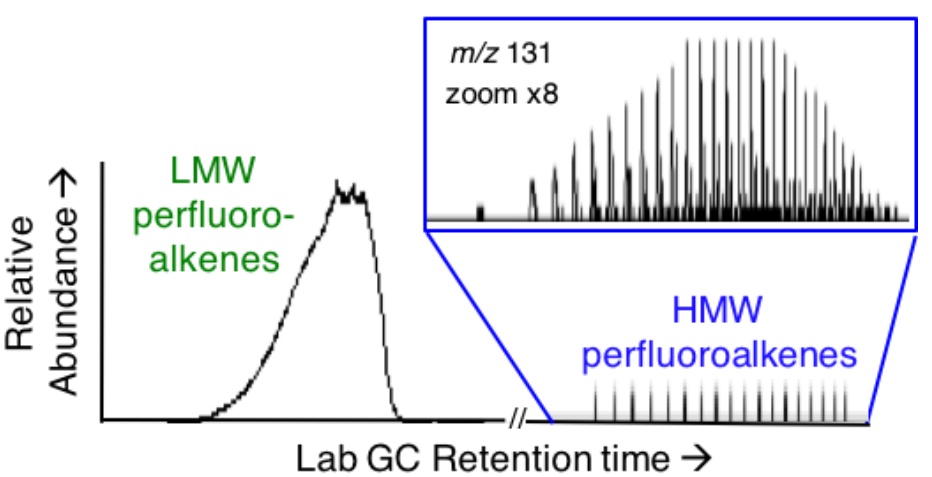

Lab GC Retention time $\rightarrow$ 
Fig. S8. Polytetrafluoroethylene (PTFE; trademarked as Teflon by Dupont Co.) particles shed from the diaphragm seal in the MSL drill bit assembly were investigated for their impact on SAM EGA and GCMS. A) Mass spectrum of pyrolysate products. (Test sample: OCM SN48; scan \# 4261). (A) Mass spectrum of low molecular weight (LMW) perfluoroalkene mixture (53) dominated by tetrafluoroethylene giving the strong $\mathrm{m} / \mathrm{z} 81$ and 100 signals (red). (B) Example mass spectrum for the high molecular weight (HMW) perfluoroalkene series. Key ion series for detection are $\mathrm{M}^{+}+100 \mathrm{n}$, where $\mathrm{M}^{+}=69,119,131$, and 181. (C) Laboratory pyrolysis-GCMS results for the diaphragm seal. Total ion chromatogram shows both LMW perfluoroalkenes (eluting from the GC column held at $35^{\circ} \mathrm{C}$ ) and HMW perfluoroalkenes (elute from the GC column $250-300^{\circ} \mathrm{C}$ ). Inset is the $\mathrm{m} / \mathrm{z} 131$ ion chromatogram that shows the $>6$ homologous series that make up the HMW perfluoroalkene component. (D) SAM breadboard EGA results for $55 \mathrm{mg}$ of Saddleback basalt rock drilled at JPL using the testbed DBA and sieved to <150 micrometer particle size (Test sample: T28.1 G; analyzed May 2012). LMW and HMW perfluoroalkenes evolve at $560-800^{\circ} \mathrm{C}\left(\mathrm{max}\right.$. at $624^{\circ} \mathrm{C}$ ) and above $800^{\circ} \mathrm{C}$ ( $\max$ at $924^{\circ} \mathrm{C}$ ), respectively. Other unresolved hydrocarbon components at $200-500^{\circ} \mathrm{C}$ are from handling of the rock sample. Y-axis for $m / z 45\left(\mathrm{CO}_{2}\right)$ is scaled to 5\% to fit the axis of other ions. (E) SAM flight model (FM) EGA analysis of Telegraph Peak, which showed the greatest abundance of TFE ( $0.64 \pm 0.32$ nanomole; equivalent to $1420 \pm 284 \mathrm{ppb}$ TFE by mass and $\sim 28.4 \mathrm{ppb}$ C) due to drilling complications. TFE abundance in Mojave is $0.08 \pm 0.04$ nanomole $(\sim 184 \mathrm{ppb})$ or $\sim 3.6 \mathrm{ppb}$ C. TFE in Confidence Hills is $0.17 \pm 0.09$ nanomole $(\sim 378 \mathrm{ppb})$ or $\sim 7.6 \mathrm{ppb}$ C. 


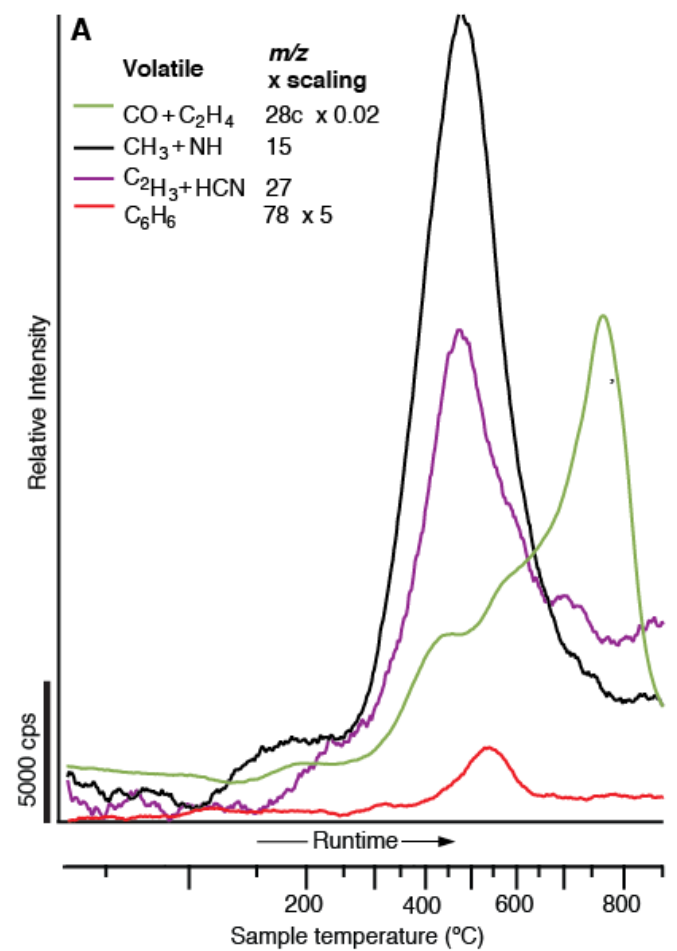

Sample temperature $\left({ }^{\circ} \mathrm{C}\right)$
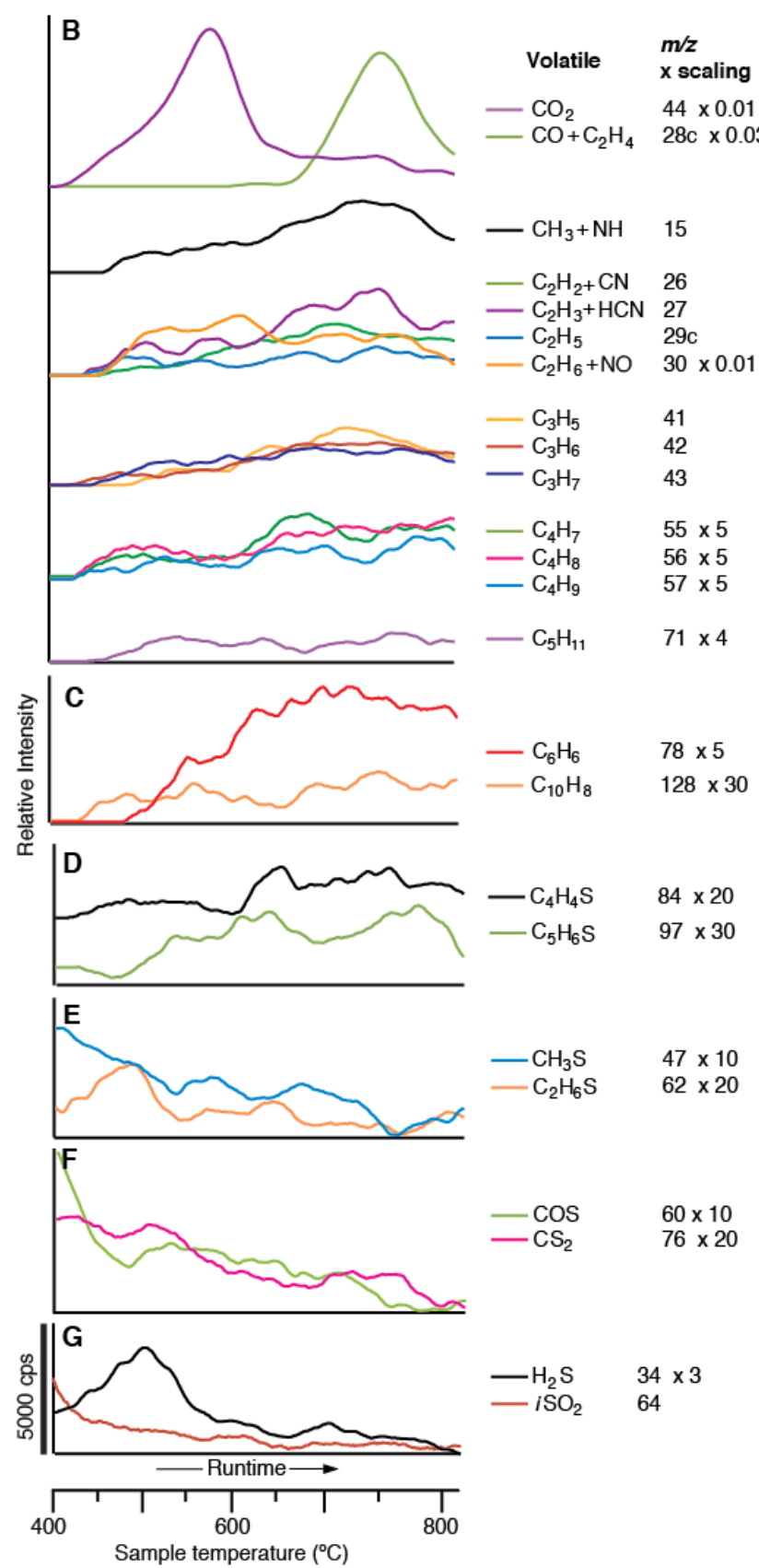

Fig. S9. Evolved gas analysis of the Murchison carbonaceous chondrite on the SAM testbed using the same analytical conditions as the Mojave analysis. The Murchison carbonaceous chondrite is used as a proxy for interplanetary dust particle composition (54). A) Most mass profiles show thermal desorption and the main pyrolysis products being released $675^{\circ} \mathrm{C}$, however the profiles do not return to background levels. B) Baseline subtraction of the main pyrolysis component allows for a closer examination of the $>675^{\circ} \mathrm{C}$ signals. While there are few discrete peaks, the mass profiles show a stead release that increases with temperature for aliphatic, aromatic, and thiophenic components. Such profiles reflect a steady degradation of macromolecular carbon that makes up the bulk of organic carbon in the Murchison $(14,55)$. Legend in B shows $\mathrm{m} / \mathrm{z}$ value, scaling factor, and related volatile (if known). Values of $\mathrm{m} / \mathrm{z}$ marked with a "c" designate corrections to the profile for interferences of other volatile contributions (11). Formulas marked that start with an " $i$ " indicate a minor isotopologue. All profiles are background subtracted and on the same scale after applying scaling factor. Profiles in B are shifted along the $\mathrm{y}$-axis to show peaks clearly. $\mathrm{X}$-axis is scaled linearly to runtime to show the changing oven ramp rate and peak areas that scale to abundances. Y-axis scale bar in counts per second (cps) is for all panes. Profiles within panes are multiplied by scaling factors. 

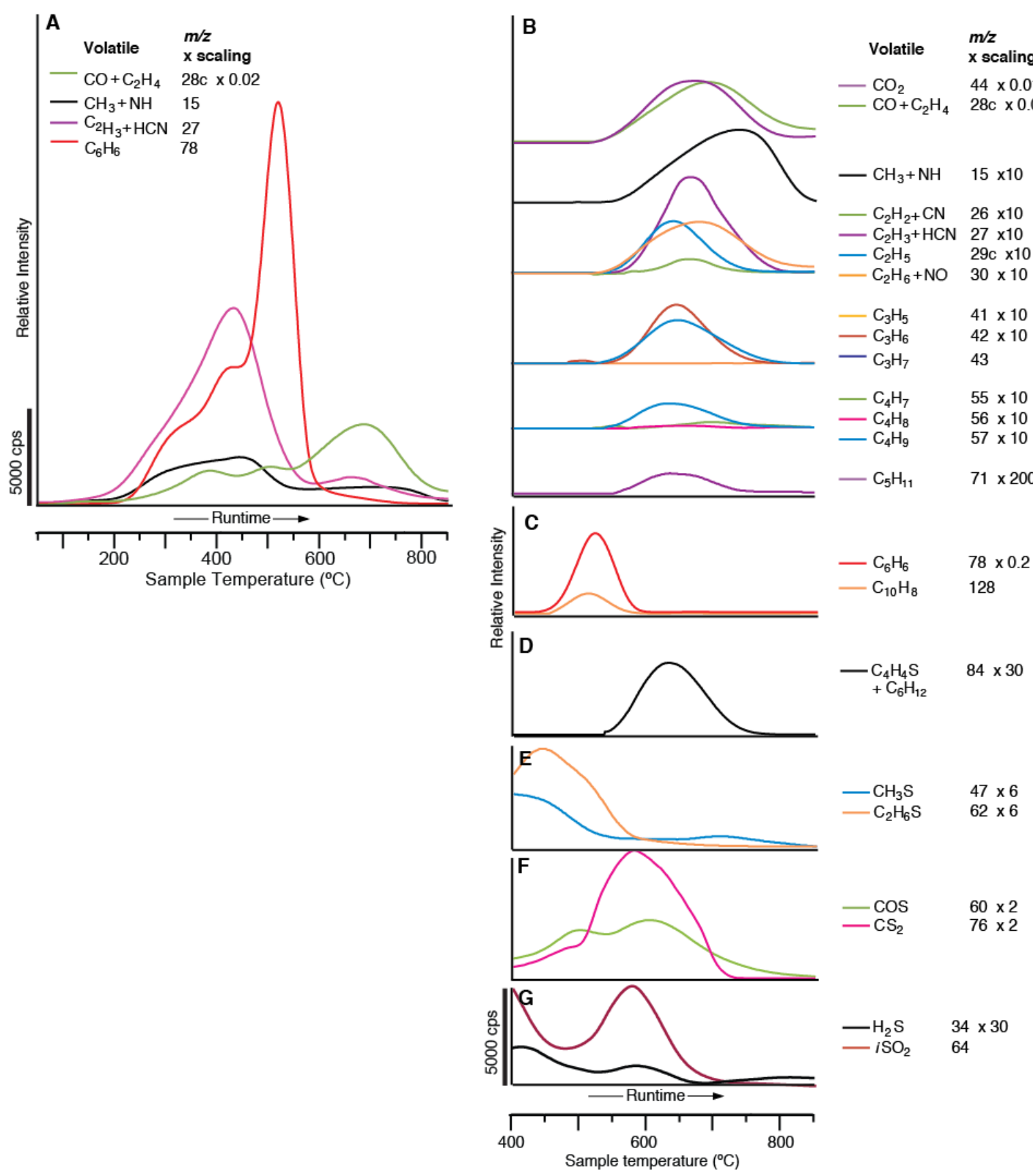

Fig. S10. Evolved gas analysis of the Tissint basaltic martian meteorite in the laboratory using conventional (non-SAM-like) analytical conditions (i.e. 1 bar He, $15 \mathrm{ml} / \mathrm{min}, 300^{\circ} \mathrm{C}$ transfer lines). A) Most mass profiles show thermal desorption and the main pyrolysis products being released $550^{\circ} \mathrm{C}$, however the profiles do not return to background levels. B) Baseline subtraction of the main pyrolysis component allows for a closer examination of the $>550^{\circ} \mathrm{C}$ signals that include several discrete peaks. One to two ringed aromatics peak at $525^{\circ} \mathrm{C}$. Aliphatic compounds (up to C5) and thiophene peak at $650^{\circ} \mathrm{C}$. The separate peak evolution for the correlated masses of each molecular group strongly suggest a separate organic phase, likely of macromolecular nature but perhaps retained by minerals at high temperatures (56). Legend in B shows $\mathrm{m} / \mathrm{z}$ value, scaling factor, and related volatile (if known). Values of $m / z$ marked with a "c" designate corrections to the profile for interferences of other volatile contributions (10). Formulas marked that start with an " $i$ " indicate a minor isotopologue. All profiles are background subtracted and on the same scale after applying scaling factor. Profiles in B are grouped by carbon number and shifted along the $\mathrm{y}$-axis to show peaks clearly. Profiles in D are similarly shifted. $\mathrm{X}$-axis is scaled linearly to runtime to show the changing oven ramp rate and peak areas that scale to abundances. $\mathrm{Y}$-axis scale bar in counts per second (cps) is for all panes. Profiles within panes are multiplied by scaling factors. 

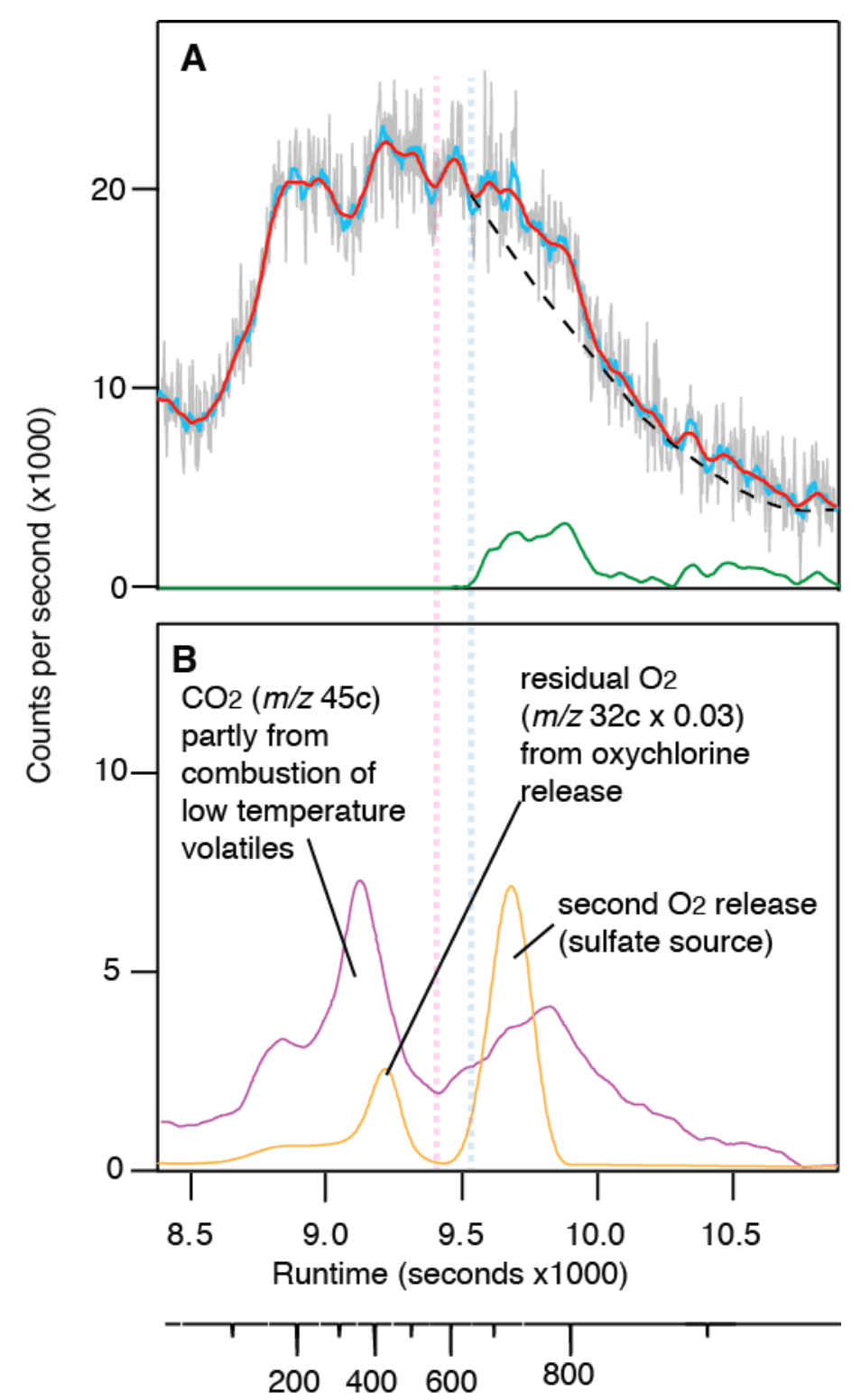

Sample Temperature $\left({ }^{\circ} \mathrm{C}\right)$
Fig. S11. An example of baseline subtraction for the $>400 \mathrm{C}$ portion of the data. The Mojave EGA $\mathrm{m} / \mathrm{z} 43$ profile is used for example. In A, data (no smoothing; gray) is smoothed using a moving average over 11 points (blue). A second smoothing over 21 points effectively removes a majority of residual noise (red). Next, the $\mathrm{CO}_{2}$ and $\mathrm{O}_{2}$ profiles in $\mathrm{B}$ are used to ascertain the timing of combustion in order to predict whether there are possible residual MTBSTFA products evolving after combustion. The vertical dashed pale pink line indicates the end of oxychlorine-derived $\mathrm{O}_{2}$ release. The vertical dashed pale blue line indicates the suspected end of post-combustion release of MTBSTFA products and it is used to define the start of the user-defined baseline (dashed black line). This baseline is drawn to make a conservative estimate of other analyte contributions is subtracted. The result is shown in green in pane A. Baseline subtraction was applied to aliphatic, aromatic, and thiophenic compounds. 
Table S1. EGA organic carbon abundance estimates for signals above $500^{\circ} \mathrm{C}$ (nanomole carbon). $* \dagger$

\begin{tabular}{|c|c|c|c|c|c|c|c|c|c|c|c|c|c|c|c|}
\hline $\begin{array}{l}\text { Geological } \\
\text { Unit }\end{array}$ & Sample & Thiophene & err & Methylthiophenes & err & Benzene & err & Toluene & err & $\begin{array}{c}\text { Benzoic } \\
\text { Acid }\end{array}$ & err & $\begin{array}{c}\text { Total } \\
\text { Thiophenes }\end{array}$ & err & $\begin{array}{c}\text { Total } \\
\text { Aromatics } \\
\end{array}$ & err \\
\hline \multirow{6}{*}{$\begin{array}{l}\text { Sheepbed } \\
\text { member } \\
\text { mudstone }\end{array}$} & JK-4 & 0.40 & 0.21 & 0.39 & 0.18 & 1.18 & 0.68 & 1.84 & 0.79 & 1.35 & 0.77 & 0.79 & 0.28 & 4.37 & 1.29 \\
\hline & CB- Blank1 & 0.16 & 0.08 & 0.25 & 0.12 & 1.12 & 0.21 & 0.57 & 0.24 & 1.02 & 0.58 & 0.41 & 0.15 & 2.71 & 0.66 \\
\hline & CB-6 & 0.21 & 0.11 & 0.12 & 0.06 & 0.37 & 0.23 & 0.61 & 0.26 & 0.28 & 0.16 & 0.33 & 0.12 & 1.26 & 0.38 \\
\hline & CB-6r & 0.10 & 0.05 & 0.09 & 0.04 & 0.17 & 0.14 & 0.38 & 0.16 & 0.30 & 0.17 & 0.19 & 0.07 & 0.86 & 0.28 \\
\hline & CB-7 & 0.16 & 0.08 & 0.09 & 0.04 & 0.26 & 0.12 & 0.33 & 0.14 & 0.39 & 0.22 & 0.24 & 0.09 & 0.97 & 0.29 \\
\hline & CB-Blank2 & 0.32 & 0.17 & 0.16 & 0.08 & 0.43 & 0.15 & 0.41 & 0.18 & 0.48 & 0.28 & 0.48 & 0.19 & 1.33 & 0.36 \\
\hline \multirow{5}{*}{$\begin{array}{l}\text { Murray } \\
\text { formation } \\
\text { mudstone }\end{array}$} & CH-Blank & 0.27 & 0.15 & 0.22 & 0.11 & 0.94 & 0.34 & 0.91 & 0.40 & 1.19 & 0.69 & 0.49 & 0.18 & 3.04 & 0.86 \\
\hline & $\mathrm{CH}$ & 1.48 & 0.79 & 0.54 & 0.26 & 3.12 & 1.24 & 3.32 & 1.44 & 1.59 & 0.91 & 2.02 & 0.84 & 8.03 & 2.11 \\
\hline & MJ & 1.66 & 0.89 & 0.54 & 0.26 & 2.12 & 1.03 & 2.76 & 1.20 & 2.11 & 1.21 & 2.20 & 0.93 & 6.99 & 1.99 \\
\hline & TP & 0.41 & 0.22 & 0.29 & 0.14 & 0.74 & 0.46 & 1.24 & 0.54 & 0.85 & 0.49 & 0.70 & 0.26 & 2.82 & 0.86 \\
\hline & BK & 0.43 & 0.23 & 0.20 & 0.10 & 0.90 & 0.51 & 1.36 & 0.59 & 0.96 & 0.55 & 0.63 & 0.25 & 3.22 & 0.95 \\
\hline
\end{tabular}

\section{Table S1 continued.}

\begin{tabular}{|c|c|c|c|c|c|c|c|c|c|c|c|}
\hline $\begin{array}{l}\text { Geological } \\
\text { Unit }\end{array}$ & Sample & Methanethiol & err & Dimethylsulfide & err & Carbonyl Sulfide & err & Carbon Disulfide & err & Total C1+C2 Sulfur Compounds & err \\
\hline \multirow{6}{*}{$\begin{array}{l}\text { Sheepbed } \\
\text { member } \\
\text { mudstone }\end{array}$} & JK-4 & 1.02 & 0.39 & 0.84 & 0.64 & 1.11 & 0.43 & 0.25 & 0.09 & 3.21 & 0.87 \\
\hline & CB- Blank1 & 0.25 & 0.10 & 0.29 & 0.22 & 0.15 & 0.06 & 0.16 & 0.06 & 0.85 & 0.25 \\
\hline & CB-6 & 0.73 & 0.28 & 0.43 & 0.33 & 0.82 & 0.31 & 0.05 & 0.02 & 2.02 & 0.53 \\
\hline & CB-6r & 0.13 & 0.05 & 0.19 & 0.14 & 0.07 & 0.03 & 0.04 & 0.01 & 0.43 & 0.15 \\
\hline & CB-7 & 0.41 & 0.16 & 0.27 & 0.21 & 0.59 & 0.23 & 0.06 & 0.02 & 1.33 & 0.34 \\
\hline & CB-Blank2 & 0.21 & 0.08 & 0.22 & 0.17 & 0.23 & 0.09 & 0.12 & 0.04 & 0.77 & 0.21 \\
\hline \multirow{5}{*}{$\begin{array}{l}\text { Murray } \\
\text { formation } \\
\text { mudstone }\end{array}$} & CH-Blank & 0.47 & 0.18 & 0.43 & 0.32 & 0.50 & 0.20 & 0.10 & 0.04 & 1.49 & 0.42 \\
\hline & $\mathrm{CH}$ & 13.6 & 5.33 & 5.32 & 4.05 & 9.18 & 3.60 & 1.25 & 0.46 & 29.3 & 7.61 \\
\hline & MJ & 23.4 & 9.18 & 6.93 & 5.27 & 11.9 & 4.67 & 1.54 & 0.57 & 43.8 & 11.6 \\
\hline & $\mathrm{TP}$ & 8.82 & 3.46 & 4.63 & 3.52 & 5.69 & 2.23 & 0.88 & 0.32 & 20.0 & 5.43 \\
\hline & BK & 8.25 & 3.24 & 2.74 & 2.08 & 4.68 & 1.84 & 0.61 & 0.22 & 16.3 & 4.27 \\
\hline
\end{tabular}

\section{Table S1 continued.}

\begin{tabular}{|c|c|c|c|c|c|c|c|}
\hline $\begin{array}{l}\text { Geological } \\
\text { Unit }\end{array}$ & Sample & Total Aliphatic Compounds & err & $\begin{array}{l}\text { Total Organic C in Thiophenes, } \\
\text { Aromatics, Aliphatic Compounds }\end{array}$ & err & $\begin{array}{c}\text { Total Organic C in Thiophenes, Aromatics, Aliphatic, } \\
\text { and C1+C2 Sulfur Compounds }\end{array}$ & err \\
\hline \multirow{6}{*}{$\begin{array}{l}\text { Sheepbed } \\
\text { member } \\
\text { mudstone }\end{array}$} & JK-4 & 14.4 & 2.01 & 19.6 & 2.41 & 22.8 & 2.56 \\
\hline & CB- Blank1 & 3.17 & 0.44 & 6.28 & 0.81 & 7.14 & 0.85 \\
\hline & CB-6 & 17.3 & 2.16 & 18.9 & 2.20 & 20.9 & 2.26 \\
\hline & CB-6r & 5.22 & 0.66 & 6.27 & 0.71 & 6.70 & 0.73 \\
\hline & CB-7 & 22.4 & 2.76 & 23.7 & 2.78 & 25.0 & 2.80 \\
\hline & CB-Blank2 & 1.61 & 0.21 & 3.42 & 0.46 & 4.19 & 0.50 \\
\hline \multirow{5}{*}{$\begin{array}{l}\text { Murray } \\
\text { formation } \\
\text { mudstone }\end{array}$} & CH-Blank & 5.35 & 0.83 & 8.88 & 1.21 & 10.4 & 1.28 \\
\hline & $\mathrm{CH}$ & 20.8 & 2.79 & 30.8 & 3.60 & 60.2 & 8.42 \\
\hline & MJ & 38.4 & 5.63 & 47.6 & 6.04 & 91.4 & 13.1 \\
\hline & $\mathrm{TP}$ & 9.51 & 1.28 & 13.0 & 1.56 & 33.1 & 5.65 \\
\hline & BK & 19.0 & 3.50 & 22.8 & 3.64 & 39.1 & 5.61 \\
\hline
\end{tabular}

* All estimates assume the identification ion (corrected if applicable) (Fig. 1-2) solely reflects the molecule estimated. Benzoic acid is assumed for $m / z 105$.

$\dagger$ Abundances are normalized to a single portion.

Err $=$ Propagated error from mean $+/-1 \sigma$ standard deviations, $N \geq 3$. 
Table S2. SAM GCMS abundances of methanethiol, dimethylsulfide $\left(\mathrm{CH}_{3}\right)_{2}$, 2-methylthiophene and 3-methylthiophene $\left(\mathrm{C}_{5} \mathrm{H}_{6} \mathrm{~S}\right)$.

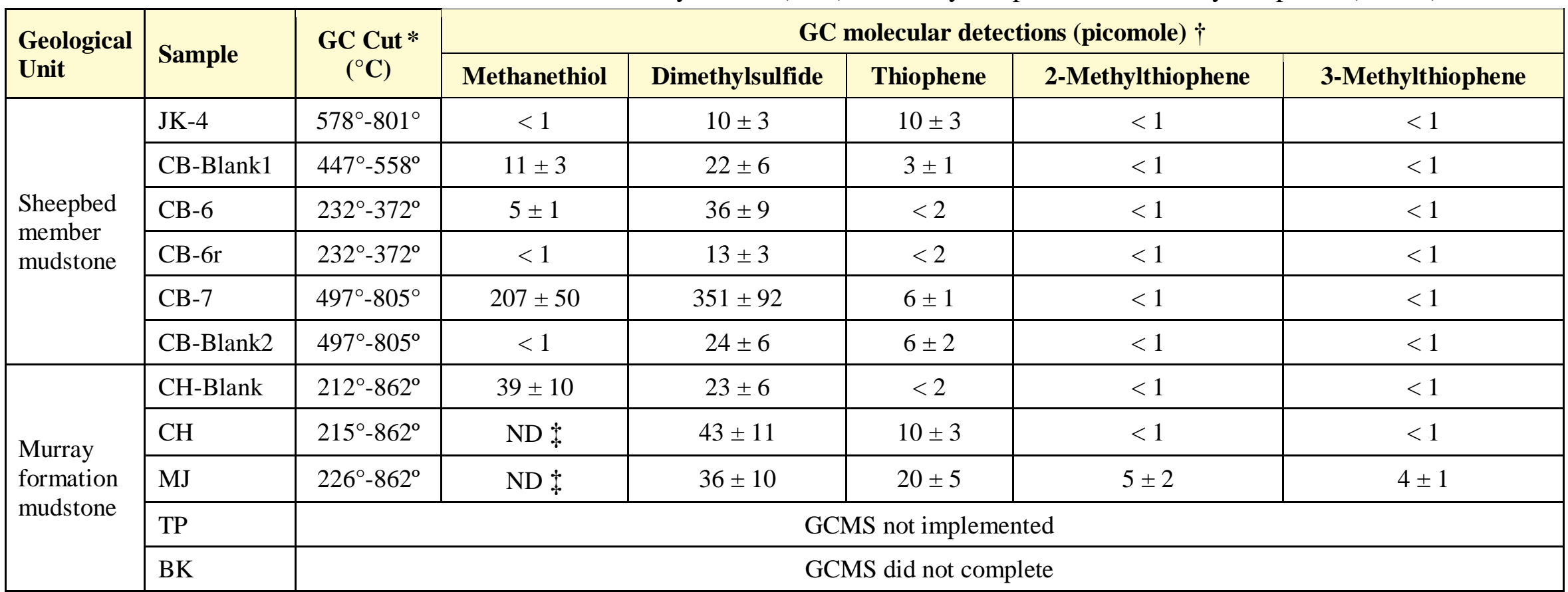

* Gas chromatography (GC) hydrocarbon trap cut refers to the cup temperature range over which volatiles were collected on the hydrocarbon trap during pyrolysis for GCMS analyses.

$\dagger$ Abundances are normalized to a single aliquot of sample. Propagated error from mean $+/-1 \sigma$ standard deviations, $\mathrm{N} \geq 3$.

$\$$ ND: Not determined. In some instances, the compound is present, however, a GC coelution with another compound prevents its quantification. 
Table S3. Comparison of GC retention time for analytical standards run on the SAM GC breadboard and the molecules detected in the MJ experiment by SAM.

\begin{tabular}{|c|c|c|}
\hline Compound & $\begin{array}{c}\text { Retention Time (min) } \\
\text { Laboratory Spare GC-5 }\end{array}$ & $\begin{array}{c}\text { Retention Time (min) } \\
\text { SAM GC-5 * }\end{array}$ \\
\hline Non-retained compound $\dagger$ & 3.0 & 3.0 \\
\hline Ethanethiol & 3.6 & N/A \\
\hline Dimethyl Sulfide & 3.8 & 3.7 \\
\hline Propanethiol & 4.8 & N/A \\
\hline Thiophene & 6.1 & 6.2 \\
\hline 2-Methylthiophene & 9.4 & 9.2 \\
\hline 3-Methylthiophene & 9.7 & 9.5 \\
\hline 2,5-Dimethylthiophene & 12.2 & $11.9+$ \\
\hline
\end{tabular}

* Laboratory spare GC5 temperature program: $40^{\circ} \mathrm{C}$ for 5 min then ramped at $10^{\circ} \mathrm{C} / \mathrm{min}$ to $190^{\circ} \mathrm{C}$.

$\dagger$ Non-retained compound is solvent in the laboratory analysis and $\mathrm{CO}_{2}$ in the SAM MJ analysis.

+ Signal-to-noise ratio for a possible peak is less than 3 .

$\S$ A small peak is present in the $\mathrm{m} / \mathrm{z} 128$ ion chromatogram of Mojave; however, its retention time does not match that of naphthalene determined on the laboratory spare GC5 possible due to differences in instrument condition following a second heating of the injection trap on the flight system. The laboratory test did not invoke a second injection trap heating. 
Table S4. EGA molecular abundance (nanomole S) estimates for sulfur volatiles evolved above $500^{\circ} \mathrm{C} . *+\dagger$

\begin{tabular}{|l|l|c|c|c|c|c|c|c|c|}
\hline $\begin{array}{l}\text { Geological } \\
\text { Unit }\end{array}$ & Sample & $\begin{array}{c}\text { Dihydrogen } \\
\text { Sulfide }\end{array}$ & err & $\begin{array}{c}\text { Sulfur } \\
\text { Dioxide }\end{array}$ & err & $\begin{array}{c}\text { Total } \\
\text { Organic- } \\
\text { Sulfur }\end{array}$ & err & $\begin{array}{c}\text { Total } \\
\text { Sulfide }\end{array}$ & err \\
\hline \multirow{4}{*}{$\begin{array}{l}\text { Sheepbed } \\
\text { member } \\
\text { mudstone }\end{array}$} & JK-4 & 53.6 & 20.6 & 624 & 240 & 4.45 & 0.67 & 58.0 & 20.6 \\
\cline { 2 - 11 } & CB- Blank1 & 19.9 & 7.68 & 6.86 & 2.64 & 1.63 & 0.17 & 21.6 & 7.68 \\
\cline { 2 - 11 } & CB-6 & 28.8 & 11.1 & 1033 & 398 & 2.49 & 0.45 & 31.3 & 11.1 \\
\cline { 2 - 11 } & CB-6r & 2.90 & 1.12 & 11.8 & 4.53 & 0.73 & 0.09 & 3.64 & 1.12 \\
\cline { 2 - 11 }$y$ & CB-Blank2 & 1.47 & 0.57 & 9.18 & 3.54 & 1.50 & 0.16 & 2.98 & 0.59 \\
\hline \multirow{4}{*}{$\begin{array}{l}\text { Murray } \\
\text { formation } \\
\text { mudstone }\end{array}$} & CH-Blank & 3.65 & 1.43 & 27.2 & 10.7 & 2.23 & 0.32 & 5.88 & 1.47 \\
\cline { 2 - 11 } & MJ & 169 & 66.4 & 18562 & 7279 & 33.0 & 6.76 & 202 & 66.7 \\
\cline { 2 - 11 } & TP & 233 & 91.7 & 14946 & 5861 & 48.0 & 10.6 & 282 & 92.3 \\
\cline { 2 - 10 } & BK & 132 & 51.8 & 7149 & 2803 & 21.9 & 4.49 & 155 & 52.0 \\
\hline
\end{tabular}

* All estimates assume the identification ion (corrected if applicable) (Fig. 1-2) reflects the molecule estimated.

$\dagger$ Abundances are normalized to a single portion.

$\$$ Err $=$ Propagated error from mean $+/-1 \sigma$ standard deviations, $N \geq 3$. 
Table S5. Known MTBSTFA and DMF reaction products, the most abundant mass fragments in their NIST mass spectra, and diagnostic ions used for their identification (underlined).

\begin{tabular}{|c|c|c|c|c|}
\hline Compound & Abbreviation & Formula & $M / z$ ( $\%$ of base peak) & $\begin{array}{l}\text { Comments on presence in SAM } \\
\text { observations }\end{array}$ \\
\hline $\begin{array}{l}\text { Bisilylated water } \\
\text { (disiloxane, 1,3-bis (1,1- } \\
\text { dimethylethyl), 1,1,3,3- } \\
\text { tetramethyl) }\end{array}$ & BSW & $\mathrm{C}_{12} \mathrm{H}_{30} \mathrm{OSi}_{2}$ & $\underline{147}, 189(17), 148(16), 73(13), 117(8), 149(8), 133(7)$ & Always \\
\hline $\begin{array}{l}\text { Monosilylated water } \\
\text { (tert-butyldimethylsilanol) }\end{array}$ & MSW & $\mathrm{C}_{6} \mathrm{H}_{16} \mathrm{OSi}$ & $\underline{75}, 76(0.8), 77(0.4)$ & Always \\
\hline $\begin{array}{l}\text { tert-butyldimethylsilyl } \\
\text { fluoride (or tert- } \\
\text { butyldimethylfluorosilane) }\end{array}$ & TBDMS-F & $\mathrm{C}_{6} \mathrm{H}_{15} \mathrm{FSi}$ & $\underline{77}, 55(92), \underline{134(18), 78(8)}$ & Always \\
\hline $\begin{array}{l}\text { tert-butyldimethylsilyl } \\
\text { chloride (or tert- } \\
\text { butlydimethylchlorosilane) }\end{array}$ & TBDMS-Cl & $\mathrm{C}_{6} \mathrm{H}_{15} \mathrm{ClSi}$ & $\begin{array}{l}\underline{93}, 56(92), 57(50), \underline{95}(36), 41(30), 65,29(17), 63, \\
94,39(10), \ldots, 79,78(4)\end{array}$ & Occasional \\
\hline Difluorodimethylsilane & & $\mathrm{C}_{2} \mathrm{H}_{6} \mathrm{~F}_{2} \mathrm{Si}$ & $\underline{81}, 47(21), 96,15(9), 77(6)$ & Possible \\
\hline Dichlorodimethylsilane & & $\mathrm{C}_{2} \mathrm{H}_{6} \mathrm{Cl}_{2} \mathrm{Si}$ & $\underline{113}, \underline{115}(70), 63,65,117,93,15(10), 128(7)$ & Possible \\
\hline $\begin{array}{l}\text { 2,2,2-Trifluoro- } \mathrm{N}- \\
\text { methylacetamide }\end{array}$ & TFMA & $\mathrm{C}_{3} \mathrm{H}_{4} \mathrm{~F}_{3} \mathrm{NO}$ & $\begin{array}{l}\frac{58}{(2)}, 69,128(2) \\
(24), 15(23), 28,78(11), \ldots, 106(2), 30,97\end{array}$ & Always \\
\hline Trifluoroacetamide $\S$ & & $\mathrm{C}_{2} \mathrm{H}_{2} \mathrm{~F}_{3} \mathrm{NO}$ & $44, \underline{69}(14), \underline{51}(13), \ldots, 113(1)$ & Often \\
\hline Trifluoroacetonitrile & & $\mathrm{C}_{2} \mathrm{~F}_{3} \mathrm{~N}$ & $\underline{69}, \underline{76}(47), 50(25), 31,12,26,38,14,19,95,24,57(1)$, & Often \\
\hline Hydrogen cyanide & $\mathrm{HCN}$ & $\mathrm{CHN}$ & $\underline{27}, \underline{26(17)}$ & Always \\
\hline Cyanogen chloride & $\mathrm{CNCl}$ & $\mathrm{CNCl}$ & $\underline{61}, \underline{63}(32), 35(11), 26(8)$ & Occasional \\
\hline Cyanogen bromide & $\mathrm{CNBr}$ & $\mathrm{CNBr}$ & $\begin{array}{l}\frac{105}{79}, \underline{107}(9), 53(7), 81(7), 54(6), 26(2)\end{array}$ & Occasional \\
\hline Cyanogen & & $\mathrm{C}_{2} \mathrm{~N}_{2}$ & $\underline{52}, 26(5), 53(3)$ & $\begin{array}{l}\text { Possible, difficult to confirm in } \\
\text { EGA }\end{array}$ \\
\hline Acetamide & & $\mathrm{C}_{2} \mathrm{H}_{5} \mathrm{NO}$ & $59,44(99), 43(60), 42(31), 28(8), 41(7), 15(7)$ & $\begin{array}{l}\text { Possible, difficult to confirm in } \\
\text { EGA }\end{array}$ \\
\hline Nitromethane & & $\mathrm{CH}_{3} \mathrm{NO}_{2}$ & $30,61(57), 15(48), 46(37), 29(11), 27(10)$ & $\begin{array}{l}\text { Possible, difficult to confirm in } \\
\text { EGA }\end{array}$ \\
\hline Methyl isocyanate & & $\mathrm{C}_{2} \mathrm{H}_{3} \mathrm{NO}$ & $57,28(38), 56(37), 27(15), 55(8), 29(7)$ & $\begin{array}{l}\text { Possible, difficult to confirm in } \\
\text { EGA }\end{array}$ \\
\hline
\end{tabular}


Table S5 continued.

\begin{tabular}{|c|c|c|c|c|}
\hline Compound & Abbreviation & Formula & $M / z$ (\% of base peak) & $\begin{array}{l}\text { Comments on presence in SAM } \\
\text { observations }\end{array}$ \\
\hline Acetonitrile & & $\mathrm{C}_{2} \mathrm{H}_{3} \mathrm{~N}$ & $41,40(50), 39(18) 38(9), 14(5)$ & $\begin{array}{l}\text { Possible, difficult to confirm in } \\
\text { EGA }\end{array}$ \\
\hline Acetone & & $\mathrm{C}_{3} \mathrm{H}_{6} \mathrm{O}$ & $43,58(25), 15(12), 42(10), 27(7), 26(5), 39(5)$ & $\begin{array}{l}\text { Possible, difficult to confirm in } \\
\text { EGA }\end{array}$ \\
\hline Acetylaldehyde & & $\mathrm{C}_{2} \mathrm{H}_{4} \mathrm{O}$ & $29,44(83), 43(47), 15(36), 42(13), 14(11)$ & $\begin{array}{l}\text { Possible, difficult to confirm in } \\
\text { EGA }\end{array}$ \\
\hline 2-Methylpropene & $\mathrm{MePr}$ & $\mathrm{C}_{4} \mathrm{H}_{8}$ & $\underline{41}, 39(45), \underline{56}(45), 28(22), 27(22), 55(16), 29(11)$ & $\begin{array}{l}\text { Pyrolysis products, always } \\
\text { detected in SAM data }\end{array}$ \\
\hline $\begin{array}{l}\text { 2-Chloro-2- } \\
\text { methylpropane }\end{array}$ & 2CMePr & $\mathrm{C}_{4} \mathrm{H}_{9} \mathrm{Cl}$ & 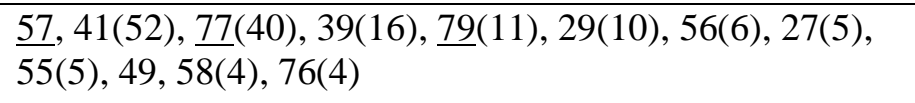 & $\begin{array}{l}\text { Possible, difficult to confirm in } \\
\text { EGA }\end{array}$ \\
\hline $\begin{array}{l}\text { 1-Chloro-2- } \\
\text { methylpropene }\end{array}$ & $1 \mathrm{CMePr}$ & $\mathrm{C}_{4} \mathrm{H}_{7} \mathrm{Cl}$ & $\begin{array}{l}\underline{55}, 39(48), \underline{90}(41), \underline{53}(28), 27(23), 54,29(20), 41(17), 75, \\
\underline{92}(13), 62,77(6), \ldots, 91(3)\end{array}$ & $\begin{array}{l}\text { Possible, difficult to confirm in } \\
\text { EGA (indistinguishable from 3- } \\
\text { Chloro-2-methylpropene) }\end{array}$ \\
\hline $\begin{array}{l}\text { 3-Chloro-2- } \\
\text { methylpropene }\end{array}$ & 3CMePr & $\mathrm{C}_{4} \mathrm{H}_{7} \mathrm{Cl}$ & $\begin{array}{l}\underline{55}, 39(45), \underline{90}(32), 54(27), 29(23), 27(20), 41(19), 53,75, \\
\frac{92}{91}(10), 28(6), 50,40,38,51,56(5), 62,26,49,77(3), \ldots\end{array}$ & $\begin{array}{l}\text { Possible, difficult to confirm in } \\
\text { EGA (indistinguishable from 1- } \\
\text { Chloro-2-methylpropene) }\end{array}$ \\
\hline Propene & $\operatorname{Pr}$ & $\mathrm{C}_{3} \mathrm{H}_{6}$ & $\underline{41}, 39(72), \underline{42}(70), 27(38), 40,38,37,26(11)$ & $\begin{array}{l}\text { Possible, difficult to confirm in } \\
\text { EGA }\end{array}$ \\
\hline Chloromethane & $\mathrm{CM}$ & $\mathrm{CH}_{3} \mathrm{Cl}$ & $50,15(72), \underline{52}(31), 49(11)$ & Always \\
\hline Dichloromethane & DCM & $\mathrm{CH}_{2} \mathrm{Cl}_{2}$ & $49, \underline{84}(65), \underline{86}(43), 51(32)$ & Always \\
\hline Trichloromethane & TriCM & $\mathrm{CHCl}_{3}$ & $\underline{83}, \underline{85}(71), 47(27), 48(13) \underline{87}(13), \ldots, 82(5)$ & Occasional \\
\hline Tetrachloromethane & TetraCM & $\mathrm{CCl}_{4}$ & $\underline{117}, \underline{119}(96), \underline{121}(35), 82(24), 47(20), 84(16)$ & Occasional \\
\hline Bromomethane & $\mathrm{BM}$ & $\mathrm{CH}_{3} \mathrm{Br}$ & 94, 96(94), 15(47), 93(21), 95(15), 91(7), 79(6) & Occasional \\
\hline Dibromomethane & DBM & $\mathrm{CH}_{2} \mathrm{Br}_{2}$ & $\begin{array}{l}\text { 174, } \underline{93}(96), \underline{95}(85), 172(51), 176(47), \underline{81}(12), 79(12), \\
91(11), 94,92(5)\end{array}$ & Possible \\
\hline Dimethylformamide & DMF & $\mathrm{C}_{3} \mathrm{H}_{7} \mathrm{NO}$ & $\underline{73}$ & $\begin{array}{l}\text { Possible, difficult to confirm in } \\
\text { EGA, not detected in GC }\end{array}$ \\
\hline Carbon dioxide & $\mathrm{CO}_{2}$ & $\mathrm{CO}_{2}$ & $\underline{44,28(10), 16(10), 12(9)}$ & Possible, difficult to confirm \\
\hline Carbon monoxide & $\mathrm{CO}$ & $\mathrm{CO}$ & $\underline{28}, \ldots, 29(1)$ & Always \\
\hline Nitric oxide & NO & NO & $\underline{30}, 14(8), 15(2), 16(2)$ & $\begin{array}{l}\text { Always (indistinguishable from } \\
\mathrm{N}_{2} \mathrm{O} \text { ) }\end{array}$ \\
\hline Nitrous oxide & $\mathrm{N}_{2} \mathrm{O}$ & $\mathrm{N}_{2} \mathrm{O}$ & $44, \underline{30}(31), 14(13), 28(11)$ & Possible \\
\hline
\end{tabular}


Table S6. Analytical conditions for SAM analyses.

\begin{tabular}{|c|c|c|c|c|c|c|c|c|c|c|c|}
\hline $\begin{array}{l}\text { Geological } \\
\text { Unit }\end{array}$ & Sample & $\begin{array}{c}\text { Mass (mg, } \\
2 \sigma \mathrm{SD})^{*}\end{array}$ & TID $\dagger$ & $\begin{array}{c}\text { Analysis } \\
\text { sol }\end{array}$ & $\begin{array}{l}\text { Oven } \\
\text { used }\end{array}$ & $\begin{array}{c}\text { GC } \\
\text { used }\end{array}$ & $\begin{array}{c}\text { SMS flush/ } \\
\text { pump/vent } \\
\text { (min) }\end{array}$ & $\begin{array}{c}\text { Pre- delivery sample } \\
\text { cup temp. } \S \\
\text { (C) }\end{array}$ & $\begin{array}{l}\text { Sample preheat } \\
\text { temp. } \S \\
(\mathrm{C})\end{array}$ & $\begin{array}{c}\text { Preheat } \\
\text { hold } \\
(\mathrm{min})\end{array}$ & $\begin{array}{c}\text { Pyrolysis final } \\
\text { temp. } \S \\
\text { (C) }\end{array}$ \\
\hline \multirow{6}{*}{$\begin{array}{l}\text { Sheepbed } \\
\text { member } \\
\text { mudstone }\end{array}$} & JK-4 & $45 \pm 18$ & 25077 & 227 & 1 & 5 & $\mathrm{NA}+$ & $\mathrm{NA}+$ & $35^{\circ}-50^{\circ}$ & 31 & $882^{\circ}$ \\
\hline & CB-Blank1 & 0 & 25083 & 277 & 1 & 5 & $\mathrm{NA}+$ & $\mathrm{NA}$ & $35^{\circ}-50^{\circ}$ & 31 & $879^{\circ}$ \\
\hline & CB6 & $135 \pm 31$ & 25130 & 382 & 1 & 5 & 360 & $\leq 249^{\circ}$ & $249^{\circ}$ & 31 & $866^{\circ}$ \\
\hline & CB6r & 0 & 25133 & 394 & 1 & 5 & 360 & $\leq 249^{\circ}$ & $249^{\circ}$ & 31 & $866^{\circ}$ \\
\hline & CB-7 & $135 \pm 31$ & 25142 & 408 & 1 & 5 & 360 & $\leq 249^{\circ}$ & $249^{\circ}$ & 31 & $866^{\circ}$ \\
\hline & CB-Blank2 & 0 & 25145 & 421 & 1 & 5 & 360 & $\leq 249^{\circ}$ & $249^{\circ}$ & 31 & $866^{\circ}$ \\
\hline \multirow{5}{*}{$\begin{array}{l}\text { Murray } \\
\text { formation } \\
\text { mudstone }\end{array}$} & CH-Blank & 0 & 25223 & 770 & 2 & 5 & $\mathrm{NA}+$ & NA & $\sim 40^{\circ}$ & 21 & $862^{\circ}$ \\
\hline & $\mathrm{CH}$ & $45 \pm 18$ & 25226 & 773 & 2 & 5 & $\mathrm{NA}+$ & $\mathrm{NA}+$ & $\sim 40^{\circ}$ & 21 & $862^{\circ}$ \\
\hline & MJ & $45 \pm 18$ & 25242 & $\begin{array}{c}887 \text { (EGA) } \\
981(\mathrm{GC}) \\
\end{array}$ & 2 & 5 & $\mathrm{NA}+$ & $\mathrm{NA}+$ & $\sim 40^{\circ}$ & 21 & $862^{\circ}$ \\
\hline & $\mathrm{TP}$ & $45 \pm 18$ & 25257 & 928 & 2 & $\mathrm{NA}+$ & $\mathrm{NA}+$ & $\mathrm{NA}+$ & $\sim 40^{\circ}$ & 5 & $862^{\circ}$ \\
\hline & $\mathrm{BK}$ & $135 \pm 31$ & 25282 & 1075 & 2 & $\mathrm{NA}+$ & $\mathrm{NA}+$ & $\mathrm{NA}+$ & $\sim 40^{\circ}$ & 21 & $862^{\circ}$ \\
\hline
\end{tabular}

* Error $=$ mean $+/-2 \sigma$ standard deviations based on extensive testing using the MSL Drill testbed on different rock samples.

$\uparrow$ SAM test identification (TID) number for looking up raw data in the NASA Planetary Data System.

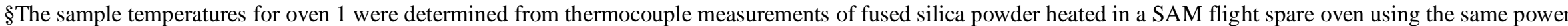
profile as the SAM flight oven. These data are recent and may thus differ from temperatures published in previous manuscript. The sample temperatures for oven 2 are based on pre-flight thermal measurements.

† NA: Not Applicable. 
Table S7. Electron-impact total and partial ionization cross-sections at $70 \mathrm{eV}$.

\begin{tabular}{|c|c|c|c|c|c|c|c|}
\hline Molecule (M) & $\begin{array}{c}\mathbf{T I C S}(\mathbf{M}) \\
\left(\AA^{2}\right)\end{array}$ & $\begin{array}{c}\text { TICS error } \\
\left(\AA^{2}\right)\end{array}$ & TICS source & Ion $\mathrm{m} / \mathrm{z}$ & $\begin{array}{c}\text { PICS(ion) } \\
\left(\AA^{2}\right)\end{array}$ & PICS error $\left(\AA^{2}\right)$ & PICS source \\
\hline Carbon dioxide $*$ & $3.57 *$ & 0.43 & $(57)$ & 44 & 2.30 & 0.28 & $(57)$ \\
\hline Carbon monoxide & 2.52 & 0.38 & $(49)$ & 28 & 0.97 & 0.19 & $(49)$ \\
\hline Methanethiol & 7.5 & 1.13 & Calculated by K. Irikura & 47 & 2.55 & 0.51 & Calculated using NIST RMR \\
\hline Dimethylsulfide & 10.86 & $1.30 \dagger$ & $(58)$ & 62 & 1.66 & $1.13 \dagger$ & $(58)$ \\
\hline Carbonyl sulfide & 4.93 & 0.74 & $(49)$ & 60 & 2.60 & 0.52 & Calculated using NIST RMR \\
\hline Carbon disulfide & 7.97 & 1.20 & $(49)$ & 76 & 4.38 & 0.64 & Calculated using NIST RMR \\
\hline Hydrogen disulfide & 4.7 & 0.71 & Calculated by K. Irikura & 34 & 2.43 & 0.49 & Calculated using NIST RMR \\
\hline Thiophene & 13.60 & $1.63 \dagger$ & $(58)$ & 84 & 2.32 & $1.47 \dagger$ & $(58)$ \\
\hline 2-Methylthiophene & 16.97 & $2.04+$ & $(58)$ & 97 & 3.61 & $1.95 \dagger$ & $(58)$ \\
\hline 3-Methylthiophene & 16.98 & $2.04 \dagger$ & $(58)$ & 97 & 3.88 & $1.93 \dagger$ & $(58)$ \\
\hline Average of methylthiophenes isomers & 15.28 & 2.38 & & 97 & 2.96 & 1.94 & \\
\hline Benzo(a)thiophene & 23.66 & $2.84 \dagger$ & $(58)$ & 134 & 7.63 & $1.87 \dagger$ & $(58)$ \\
\hline Benzene $\left(\mathrm{C}_{6} \mathrm{H}_{6}\right)$ & 15.52 & $1.86 \dagger$ & $(58)$ & 78 & 3.93 & $1.17 \dagger$ & $(58)$ \\
\hline Toluene & 18.48 & $2.22 \dagger$ & $(58)$ & 91 & 5.29 & $1.45 \dagger$ & $(58)$ \\
\hline Benzoic acid & 19.13 & $2.30 \dagger$ & $(58)$ & 105 & 2.90 & $1.35 \dagger$ & $(58)$ \\
\hline Methane $\left(\mathrm{CH}_{4}\right)$ & 3.52 & 0.53 & $(49)$ & 16 & 1.48 & 0.01 & Calculated by K. Irikura \\
\hline Ethane $\left(\mathrm{C}_{2} \mathrm{H}_{6}\right)$ & 6.42 & 0.96 & $(49)$ & 30 & 0.77 & 0.02 & Calculated by K. Irikura \\
\hline Propane $\left(\mathrm{C} 3 \mathrm{H}_{8}\right)$ & 8.62 & 1.29 & $(49)$ & 29 & 2.64 & 0.53 & Calculated using NIST RMR \\
\hline Ethene $\left(\mathrm{C}_{2} \mathrm{H} 4\right)$ & 5.12 & 0.77 & $(49)$ & 27 & 1.38 & 0.28 & Calculated using NIST RMR \\
\hline Propene $\left(\mathrm{C}_{3} \mathrm{H}_{6}\right)$ & 8.74 & 1.31 & $(49)$ & 41 & 0.30 & 0.05 & $(59)$ \\
\hline 1-Butene $+\left(\mathrm{C}_{4} \mathrm{H}_{8}\right)$ & 11.79 & 1.77 & $(49)$ & 56 & 1.49 & 0.30 & Calculated using NIST RMR \\
\hline 2-Butene $\left(\mathrm{C}_{4} \mathrm{H}_{8}\right)$ & 4.14 & 0.62 & $(49)$ & 56 & 0.48 & 0.10 & Calculated using NIST RMR \\
\hline
\end{tabular}

* ICSs for $\mathrm{CO}_{2}$ from Tian et al. (57) are deemed the most accurate measurement (K. Irikura, personal communication).

$\dagger$ Uncertainties for BEB-calculated PICSs are calculated mean $+/-1 \sigma$ standard deviations $(\mathrm{N} \geq 10)$, assuming a normal distribution. 
Table S8. EGA molecular abundance estimates for signals above $500^{\circ} \mathrm{C}$ (nanomole molecule). $*_{\dagger}^{\dagger}$

\begin{tabular}{|c|c|c|c|c|c|c|c|c|c|c|c|c|c|c|c|}
\hline $\begin{array}{l}\text { Geological } \\
\text { Unit }\end{array}$ & Sample & Thiophene & err & $\begin{array}{l}\text { Methyl- } \\
\text { thiophenes }\end{array}$ & err & Benzene & err & Toluene & err & $\begin{array}{c}\text { Benzoic } \\
\text { Acid }\end{array}$ & err & $\begin{array}{c}\text { Total } \\
\text { Thiophenes }\end{array}$ & err & $\begin{array}{c}\text { Total } \\
\text { Aromatics }\end{array}$ & err \\
\hline \multirow{6}{*}{$\begin{array}{l}\text { Sheepbed } \\
\text { member } \\
\text { mudstone }\end{array}$} & JK-4 & 0.10 & 0.05 & 0.08 & 0.04 & 0.20 & 0.11 & 0.26 & 0.11 & 0.19 & 0.11 & 0.18 & 0.06 & 0.65 & 0.19 \\
\hline & CB- Blank1 & 0.04 & 0.02 & 0.05 & 0.02 & 0.19 & 0.03 & 0.08 & 0.03 & 0.15 & 0.08 & 0.09 & 0.03 & 0.41 & 0.10 \\
\hline & CB-6 & 0.05 & 0.03 & 0.02 & 0.01 & 0.06 & 0.04 & 0.09 & 0.04 & 0.04 & 0.02 & 0.08 & 0.03 & 0.19 & 0.06 \\
\hline & CB-6r & 0.03 & 0.01 & 0.02 & 0.01 & 0.03 & 0.02 & 0.05 & 0.02 & 0.04 & 0.02 & 0.04 & 0.02 & 0.13 & 0.04 \\
\hline & CB-7 & 0.04 & 0.02 & 0.02 & 0.01 & 0.04 & 0.02 & 0.05 & 0.02 & 0.06 & 0.03 & 0.06 & 0.02 & 0.15 & 0.04 \\
\hline & CB-Blank2 & 0.08 & 0.04 & 0.03 & 0.02 & 0.07 & 0.03 & 0.06 & 0.03 & 0.07 & 0.04 & 0.11 & 0.05 & 0.20 & 0.05 \\
\hline \multirow{5}{*}{$\begin{array}{l}\text { Murray } \\
\text { formation } \\
\text { mudstone }\end{array}$} & CH-Blank & 0.07 & 0.04 & 0.04 & 0.02 & 0.16 & 0.06 & 0.13 & 0.06 & 0.17 & 0.10 & 0.11 & 0.04 & 0.46 & 0.13 \\
\hline & $\mathrm{CH}$ & 0.37 & 0.20 & 0.11 & 0.05 & 0.52 & 0.21 & 0.47 & 0.21 & 0.23 & 0.13 & 0.48 & 0.21 & 1.22 & 0.32 \\
\hline & MJ & 0.42 & 0.22 & 0.11 & 0.05 & 0.35 & 0.17 & 0.39 & 0.17 & 0.30 & 0.17 & 0.52 & 0.23 & 1.05 & 0.30 \\
\hline & TP & 0.10 & 0.06 & 0.06 & 0.03 & 0.12 & 0.08 & 0.18 & 0.08 & 0.12 & 0.07 & 0.16 & 0.06 & 0.42 & 0.13 \\
\hline & BK & 0.11 & 0.06 & 0.04 & 0.02 & 0.15 & 0.08 & 0.19 & 0.08 & 0.14 & 0.08 & 0.15 & 0.06 & 0.48 & 0.14 \\
\hline
\end{tabular}

\section{Table S8 continued.}

\begin{tabular}{|c|c|c|c|c|c|c|c|c|c|c|c|}
\hline $\begin{array}{l}\text { Geological } \\
\text { Unit }\end{array}$ & Sample & Methane-thiol & err & $\begin{array}{l}\text { Dimethyl- } \\
\text { sulfide }\end{array}$ & err & $\begin{array}{c}\text { Carbonyl } \\
\text { Sulfide }\end{array}$ & err & $\begin{array}{l}\text { Carbon } \\
\text { Disulfide }\end{array}$ & err & $\begin{array}{c}\text { Total C1+C2 } \\
\text { Sulfur } \\
\text { Compounds }\end{array}$ & err \\
\hline \multirow{6}{*}{$\begin{array}{l}\text { Sheepbed } \\
\text { member } \\
\text { mudstone }\end{array}$} & JK-4 & 1.02 & 0.39 & 0.42 & 0.32 & 1.11 & 0.43 & 0.25 & 0.09 & 2.79 & 0.67 \\
\hline & CB- Blank1 & 0.25 & 0.10 & 0.15 & 0.11 & 0.15 & 0.06 & 0.16 & 0.06 & 0.70 & 0.17 \\
\hline & CB-6 & 0.73 & 0.28 & 0.22 & 0.16 & 0.82 & 0.31 & 0.05 & 0.02 & 1.81 & 0.45 \\
\hline & CB-6r & 0.13 & 0.05 & 0.09 & 0.07 & 0.07 & 0.03 & 0.04 & 0.01 & 0.33 & 0.09 \\
\hline & CB-7 & 0.41 & 0.16 & 0.14 & 0.10 & 0.59 & 0.23 & 0.06 & 0.02 & 1.19 & 0.29 \\
\hline & CB-Blank2 & 0.21 & 0.08 & 0.11 & 0.08 & 0.23 & 0.09 & 0.12 & 0.04 & 0.66 & 0.15 \\
\hline \multirow{5}{*}{$\begin{array}{l}\text { Murray } \\
\text { formation } \\
\text { mudstone }\end{array}$} & CH-Blank & 0.47 & 0.18 & 0.21 & 0.16 & 0.50 & 0.20 & 0.10 & 0.04 & 1.28 & 0.32 \\
\hline & $\mathrm{CH}$ & 13.6 & 5.33 & 2.66 & 2.02 & 9.18 & 3.60 & 1.25 & 0.46 & 26.7 & 6.76 \\
\hline & MJ & 23.4 & 9.18 & 3.46 & 2.63 & 11.9 & 4.67 & 1.54 & 0.57 & 40.3 & 10.6 \\
\hline & TP & 8.82 & 3.46 & 2.32 & 1.76 & 5.69 & 2.23 & 0.88 & 0.32 & 17.71 & 4.49 \\
\hline & BK & 8.25 & 3.24 & 1.37 & 1.04 & 4.68 & 1.84 & 0.61 & 0.22 & 14.91 & 3.87 \\
\hline
\end{tabular}

* All estimates assume the identification ion (corrected if applicable) (Fig. 1-2) solely reflects the molecule estimated. Benzoic acid is assumed for $m / z$. 105 .

$\uparrow$ Abundances are normalized to a single portion.

Err $=$ Propagated error from mean $+/-1 \sigma$ standard deviations, $N \geq 3$. 
Table S9. EGA molecular concentration estimates for signals above $500^{\circ} \mathrm{C}$ (parts per billion molecules by mass). *†t

\begin{tabular}{|c|c|c|c|c|c|c|c|c|c|c|c|c|c|c|c|}
\hline $\begin{array}{l}\text { Geological } \\
\text { Unit }\end{array}$ & Sample & Thiophene & err & $\begin{array}{c}\text { Methyl- } \\
\text { thiophenes }\end{array}$ & err & Benzene & err & Toluene & err & $\begin{array}{c}\text { Benzoic } \\
\text { Acid }\end{array}$ & err & $\begin{array}{c}\text { Total } \\
\text { Thiophenes }\end{array}$ & err & $\begin{array}{c}\text { Total } \\
\text { Aromatics } \\
\end{array}$ & err \\
\hline \multirow{6}{*}{$\begin{array}{l}\text { Sheepbed } \\
\text { member } \\
\text { mudstone }\end{array}$} & JK-4 & 186 & 109 & 170 & 90 & 340 & 212 & 538 & 264 & 525 & 325 & 356 & 141 & 1400 & 469 \\
\hline & CB- Blank1 & 73 & 43 & 109 & 58 & 324 & 99 & 167 & 82 & 395 & 245 & 182 & 72 & 886 & 276 \\
\hline & CB-6 & 98 & 57 & 51 & 27 & 106 & 70 & 179 & 88 & 108 & 67 & 149 & 63 & 393 & 131 \\
\hline & CB-6r & 47 & 28 & 37 & 20 & 50 & 42 & 111 & 54 & 118 & 73 & 85 & 34 & 279 & 100 \\
\hline & CB-7 & 73 & 43 & 37 & 20 & 75 & 39 & 95 & 47 & 150 & 93 & 110 & 47 & 321 & 111 \\
\hline & CB-Blank2 & 149 & 87 & 71 & 38 & 124 & 53 & 121 & 59 & 188 & 116 & 220 & 95 & 433 & 141 \\
\hline \multirow{5}{*}{$\begin{array}{l}\text { Murray } \\
\text { formation } \\
\text { mudstone }\end{array}$} & CH-Blank & 128 & 75 & 97 & 52 & 273 & 118 & 266 & 132 & 462 & 288 & 224 & 91 & 1000 & 338 \\
\hline & $\mathrm{CH}$ & 692 & 407 & 237 & 127 & 903 & 418 & 971 & 482 & 616 & 384 & 929 & 426 & 2490 & 745 \\
\hline & MJ & 777 & 457 & 236 & 127 & 614 & 332 & 807 & 401 & 818 & 510 & 1013 & 474 & 2240 & 729 \\
\hline & $\mathrm{TP}$ & 193 & 114 & 126 & 68 & 214 & 143 & 362 & 180 & 329 & 205 & 319 & 132 & 904 & 308 \\
\hline & BK & 199 & 117 & 88 & 47 & 261 & 159 & 397 & 197 & 372 & 232 & 287 & 126 & 1030 & 343 \\
\hline
\end{tabular}

\section{Table S9 continued.}

\begin{tabular}{|c|c|c|c|c|c|c|c|c|c|c|c|}
\hline $\begin{array}{l}\text { Geological } \\
\text { Unit }\end{array}$ & Sample & Methane-thiol & err & $\begin{array}{l}\text { Dimethyl- } \\
\text { sulfide }\end{array}$ & err & $\begin{array}{l}\text { Carbonyl } \\
\text { Sulfide }\end{array}$ & err & $\begin{array}{c}\text { Carbon } \\
\text { Disulfide }\end{array}$ & err & $\begin{array}{c}\text { Total C1+C2 } \\
\text { Sulfur } \\
\text { Compounds }\end{array}$ & err \\
\hline \multirow{6}{*}{$\begin{array}{l}\text { Sheepbed } \\
\text { member } \\
\text { mudstone }\end{array}$} & JK-4 & 1090 & 494 & 580 & 461 & 1480 & 670 & 415 & 179 & 3560 & 969 \\
\hline & CB- Blank1 & 268 & 122 & 202 & 160 & 203 & 92 & 263 & 114 & 936 & 249 \\
\hline & CB-6 & 775 & 352 & 298 & 237 & 1090 & 495 & 82 & 36 & 2250 & 653 \\
\hline & CB-6r & 135 & 61 & 131 & 104 & 98 & 45 & 67 & 29 & 431 & 132 \\
\hline & CB-7 & 437 & 198 & 187 & 149 & 783 & 355 & 101 & 44 & 1510 & 435 \\
\hline & CB-Blank2 & 223 & 101 & 152 & 121 & 302 & 137 & 195 & 85 & 872 & 225 \\
\hline \multirow{5}{*}{$\begin{array}{l}\text { Murray } \\
\text { formation } \\
\text { mudstone }\end{array}$} & CH-Blank & 501 & 230 & 294 & 235 & 668 & 307 & 163 & 72 & 1627 & 456 \\
\hline & $\mathrm{CH}$ & 14500 & 6680 & 3670 & 2930 & 12300 & 5640 & 2120 & 928 & 32600 & 9260 \\
\hline & MJ & 25000 & 11500 & 4780 & 3810 & 15900 & 7310 & 2610 & 1150 & 48300 & 14200 \\
\hline & TP & 9430 & 4340 & 3200 & 2550 & 7600 & 3490 & 1500 & 656 & 21700 & 6160 \\
\hline & BK & 8820 & 4060 & 1890 & 1510 & 6250 & 2870 & 1040 & 454 & 18000 & 5210 \\
\hline
\end{tabular}

* All estimates assume the identification ion (corrected if applicable) (Fig. 1-2) reflects the molecule estimated. Benzoic acid is assumed for $m / z$. 105.

$\uparrow$ Abundances are normalized to a single portion.

Err $=$ Propagated error from mean $+/-1 \sigma$ standard deviations, $N \geq 3$. 
Table S10. EGA organic carbon concentration estimates for signals above $500^{\circ} \mathrm{C}$ (parts per billion $\mathrm{C}$ by mass, unless noted ppm $\mathrm{C}$ ). $*+t$

\begin{tabular}{|c|c|c|c|c|c|c|c|c|c|c|c|c|c|c|c|}
\hline $\begin{array}{l}\text { Geological } \\
\text { Unit }\end{array}$ & Sample & Thiophene & err & $\begin{array}{c}\text { Methyl- } \\
\text { thiophenes }\end{array}$ & err & Benzene & err & Toluene & err & $\begin{array}{c}\text { Benzoic } \\
\text { Acid }\end{array}$ & err & $\begin{array}{c}\text { Total } \\
\text { thiophenes }\end{array}$ & err & $\begin{array}{c}\text { Total } \\
\text { aromatics }\end{array}$ & err \\
\hline \multirow{6}{*}{$\begin{array}{l}\text { Sheepbed } \\
\text { member } \\
\text { mudstone }\end{array}$} & JK-4 & 106 & 62.0 & 104 & 55.2 & 314 & 195 & 491 & 241 & 361 & 224 & 210 & 83.0 & 1166 & 382 \\
\hline & CB- Blank1 & 41.9 & 24.5 & 66.7 & 35.5 & 299 & 91.0 & 152 & 74.7 & 272 & 168 & 109 & 43.1 & 723 & 206 \\
\hline & CB-6 & 56.0 & 32.7 & 31.0 & 16.5 & 97.8 & 64.5 & 164 & 80.3 & 74.4 & 46.1 & 87.0 & 36.6 & 336 & 113 \\
\hline & CB-6r & 27.0 & 15.8 & 22.9 & 12.2 & 46.3 & 38.7 & 101 & 49.6 & 81.2 & 50.2 & 49.9 & 19.9 & 229 & 80.5 \\
\hline & CB-7 & 41.7 & 24.3 & 22.8 & 12.1 & 69.4 & 36.1 & 87.0 & 42.8 & 103 & 64.0 & 64.5 & 27.2 & 260 & 85.0 \\
\hline & CB-Blank2 & 85.0 & 49.6 & 43.5 & 23.1 & 114 & 49.0 & 111 & 54.3 & 129 & 80.0 & 129 & 54.7 & 354 & 108 \\
\hline \multirow{5}{*}{$\begin{array}{l}\text { Murray } \\
\text { formation } \\
\text { mudstone }\end{array}$} & CH-Blank & 72.8 & 42.8 & 59.3 & 31.8 & 252 & 109 & 242 & 120 & 318 & 198 & 132 & 53.4 & 812 & 256 \\
\hline & $\mathrm{CH}$ & 395 & 232 & 145 & 77.9 & 833 & 386 & 886 & 440 & 424 & 265 & 540 & 245 & 2140 & 642 \\
\hline & MJ & 444 & 261 & 144 & 77.5 & 566 & 306 & 736 & 366 & 563 & 351 & 588 & 272 & 1870 & 592 \\
\hline & TP & 110 & 64.9 & 77.2 & 41.4 & 198 & 132 & 330 & 164 & 226 & 141 & 188 & 77.0 & 754 & 253 \\
\hline & BK & 114 & 66.9 & 53.9 & 29.0 & 241 & 147 & 362 & 180 & 256 & 160 & 168 & 72.9 & 859 & 282 \\
\hline
\end{tabular}

Table S10 continued.

\begin{tabular}{|c|c|c|c|c|c|c|c|c|c|c|c|c|c|}
\hline $\begin{array}{l}\text { Geological } \\
\text { Unit }\end{array}$ & Sample & Methanethiol & err & Dimethylsulfide & err & $\begin{array}{l}\text { Carbonyl } \\
\text { Sulfide }\end{array}$ & err & $\begin{array}{c}\text { Carbon } \\
\text { Disulfide }\end{array}$ & err & $\begin{array}{c}\text { Total C1+C2 } \\
\text { Sulfur Compounds }\end{array}$ & err & $\begin{array}{c}\text { Total Aliphatic } \\
\text { Compounds }\end{array}$ & err \\
\hline \multirow{6}{*}{$\begin{array}{l}\text { Sheepbed } \\
\text { member } \\
\text { mudstone }\end{array}$} & JK-4 & 272 & 123 & 224 & 178. & 295. & 134 & 65.5 & 28.3 & 857 & 256 & 3860 & 925 \\
\hline & CB- Blank1 & 66.9 & 30.3 & 77.9 & 61.9 & 40.7 & 18.5 & 41.5 & 17.9 & 227 & 74 & 846 & 195 \\
\hline & CB-6 & 194 & 87.8 & 115 & 91.6 & 218. & 99.0 & 13.0 & 5.6 & 540 & 161 & 4620 & 1020 \\
\hline & CB-6r & 33.7 & 15.3 & 50.7 & 40.2 & 19.6 & 8.9 & 10.6 & 4.6 & 115 & 44.2 & 1390 & 175 \\
\hline & CB-7 & 109 & 49.5 & 72.3 & 57.4 & 156. & 71.0 & 15.9 & 6.9 & 354 & 104 & 5990 & 737 \\
\hline & CB-Blank2 & 55.6 & 25.2 & 58.8 & 46.7 & 60.4 & 27.4 & 30.8 & 13.3 & 206 & 61.2 & 431 & 108 \\
\hline \multirow{5}{*}{$\begin{array}{l}\text { Murray } \\
\text { formation } \\
\text { mudstone }\end{array}$} & CH-Blank & 125 & 57.5 & 113 & 90.7 & 133. & 61.4 & 25.7 & 11.3 & 398 & 124 & 1430 & 360 \\
\hline & $\mathrm{CH}$ & 3630 & 1670 & 1420 & 1130 & 2450 & 1130 & 334 & 146 & 7830 & 2310 & 5540 & 1230 \\
\hline & MJ & 6250 & 2870 & 1850 & 1470 & 3180 & 1461 & 412 & 181 & 11700 & 3550 & 10200 & 2350 \\
\hline & $\mathrm{TP}$ & 2350 & 1080 & 1240 & 986 & 1520 & 698 & 236 & 104 & 5350 & 1630 & 2540 & 559 \\
\hline & BK & 2200 & 1010 & 731 & 583 & 1250 & 574 & 163 & 71.7 & 4350 & 1300 & 5060 & 1310 \\
\hline
\end{tabular}

\section{Table S10 continued.}

\begin{tabular}{|c|c|c|c|c|c|}
\hline $\begin{array}{l}\text { Geological } \\
\text { Unit }\end{array}$ & Sample & $\begin{array}{l}\text { Total Organic C in Thiophenes, } \\
\text { Aromatics, Aliphatic Compounds (ppm C) }\end{array}$ & err & $\begin{array}{l}\text { Total Organic C in Thiophenes, Aromatics, } \\
\text { Aliphatic, and C1+C2 Sulfur Compounds (ppm C) }\end{array}$ & err \\
\hline \multirow{6}{*}{$\begin{array}{l}\text { Sheepbed } \\
\text { member } \\
\text { mudstone }\end{array}$} & JK-4 & 5.23 & 1.00 & 6.09 & 0.26 \\
\hline & CB- Blank1 & 1.68 & 0.29 & 1.90 & 0.07 \\
\hline & CB-6 & 5.04 & 1.03 & 5.58 & 0.16 \\
\hline & CB-6r & 1.67 & 0.19 & 1.79 & 0.04 \\
\hline & CB-7 & 6.31 & 0.74 & 6.67 & 0.10 \\
\hline & CB-Blank2 & 0.91 & 0.16 & 1.12 & 0.06 \\
\hline \multirow{5}{*}{$\begin{array}{l}\text { Murray } \\
\text { formation } \\
\text { mudstone }\end{array}$} & CH-Blank & 2.37 & 0.45 & 2.77 & 0.12 \\
\hline & $\mathrm{CH}$ & 8.23 & 1.41 & 16.1 & 2.31 \\
\hline & MJ & 12.7 & 2.44 & 24.4 & 3.55 \\
\hline & TP & 3.48 & 0.62 & 8.83 & 1.63 \\
\hline & BK & 6.09 & 1.34 & 10.4 & 1.30 \\
\hline
\end{tabular}

* All estimates assume the identification ion (corrected if applicable) (Fig. 1-2) reflects the molecule estimated. Benzoic acid is assumed for $m / z, 105$.

$\dagger$ Abundances are normalized to a single portion.

$\ddagger$ Err $=$ Propagated error from mean $+/-1 \sigma$ standard deviations, $N \geq 3$ 